\title{
PROCEEDINGS OF THE INTERNATIONAL WORKSHOP ON
}

\section{"CALCIUM RELEASE AND CELLULAR CALCIUM SIGNALLING DOMAINS"}

MARBELLA, CHILE, SEPTEMBER 28 - OCTOBER 2, 2003

Organized by FONDAP Center for Molecular Studies of the Cell, Facultad de Medicina. Universidad de Chile 


\title{
INTERNATIONAL WORKSHOP "CALCIUM RELEASE AND CELLULAR CALCIUM SIGNALLING DOMAINS"
}

\author{
MARBELLA, CHILE, SEPTEMBER 28-OCTOBER 2, 2003
}

\section{PROGRAM}

Sunday, Sept. 28

Opening lecture: Ernesto Carafoli (Italy) Calcium signalling, a historical perspective

\section{Chair: Cecilia Hidalgo}

Monday, Sept. 29 - FIRST TOPIC: CALCIUM RELEASE CHANNELS

Session 1: Calcium Release Channels (RyR and InsP3-gated channels). Structural aspects and single channel studies

Chair: Barbara Ehrlich

Clara Franzini-Armstrong (USA). The junctional supramolecular complex

Susan Hamilton (USA) RYR1 Phosphorylation by PKA and the role of FKBP12

Gregory Mignery (USA) Structure and function of InsP3 Receptor

Ricardo Bull (Chile) Regulation of single RyR channels from brain by endogenous modulators

Allan Williams (UK) The interaction of ryanoids with single RyR channels

Kevin Foskett (USA) Novel model of calcium and inositol 1,4,5-trisphosphate regulation of $\mathrm{InsP}_{3}$ receptor channel gating in native endoplasmic reticulum

\section{POSTER SESSION 1}

Session 2: Calcium Release Channels: RyR, NAADP- and InsP3-gated channels.

Chair: Kevin Foskett

Michael Fill (USA) Calcium regulation of single ryanodine receptor channels

Barbara Ehrlich (USA). Regulation of the InsP3 receptor from both sides

Antony Galione (UK). NAADP signalling mechanisms

Eduardo Chini (USA). NAADP a new second messenger?

Tuesday Sept. 30 - Session 3: Regulation of Calcium Release Channels (RyR and InsP3-gated channels)

\section{Chair: Susan Hamilton}

Paul Allen (USA). Structure Function Studies of RyR1

Colin Taylor (UK). Structure and regulation of InsP3 receptors

Roberto Coronado (USA). Functional interactions between dihydropyridine and ryanodine receptors in skeletal muscle

Kurt Beam (USA). Arrangement of proteins involved in excitation-contraction coupling as analyzed by FRET

Hector Valdivia (USA). Modulation of cardiac ryanodine receptors by sorcin, a novel regulator of excitation-contraction coupling

Humbert De Smedt (Belgium). InsP3induced $\mathrm{Ca}^{2+}$ release and Calmodulin

\section{POSTER SESSION 2}

Session 4: Regulation of Calcium Release Channels (RyR and InsP3-gated channels), continued

\section{Chair: Enrique Jaimovich}

Sandor Gyorke (USA). SR intra-luminal Ca signalling in the heart: the role of calsequestrin

Cecilia Hidalgo (Chile) Redox regulation of calcium release through RyR channels

David Yule (USA). Regulation of $\mathrm{Ca}^{2+}$ release by $\mathrm{InsP}_{3}$ receptor phosphorylation

Plenary lecture: Ole Petersen (UK) Local and global $\mathrm{Ca}^{2+}$ signals: physiology and pathophysiology

Chair: Enrique Jaimovich

Wednesday, Oct. $1^{\text {st }}$. SECOND TOPIC: CELLULAR RESPONSES TRIGGERED BY CALCIUM RELEASE

Session 5: Cellular Calcium Signals generated by Calcium Release through RyR-channels and InsP3-gated channels

\section{Chair: Kevin Foskett}

Martin Schneider (USA). Local $\mathrm{Ca}^{2+}$ release events in skeletal muscle. 
Eduardo Ríos (USA). Control of dual isoforms of Ca release channels in muscle David Eisner (UK). Control and miscontrol of the cardiac calcium transient

Martin Bootman (UK) Spatial and temporal properties of calcium transients in cardiac myocytes

Enrique Jaimovich (Chile). InsP3 dependent calcium signals in skeletal muscle cells

Susan Wray (UK). Calcium signals and function in smooth muscle

Shmuel Muallen (USA). Homer proteins in $\mathrm{Ca}^{2+}$ signaling

\section{POSTER SESSION 3}

\section{Session 6: Mitochondrial and Store-Operated Calcium Signals}

\section{Chair: Ernesto Carafoli}

Rosario Rizzuto (Italy). Mitochondrial $\mathrm{Ca}^{2+}$ homeostasis: molecular determinants and functional role

Javier Garcia-Sancho (Spain). The contribution of mitochondria to the genesis of the calcium signal in excitable cells

James Putney (USA). TRPCs and mechanisms of calcium entry

Ricardo Boland (Argentina). Modulation of store operated calcium channels by the steroid hormone $1 \alpha, 25$-dihydroxy-vitamin $\mathrm{D}_{3}$ Isaac Pessah (USA). Excitation-SOC entry coupling in skeletal myotubes
Thursday, Oct. 2nd THIRD TOPIC: CELLULAR CALCIUM SIGNALLING

\section{Session 7: Cellular Calcium Signalling Domains}

\section{Chair: Cecilia Hidalgo}

Pedro Verdugo (USA). Calcium/Proton signalling in secretion: crosstalk, redundancy, or complementation?

Patricia Camacho (USA). ER chaperones modulate intracellular calcium oscillations Jordi Molgó (France). Localization of InsP3 receptors in muscle satellite cells, and components of the mouse neuromuscular junction Patrick Delmas (France). Polycystin ion channel signalling complex

Ian Parker (USA) Imaging single-channel $\mathrm{Ca}^{2+}$ microdomains; and effects of buffers on interactions between InsP3 receptors

Alex Verkhratsky (UK) ER $\mathrm{Ca}^{2+}$ homeostasis and neuronal signalling

David Friel (USA) Interplay between ER $\mathrm{Ca}^{2+}$ uptake and release fluxes in neurons and its impact on $\left[\mathrm{Ca}^{+}\right]$dynamics in neurons

Session 8: Nuclear Calcium Signals and Calciumdependent Gene Expression

Chair: Ole Petersen

M. Angélica Carrasco (Chile) Signal transduction and gene expression regulated by calcium release from internal stores in excitable cells James Lechleiter (USA) The role of calcium in cell survival and cell death 
ABSTRACTS AND SESSION SUMMARIES 


\section{OPENING LECTURE:}

\section{CALCIUM SIGNALLING, A HISTORICAL PERSPECTIVE}

\section{ERNESTO CARAFOLI}

Department of Biochemistry, University of Padova, 35121 Padova, Italy, and Venetian Institute of Molecular Medicine (VIMM), 35129 Padova, Italy

When the foundations of physiology were established, $\mathrm{Ca}^{2+}$ was recognised as a structural element, essentially for the stability of bones. Unexpectedly, however, a stunning experiment performed by Ringer 120 years ago showed that $\mathrm{Ca}^{2+}$, was also a carrier of biological information. In the case of Ringer, the information was carried to the myofibrils of heart cells, eliciting their contraction. In the decades to follow, $\mathrm{Ca}^{2+}$ was found to transmit signals to an increasing number of cellular functions: $\mathrm{Ca}^{2+}$ is now universally recognised as the most important transducer of biological signals.

The signalling function demands that the concentration and the movements of free $\mathrm{Ca}^{2+}$ inside cells be carefully controlled. $\mathrm{Ca}^{2+}$ inside cells is indeed maintained at a concentration oscillating around 10-7 M, since most targets respond to the calcium signal in this concentration range. Deviations of $\mathrm{Ca}^{2+}$ to concentrations much above this level will lead to the permanent activation of all $\mathrm{Ca}^{2+}$ targets, a situation incompatible with cell life. The maintenance of the concentration of $\mathrm{Ca}^{2+}$ in the sub- $\mu \mathrm{M}$ range is achieved through the reversible complexation to binding proteins, the best known of which are the EF-hand proteins: These proteins buffer $\mathrm{Ca}^{2+}$, however, their most important task is the processing of the information it carries. They decode the $\mathrm{Ca}^{2+}$ signal by undergoing conformational changes, at the end of which $\mathrm{Ca}^{2+}$ information is transferred to the targets. Other cellular proteins only buffer $\mathrm{Ca}^{2+}$ without processing its signal. They are intrinsic to membranes, and transport it across them. They are located in the plasma membrane and in the membrane of organelles, and belong to several classes: Channels, ATPases (pumps), $\mathrm{Na}^{+} / \mathrm{Ca}^{2+}$ $\left(\mathrm{H}^{+} / \mathrm{Ca}^{2+}\right)$ exchangers and an electrophoretic $\mathrm{Ca}^{2+}$ uniporter in the inner mitochondrial membrane. These transporters function with different $\mathrm{Ca}^{2+}$ affinities and total transport capacities, thus satisfying the various $\mathrm{Ca}^{2+}$ homeostasis demands of cells. Channels, mediate the influx of $\mathrm{Ca}^{2+}$ into cells, and are gated by voltage changes, by specific ligands, or by the emptying of cellular $\mathrm{Ca}^{2+}$ stores. Pumps operate with high $\mathrm{Ca}^{2+}$ affinity in the plasma membrane (PMCA), in the endo(sarco)plasmic reticulum(SERCA) and in the Golgi membranes (HMCA). The pumps are the products of multigene families: Of the four basic isoforms of the PMCA, two are ubiquitously distributed, two are restricted to neurons: The neuronal isoforms eject $\mathrm{Ca}^{2+}$ from cells much more efficiently than the ubiquitous-pumps. $\mathrm{Na}^{+} / \mathrm{Ca}^{2+}$ exchangers are low $\mathrm{Ca}^{2+}$ affinity systems located in the plasma membrane and in the inner membrane of mitochondria: They are particularly active in excitable cells, where the physiological cycle permits the concentration of free $\mathrm{Ca}^{2+}$ to rise towards the $\mu \mathrm{M}$ range. The endo (sarco) plasmic reticulum accumulates $\mathrm{Ca}^{2+}$ using the SERCA pump, whose tertiary structure has recently been solved at atomic resolution, elucidating the details of the reaction cycle and the molecular pathway for $\mathrm{Ca}^{2+}$ across the protein. $\mathrm{Ca}^{2+}$ is discharged from the reticulum by channels that are gated by $\mathrm{Ca}^{2+}$ itself, but require the interaction with second messengers. The best understood ligand is 1,4,5 inositol-tris-phosphate, (InsP3) which is generated by the interaction of first messengers with receptors in the plasma membrane. In sarcoplasmic reticulum $\mathrm{Ca}^{2+}$ is released through a channel which is sensitive to the alkaloid ryanodine (the ryanodine receptor), but probably operates also in non-muscle cells, where it is activated by another ligand, cyclic ADP ribose. The nicotinic acid derivative of NADP (NAADP) has also been shown to discharge $\mathrm{Ca}^{2+}$ from a store which is different from the stores sensitive to InsP3 or to cADPr. $\mathrm{Ca}^{2+}$ released from the reticulum creates micro domains of high concentration, which activate the electrophoretic uptake uniporter. The uniporter is essentially inactive at the ionic $\mathrm{Ca}^{2+}$ concentrations of the cytosol at rest. When a vicinal $\mathrm{Ca}^{2+}$ hotspot is generated the uniporter rapidly dissipates it. Mitochondrial $\mathrm{Ca}^{2+}$ uptake, long considered unimportant, has now come back as a powerful means to regulate cell $\mathrm{Ca}^{2+}$, and, especially, $\mathrm{Ca}^{2+}$-sensitive intramitochondrial dehydrogenases. The system, however, also has another important role. Since mitochondria can also accumulate phosphate, they store large amounts of $\mathrm{Ca}^{2+}$ as insoluble phosphate in situations of persistent cellular $\mathrm{Ca}^{2+}$ overload, temporarily freeing the cytosol of excess $\mathrm{Ca}^{2+}$. Mitochondria are thus vital in the protection of cells in situations of $\mathrm{Ca}^{2+}$ emergency, a function that stresses the ambivalent role of the $\mathrm{Ca}^{2+}$ signal, which is essential to the proper functioning of cells when correctly controlled, but becomes a conveyor of doom when control fails. 


\section{FIRST TOPIC:}

\section{CALCIUM RELEASE CHANNELS}

\section{SESSION 1:}

\section{CALCIUM RELEASE CHANNELS (RYR AND INSP3- GATED CHANNELS). STRUCTURAL ASPECTS AND SINGLE CHANNEL STUDIES}

\section{BARBARA EHRLICH, CHAIR}

Session Chair's Summary: The first session of the meeting started with a presentation by Clara FranziniArmstrong discussing "Functional implications of RyRDHPR relationships in skeletal and cardiac muscle". She identified the proteins of the junctional complex required for excitation-contraction coupling and then showed the location of the proteins and the positioning relative to each other with respect to the function interactions and the role they play in excitation-contraction coupling. Within the protein arrays, groups of four dihydropyridine receptors (DHPR) are located at predetermined locations relative to the subunits of the ryanodine receptor (RyR). Experiments using cells engineered for null mutations of either channel, their isoforms and induced to express chimeric proteins were used to support the compelling model presented.

The second presentation was by Susan Hamilton discussing "RyR1 phosphorylation by PKA and the role of FKBP12". She showed that the regulatory subunit of PKA copurifies with RyR and that the both FKBP12 and FKBP12.6 bind to RyR1, albeit with different affinities. Phosphorylation occurred at serine 2843, which could be dephosphorylated by alkaline phosphatase. Using defined assay conditions, FKBP12 did not protect serine 2843 from phosphorylation nor did phosphorylation at this site prevent FKBP12 from binding. Experiments using FKBP12 deficient mice further supported her conclusions that the role of phosphorylation by PKA and its functional effects are potentially exciting, but complex.

The third presentation was by Gregory Mignery discussing "Structure functional analysis of the inositol 1,4,5trisphosphate receptor". He showed the 3-D structure of the InsP3R at $30 \AA$ resolution where there is the expected 4fold symmetry and two domains, a pinwheel region with four radial spokes interconnected to the central core and a transmembrane region. He then discussed the determinants for assembly into a tetramer and the minimal pore structure. As the minimal pore structure makes a constitutively active channel it will be possible to study channel conformation changes needed for channel opening. The fourth presentation was by Ricardo Bull discussing “ The regulation of single RyR channels from brain by endogenous modulators". In this presentation the effect of redox state on the activation of the RyR was investigated. Effects on both calcium and ATP-dependent activation were analyzed. The conclusion was that both redox state and the concentration of ATP are required to explain changes in the sensitivity of the calcium induced calcium release process. The fifth presentation was by Alan Williams discussing "The interaction of ryanoids with single ryanodine receptor channels". A series of analogs of ryanodine were used to probe the function of single RyR. Different ryanoids were shown to produce graded subconductance changes in the channel. Some of ryanoids showed a voltage-dependent effect on the channel, suggesting that the high affinity binding site for these molecules is within the membrane field.
The final presentation of the session was by Kevin Foskett discussing "Regulation of InsP3 single channel gating in native endoplasmic reticulum". A model for the function of the InsP3 was presented which took into account some new data obtained at very low cytoplasmic calcium concentrations $(10 \mathrm{nM})$. As expected, the model uses one InsP3 binding site; the unique feature of the model is that it uses three calcium binding sites where one of the calcium binding sites is essential for determining InsP3 sensitivity. The conclusions from the fit of the model to the experimental data are that InsP3 is required for channel opening, except when the calcium concentration is very low $(10 \mathrm{nM})$, that calcium dependent activation of the channel was independent of the InsP3 concentration, but calcium dependent inhibition could be modified by the InsP3 concentration.

\section{Abstracts for these presentations follow: \\ FUNCTIONAL IMPLICATIONS OF RYR-DHPR RELATIONSHIPS IN SKELETAL AND CARDIAC MUSCLES}

\section{CLARA FRANZINI-ARMSTRONG}

Dept. Cell Developmental Biology University of Pennsylvania School of Medicine, Anatomy/Chemistry Building B42, Philadelphia, PA 19104-6058, USA

Excitation-contraction coupling in muscle cells requires an interaction between $\mathrm{L}$ type calcium channels of surface membrane/T tubules (the dihydropyridine receptors, DHPRs) and the calcium release channels or ryanodine receptors (RyRs) of the sarcoplasmic reticulum(SR). Immunolabeling with specific antibodies shows that the two types of calcium channels form part of discrete macromolecular complexes, called calcium release units, that are located at the surface membrane and/or along the $\mathrm{T}$ tubules. The complexes include several SR proteins (calsequestrin, triadin, junctin), RyR associated proteins (Homer, FKBP12); the DHPRs and a docking protein that connects SR and surface membranes (junctophilin). Skeletal and cardiac muscles contain three types of RyRs: (RyR1 and RyR3 for skeletal; RyR2 for cardiac) and two forms of the a1 subunit of DHPRs (a1s and a1c). The location of these isoforms and their positioning relative to each other, are quite informative in regard to their functional interactions and to the role they play in excitation-contraction coupling. We have explored this question in a variety of native muscles and in cells engineered for null mutations of either channel and induced to express chimeric forms of the cardiac and isoforms.

a1sDHPR and RyR1 are essential components of the skeletal muscle e-c coupling machinery and they are located in coextensive and interlocked arrays. Within the arrays, groups of four DHPRs (forming a tetrad) are located at predetermined specific locations relative to the four subunits of every other RyR1 in the array. Grouping of DHPRs into tetrads requires the presence of RyR1. This association provides the structural framework for the reciprocal signaling that is known to occur between the two types of channels.

RyR3 are present in some but not all skeletal muscles, always in association with RyR 1 , and in ratios as high as $1: 1$ ratio with the latter. RyR3 neither induce formation of tetrads by DHPRs, nor sustain e-c coupling. In CRUs of muscle fibres, RyR3 are located in a parajunctional position, in proximity of the RyR1-DHPR complexes. It is thus expected that they may be indirectly activated by calcium liberated via the RyR 1 channels.

RyR2 channels, the only isoform present in cardiac muscle, have two locations. One is at CRUs formed by the 
association of SR cisternae with domains of surface membrane and/or $\mathrm{T}$ tubules that contain DHPRs. In these cardiac CRUs, RyR2 and a1cDHPR are in proximity of each other, but not closely linked. This is in keeping with the proposed indirect DHPR-RyR interaction during e-c coupling of cardiac muscle. A second location is on SR cisternae that are not directly linked to surface membrane/T tubules. The RyR2 in these cisternae, which are often several microns away from any DHPRs, must necessarily be activated indirectly,

The positioning and abundance of calsequestrin in the SR lumen are regulated in a developmentally and muscle type specific manner. Overexpression of triadin and junctin in cardiac muscle demonstrates that these two proteins play a major role in the organization of calsequestrin within the junctional SR complex.

\section{RYR1 PHOSPHORYLATION BY PKA AND THE ROLE OF FKBP12}

\section{CRISTINA DANILA, JIA-ZHENG ZHANG, RAO PAPINENI, WEI TANG, SERAP SENCER, AND SUSAN L. HAMILTON}

Department of Molecular Physiology and Biophysics, Baylor College of Medicine.

The skeletal muscle $\mathrm{Ca}^{2+}$ release channel, also known as the ryanodine receptor (RYR1), regulates the release of $\mathrm{Ca}^{2+}$ from sarcoplasmic reticulum (SR) stores. RYR1 binds the immunophilin FKBP12 with high affinity and with a stoichiometry of 1 FKBP12 per subunit. A second isoform, FKBP12.6, also binds to RYR1 with even higher affinity than FKBP12 and with a stoichiometry of 1 FKBP12.6 per subunit. Preferential association of FKBP12 compared to FKBP12.6 with RYR1 is likely to reflect the much higher tissue concentrations of the FKBP12 isoform, not the selectivity of RYR1 for one of the two isoforms.

Hyperphosphorylation of RYR1 has been shown to displace FKBP12 from its binding site (Reiken et al, 2003). Using antibodies specific for either the phosphorylated or dephosphorylated sequence around amino acid 2843, we show that RYR1, as isolated, is partially phosphorylated at this site and can be further phosphorylated with PKA and dephosphorylated with alkaline phosphatase. Phosphorylation with PKA under these conditions produces a small enhancement of $\left[{ }^{3} \mathrm{H}\right]$-ryanodine binding. Neither the removal of FKBP12 with rapamycin nor saturation with FKBP12 alters the ability of PKA to phosphorylate serine 2843. Conversely, phosphorylation of RYR1 with the catalytic subunit of PKA does not have major effects on $\left[{ }^{35} \mathrm{~S}\right] \mathrm{FKBP} 12$ binding to sarcoplasmic reticulum membranes under our assay conditions. RYR1 from FKBP12 deficient mice appears to have a lower level of endogenous phosphorylation than RYR1 from wildtype animals. This finding does not appear to be consistent with a role for FKBP12 in either protecting serine 2843 from phosphorylation or anchoring the phosphatase, calcineurin to RYR1, but could indicate increased calcineurin activity in the absence of its potential inhibitor, FKBP12.

In agreement with the work of others (Marx et al, 2001, Ruehr et al, 2003), we find that the regulatory (RII) subunit of PKA copurifies with RYR. We also find that RII can be displaced from RYR1 by the peptide $\mathrm{Ht} 31$, supporting an anchoring of RII to RYR1 via an AKAP. Extraction of RII with $\mathrm{Ht} 31$ decreases $\left[{ }^{3} \mathrm{H}\right]$ ryanodine binding to RYR1. After extraction of RII with Ht31, RYR1 phosphorylation with the catalytic subunit of PKA again has only small effects on $\left[{ }^{3} \mathrm{H}\right]$ ryanodine binding and now the effect is inhibitory. Studies of RYR1 phosphorylation have produced highly variable results in a number of laboratories, most likely due to the differences in the components of the isolated membranes and/or the assay conditions. In our studies the presence of $\mathrm{Ca}^{2+}$ greatly decreases the extent of RYR1 phosphorylation by the catalytic subunit of PKA. This may indicate the activity of a calcium activated phosphatase (e.g., calcineurin) associated with RYR1 in these membrane preparations (Shin et al, 2003). Alternatively, the extent of phosphorylation may depend on the functional state of the channel. Differences in the functional state of RYR1 and variable amounts of proteins such as RII (in the absence of the catalytic subunit) or calcineurin could lead to variable phosphorylation and, consequently, variable functional outcomes. Our findings suggest that, under our conditions, FKBP12 does not protect serine 2843 from phosphorylation, nor does phosphorylation at this site prevent $\left[{ }^{35} \mathrm{~S}\right]-\mathrm{FKBP} 12$ binding. In our FKBP12 deficient mice, the absence of FKBP12 does not lead to increased RYR1 phosphorylation of serine 2843 , possibility due to increased dephosphorylation and/or compensatory effects in the FKBP12 deficient mice. We cannot, however, exclude a protective effect of FKBP12 on the phosphorylation of other sites on RYR1. Our data also suggest the possibility that the regulatory subunit of PKA may itself have functional effects on RYR1.

\section{References:}

1. Marx SO, Reiken S, Hisamatsu Y, Gaburjakova M, Gaburjakova J, Yang Y-M, Rosemblit N, Marks AR (2001) J Cell Biol 153:699-708

2. Reiken S, Lacampagne A, Zhou H, Kherani A, Lehnart SE, Ward C,Huang F, Gaburjakova M, Gaburjakova J, Rosemblit N, Warren MS, He K-L, Yi G-H, Wang J, Burkhoff D, Vassort G, Marks, AR (2003) J Cell Biol 160: 919-928

3. Ruehr ML, Russell MA, Ferguson DG, Bhat M, Ma J, Damron DS, Scott JD, Bond M (2003) J Biol Chem 278:24831-24836

4. Shin DW, Pan Z, Bandyopadhyay A, Bhat MB, Kim DH, Ma J (2003) Biophys J 83:2539-2549

\section{STRUCTURE FUNCTIONAL ANALYSIS OF THE INOSITOL 1,4,5-TRISPHOSPHATE RECEPTOR}

\section{DANIEL GALVÁN ${ }^{1}$, CLAUDIA KETTLUN ${ }^{1}$, DAN BARE $^{1}$, IRINA SERYSHEVA ${ }^{2}$ AND GREGORY MIGNERY ${ }^{1}$ \\ ${ }^{1}$ Department of Physiology, Loyola University Chicago, 2160 South First Avenue, Maywood, Illinois 60153. ${ }^{2}$ Department of Molecular Physiology and Biophysics, Baylor College of Medicine, One Baylor Plaza, Houston, TX 77030 Baylor College}

The inositol 1,4,5-trisphosphate receptor $\left(\mathrm{InsP}_{3} \mathrm{R}\right)$ occupies a crucial role in intracellular calcium signaling. The $\mathrm{InsP}_{3} \mathrm{R}$ protein is a tetrameric structure resulting from the homo- or hetero- oligomerization of the receptor subunits. Each subunit is divided into three domains consisting of an amino terminal ligand binding domain of $\sim 600$ A.A., a $\sim 1600$ A.A. coupling or regulatory domain and a $\sim 500$ A.A. carboxyl-terminal domain containing the membrane spanning helices and intrinsic calcium release channel. We reported a preliminary $30 \AA 3$-D structure of the $\operatorname{Ins}_{3} \mathrm{R} 1$ tetramer determined by electron cryomicroscopy and single-particle reconstruction (1). The receptor was immunoaffinity purified and formed functional $\mathrm{InsP}_{3}$ and heparin sensitive channels with a similar unitary conductance to native InsP $\mathrm{P}_{3} \mathrm{Rs}$. The channel structure exhibits the expected four-fold symmetry and comprises 
two morphologically distinct regions: a large pinwheel and a smaller square. The pinwheel region has four radial curved spokes interconnected by a central core. The $\mathrm{InsP}_{3}-$ binding core domain was localized within each spoke of the pinwheel region by fitting its X-ray structure into our reconstruction.

Analysis of the sequences mediating receptor subunit oligomerization reveals that assembly into a tetramer appears to be a multi-determinant process involving an additive contribution of membrane spanning helices and the short cytosolic carboxyl-terminus. We have shown that of the six transmembrane regions (TMRs) in each subunit, the $5^{\text {th }}$ and $6^{\text {th }}$ along with the carboxyl-terminus are strong determinants for assembly (2). The fifth and sixth TMRs contain numerous 2-branched amino acids that may participate in coiled/coil formation via putative leucine zipper motifs. InsP ${ }_{3} \mathrm{R}$ truncation mutants were analyzed by sucrose density gradient sedimentation and gel filtration for their ability to assemble. Chemical cross-linking with sDST or DMS of mammalian and bacterially expressed carboxylterminal receptor fragments revealed that sequences within the region confer the formation of subunit dimers. A series of $\mathrm{Ins}_{3}$ receptor carboxyl-terminal fragments and glutathione $\mathrm{S}$-transferase $(\mathrm{GST}) / \mathrm{InsP}_{3} \mathrm{R}$ chimeras were expressed in $E$. coli and used in an in vitro assay to elucidate the minimal sequence responsible for association of the carboxyl-termini into dimers. The minimal sequence is approximately 30 residues in length and is localized between residues 2629 and 2654 . These residues are highly conserved between the three $\operatorname{InsP}_{3} \mathrm{R}$ isoforms $(\sim 80 \%$ identity) as well as the ryanodine receptor ( $40 \%$ identity) and suggest that a conserved assembly motif may exist between the two $\mathrm{Ca}^{2+}$-channel families (3). Substitution of the $\operatorname{Ins}_{3} \mathrm{R}$ carboxyl termini with that of the Ryanodine receptor results in chimeric protein tetramer formation that encodes cesium-conducting channels.

Previously we reported (4) that an $\mathrm{InsP}_{3} \mathrm{R}$ construction containing only the $5^{\text {th }}$ and $6^{\text {th }}$ TMRs formed nearly constitutively open channels with properties very similar to wild type. Though able to bind $\operatorname{InsP}_{3}$, the mutant is insensitive to ligand as well as heparin suggesting that the first four membrane spanning elements are involved in the transduction of ligand occupancy at the $\mathrm{NH}_{2}$-terminus to channel opening. We have examined the calcium dependency of the mutant channel and found that it is relatively insensitive to $\mathrm{Ca}^{2+}$ in the absence of ligand. However, in the presence of either $\mathrm{InsP}_{3}$ or adenophostin $\mathrm{A}$ the channel activity is inhibited by calcium. These results suggest that ligand induced protein conformational changes are necessary for calcium inactivation.

This research is supported by grants from NIH to G. A. M. (MH53367), Susan Hamilton (AR41729) and the MDA and AHA $(9730258 \mathrm{~N})$ to I.I.S.

\section{References:}

1. Serysheva II, Bare, DJ, Ludtke SJ, Kettlun CS, Chiu W, Mignery GA (2003) J Biol Chem 278: 21319-21322

2. Galvan D, Borrego-Diaz E, Peres PJ, Mignery GA (1999) J Biol Chem 274: 29483-29492

3. Galvan DL, Mignery GA (2002) J Biol Chem 277: 48248-48260

4. Ramos-Franco J, Galvan D, Mignery GA, Fill M (1999) J Gen Physiol 114: 243-250

\section{REGULATION OF SINGLE RYR CHANNELS FROM BRAIN BY ENDOGENOUS MODULATORS}

\section{RICARDO BULL, JOSÉ FINKELSTEIN, RODRIGO MAASS AND MARÍA ISABEL BEHRENS. ICBM, Facultad de Medicina, Universidad de Chile, CHILE.}

Ryanodine receptor (RyR) channels form a pathway that allows the release of calcium from endo/sarcoplasmic reticulum to the cytoplasm. RyR-channels are activated by several cytoplasmic agonists/modulators such as $\mathrm{Ca}^{2+}$ and ATP. Single RyR channels from rat brain cortex incorporated in bilayers display three different responses to cytoplasmic free calcium concentration depending on their redox state: low, moderate, and high Po behavior (Marengo et al, Biophys J 74: 1263,1998). The most frequent spontaneous response to calcium is the low Po behavior, characterized by low apparent affinity for activation by calcium $\left(\mathrm{KaCa}^{2+}=110 \mu \mathrm{M}\right)$ and high apparent affinity for inhibition by calcium $\left(\mathrm{KiCa}^{2+}=5 \mu \mathrm{M}\right)$. Decreasing the ratio GSH/GSSG in the cytoplasmic compartment from $40: 1$ to $3: 1$, activated the channel reducing $\mathrm{KaCa}^{2+}$ to 15 $\mu \mathrm{M}$ and increasing $\mathrm{KiCa}^{2+}$ to $23 \mu \mathrm{M}$. Activation by ATP of RyR channels depended on the calcium concentration and on their response to cytoplasmic calcium. Low Po channels presented lower apparent affinity to activation by ATP than moderate Po channels. Oxidation of low Po channels with thimerosal or 2,2'-dithiodipyridine gave rise to moderate Po channels and decreased KaATP. ATP modified the calcium response of RyR channels, increasing apparent affinity for calcium activation and decreasing apparent affinity for calcium inhibition. $3 \mathrm{mM}$ ATP decreased $\mathrm{KaCa}^{2+}$ of low Po channels from 50 to $10 \mu \mathrm{M}$ and increased $\mathrm{KiCa}^{2+}$ from 3 to $70 \mu \mathrm{M} . \mathrm{KaCa}^{2+}$ of moderate Po channels was reduced by 3 mM ATP from 11 to $1.5 \mu \mathrm{M}$ and whereas $\mathrm{KiCa}^{2+}$ was increased $(80 \mu \mathrm{M}$ to $>1 \mathrm{mM})$. ATP decreased $\mathrm{KaCa}^{2+}$ of high Po channels from 1 to $0.1 \mu \mathrm{M}$. Therefore, both the concentration of ATP and the redox state of SH groups determines the response of RyR channels to cytoplasmic calcium concentration. This modulation can underlie changes in the sensitivity of the calcium induced calcium release process that participates in neuronal plasticity. Supported by FONDAP grant 15010006 .

\section{THE INTERACTION OF RYANOIDS WITH SINGLE RYANODINE RECEPTOR CHANNELS (RYR)}

\section{ALAN J WILLIAMS \\ Cardiac Medicine, National Heart and Lung Institute, Faculty of Medicine, Imperial College London, LONDON SW3 6LY, U.K.}

The plant alkaloid ryanodine binds with high affinity and specificity to a class of intracellular $\mathrm{Ca}^{2+}$-release channel known as ryanodine receptors (RyR).

Ryanodine has proven to be an extremely useful tool for identifying sites and levels of expression of the RyR $\mathrm{Ca}^{2+}$ release channel in tissues, for investigation of the role of this channel in cell function and for studying channel function. The high affinity interaction of ryanodine with RyR results in a dramatic alteration in channel function. On formation of the RyR-ryanodine complex, channel open probability (Po) increases markedly and rates of ion translocation are modified. We are investigating the structural features of ryanodine that govern the interaction of the ligand with RyR and the mechanisms underlying the subsequent alterations in channel function by monitoring the effects of a group of congeners and derivatives of 
ryanodine (ryanoids) on individual RyR2 channels incorporated into planar phospholipid bilayers under voltage clamp conditions. The interaction with RyR2 of all ryanoids so far examined results in an increase in $\mathrm{Po}$, however the amplitude of the ryanoid-induced altered conductance state is dependent upon the structure of the ryanoid. Using comparative molecular field analysis of a basis set of ryanoids we have established that specific structural loci on the ligand correlate with the rate of ion translocation in the ryanoid-modified state and that electrostatic effects are more prominent than steric effects. Altered rates of ion translocation in the RyR-ryanoid complex reflect changes in both the relative affinity and permeability of the channel pore for cations.

We propose that the different rates of cation translocation observed in the various RyR-ryanoid complexes represent different conformations of the channel stabilised by specific conformers of the ligand. On the time scale of a single channel experiment ryanodine binds irreversibly to the RyR channel. However, alterations in structure yield some ryanoids with dissociation rate constants orders of magnitude greater than ryanodine. Using representative ryanoids we have characterised a range of parameters for the interaction of these ligands with single RyR channels. The interaction is well described by a simple bimolecular scheme in which the interaction of a single ryanoid molecule with an open conformation of RyR results in altered channel function. The probability of occurrence of the RyR-ryanoid complex is sensitive to trans-membrane voltage and we have investigated the source of this voltage dependence by monitoring parameters of interaction for ryanoids of different formal charge. These investigations demonstrate that the vast majority of the influence of potential arises from a voltage-driven alteration in the affinity of the ryanoid-binding site. The nature and possible location of the high affinity ryanoid binding site on RyR will be discussed.
NOVEL MODEL OF CALCIUM AND INOSITOL 1,4,5-TRISPHOSPHATE REGULATION OF INSP RECEPTOR CHANNEL GATING IN NATIVE ENDOPLASMIC RETICULUM

\section{J. KEVIN FOSKETT \\ Department of Physiology, University of Pennsylvania, Philadelphia, PA 19104 \\ (foskett@mail.med.upenn.edu).}

The InsP ${ }_{3} \mathrm{R} \mathrm{Ca}^{2+}$-release channel has a biphasic dependence on cytoplasmic free $\mathrm{Ca}^{2+}$ concentration $\left(\left[\mathrm{Ca}^{2+}\right]_{\mathrm{i}}\right)(1) . \mathrm{InsP}_{3}$ activates gating primarily by reducing the ability of high $\left[\mathrm{Ca}^{2+}\right]_{\mathrm{i}}$ to inhibit the channel (1). To determine if relieving $\mathrm{Ca}^{2+}$ inhibition is sufficient for channel activation, we examined single-channel activities in low $\left[\mathrm{Ca}^{2+}\right]_{\mathrm{i}}$ in the absence of $\operatorname{Ins}_{3}$, by patch clamping isolated Xenopus oocyte nuclei. For both endogenous Xenopus type 1 and recombinant rat type $3 \mathrm{InsP}_{3} \mathrm{R}$ channels, spontaneous $\mathrm{InsP}_{3}$ independent channel activities with low open probability $P_{\mathrm{o}}$ $(\sim 0.03)$ were observed in $\left[\mathrm{Ca}^{2+}\right]_{\mathrm{i}}<5 \mathrm{nM}$ with the same frequency as in the presence of $\mathrm{InsP}_{3}$, whereas no activities were observed in $25 \mathrm{nM} \mathrm{Ca}^{2+}(2)$. These results establish the half-maximal inhibitory $\left[\mathrm{Ca}^{2+}\right]_{\mathrm{i}}$ of the channel in the absence of $\operatorname{InsP}_{3}(\sim 1.2-4.0 \mathrm{nM})$, and demonstrate that the channel can be active when all (including $\mathrm{InsP}_{3}$ ) of its ligand-binding sites are unoccupied. In the simplest allosteric model that fits all observations in nuclear patchclamp studies of $\left[\mathrm{Ca}^{2+}\right]_{i}$ and $\mathrm{InsP}_{3}$ regulation of steadystate channel gating behavior of types 1 and $3 \operatorname{InsP}_{3} R$ isoforms (1-4), including spontaneous $\mathrm{InsP}_{3}$-independent channel activities (2) and abrogation of high $\left[\mathrm{Ca}^{2+}\right]_{\mathrm{i}}$ inhibition after exposure of $\operatorname{InsP}_{3} \mathrm{R}$ to a low $(<5 \mathrm{nM}) \mathrm{Ca}^{2+}$ bath (5), the tetrameric channel can adopt six different conformations, the equilibria among which are controlled by two inhibitory and one activating $\mathrm{Ca}^{2+}$-binding and one Ins $\mathrm{P}_{3}$-binding sites in a manner similar to the MonodWyman-Changeux model. InsP $\mathrm{P}_{3}$ binding activates gating by affecting the relative affinity for $\mathrm{Ca}^{2+}$ of one of the inhibitory sites in different channel conformations, transforming it into an activating site. $\mathrm{Ca}^{2+}$ inhibition of Ins $\mathrm{P}_{3}$-liganded channels is mediated by an $\operatorname{InsP}_{3}$ independent second inhibitory site. The model also suggests that besides the mechanism controlling liganddependent conformation transitions, there is a ligandindependent gating mechanism that accounts for maximum channel $P_{\mathrm{o}}$ of less than unity (2).

\section{References:}

1. Mak DO, S McBride, JK Foskett (1998) Proc Natl Acad Sci USA 95: 15812-15825

2. Mak DO, S McBride, JK Foskett (2003) J Gen Physiol 122: $583-603$

3. Mak DO, S McBride, V Raghuram, Y.Yue, SK Joseph, JK Foskett (2000) J Gen Physiol 115: 241-255

4. Mak DO, JK Foskett (1997) J Gen Physiol 109: 571-587

5. Mak DO, S McBride, NB Petrenko, JK Foskett (2003). J Gen Physiol 122: 569-581 


\section{SESSION 2:}

CALCIUM RELEASE CHANNELS: RYR, NAADPAND INSP3-GATED CHANNELS

\section{KEVIN FOSKETT, CHAIR}

Session Chair's Summary: Michael Fill presented his recent work that has focused on the issue of how the cardiac ryanodine receptor channel (RyR) turns on and off in response to $\mathrm{Ca}^{2+}$ activation. He described a novel approach for analyzing the behavior of single RyR channels in response to rapid changes in cytoplasmic $\mathrm{Ca}^{2+}$ concentration that employed an ultra-stable bilayer recording system with laser-induced uncaging of $\mathrm{Ca}^{2+}$. Using this system, he has explored three types of channel activation, including neighbor-induced $\mathrm{Ca}^{2+}$-induced $\mathrm{Ca}^{2+}$ release (CICR), feed-through CICR and paired pulse potentiation. He found that a fast transient $\mathrm{Ca}^{2+}$ stimulus induced a burst of channel activity. As the interval between repeated stimuli became shorter, the response to a second stimulus became larger. This response was unexpected, and not yet understood. Also discussed were the mechanisms that terminate channel activity. It was concluded that $\mathrm{Ca}^{2+}$ inhibition was too low affinity, that adaptation or modal gating was probably too slow, and that local ER $\mathrm{Ca}^{2+}$ depletion was a possibility but that we lacked sufficient information.

Barbara Ehrlich discussed the issue of how $\operatorname{InsP}_{3}$ mediated $\mathrm{Ca}^{2+}$ release events could be localized in cells. One hypothesis that her research has explored recently is that interacting proteins of the $\operatorname{Ins}_{3} \mathrm{R}$ release channel might influence its channel properties and play a role in this regard. She described the interaction of chromogranin, a low-affinity $\mathrm{Ca}^{2+}$ binding protein located in the lumen of secretory granules. Addition of this protein to the lumenal side of Ins $_{3} \mathrm{R}$ channels recorded in lipid bilayer membranes enhanced its $\mathrm{InsP}_{3}$-induced gating activity. Expression in cells of a peptide that blocked the interaction in vitro attenuated $\mathrm{Ca}^{2+}$ release in a neuronal cell line, suggesting that this interaction is of physiological importance.

Anthony Galione and Eduardo Chini presented overviews of the evidence that has implicated NAADP as a novel second messenger that mobilizes $\mathrm{Ca}^{2+}$ from intracellular stores in a number of different cell types. The stores and release channel appear to be distinct from those associated with the RyR and InsP $\mathrm{P}_{3} \mathrm{R}$. Indeed, the most recent evidence suggests that perhaps lysosomes are the target store, with $\mathrm{Ca}^{2+}$ accumulation being dependent on a proton pump and $\mathrm{Ca}^{2+} / \mathrm{H}^{+}$exchange. Both presentations demonstrated the physiological significance of this pathway, and highlighted the need to understand the biochemical pathways that couple receptor activation to changes in NAADP levels, as well as the nature of the NAADP receptor and the release channel involved.

\section{Abstracts for these talks follow:}

\section{CALCIUM REGULATION OF SINGLE CARDIAC} RYANODINE RECEPTOR CHANNELS

\section{MICHAEL FILL}

Loyola University Chicago, Department of Physiology, Maywood, IL 60106

In cardiac muscle, $\mathrm{Ca}^{2+}$-sensitive ryanodine receptor ( $\mathrm{RyR}$ ) $\mathrm{Ca}^{2+}$ release channels mediate the intracellular $\mathrm{Ca}^{2+}$ signals that govern contraction. The RyR channels operate in tightly organized arrays at discrete sites on the sarcoplasmic reticulum (SR). It is believed that $\mathrm{Ca}^{2+}$ entry during the action potential activates $\mathrm{Ca}^{2+}$ release from these sites, a process that is called $\mathrm{Ca}^{2+}$-induced $\mathrm{Ca}^{2+}$ release (CICR). Intuitively, the CICR should be self-regenerating (i.e. $\mathrm{Ca}^{2+}$ released triggering further $\mathrm{Ca}^{2+}$ release). However, the CICR process in vivo is precisely controlled. It is assumed that some local negative feedback must exist to counter the inherent positive feedback of CICR. Several candidate mechanisms have been proposed including $\mathrm{Ca}^{2+}$ dependent inactivation, stochastic attrition, adaptation and "fateful" inactivation. Studies to date on intact or permeabilized cells have not definitively identified the negative feedback that controls the CICR process. Likewise, single channel studies have not clearly established mechanism(s) that "turn off" the RyR channel. In cells, RyR channels are subject to regulation by numerous soluble regulatory factors and respond to large fast trigger $\mathrm{Ca}^{2+}$ stimuli. Here, we combine single RyR channel recording, flash photolysis and near-field epifluorescence $\mathrm{Ca}^{2+}$ detection to define how single RyR channels respond to large fast $\mathrm{Ca}^{2+}$ stimuli. Single cardiac RyR channels were incorporated into bilayers and a novel flash-stir method was used to generate fast $\mathrm{Ca}^{2+}$ transients on the cytosolic side of the channel. A high numerical aperture, multimode optic fiber was used to carry photolytic UV flashes as well as excitation/emitted light for local $\mathrm{Ca}^{2+}$ detection by Rhod-2. A fast transient $\mathrm{Ca}^{2+}$ stimulus induced a brief burst of channel activity. We found that as the interval between two identical fast transient stimuli became shorter $(<300 \mathrm{~ms})$, the channel's response to the $2^{\text {nd }}$ stimulus became larger. This pairedpulse facilitation may be due to an elevated local $\mathrm{Ca}^{2+}$ in the channel's microenvironment after the $1^{\text {st }}$ stimulus. If so, then this elevated $\mathrm{Ca}^{2+}$ does not inactivate the channel prior to the $2^{\text {nd }}$ stimulus (i.e. there is no high affinity $\mathrm{Ca}^{2+}$ inactivation). Another possibility is that the channel undergoes some sort of recovery process following the $1^{\text {st }}$ $\mathrm{Ca}^{2+}$ stimulus and the $2^{\text {nd }} \mathrm{Ca}^{2+}$ stimulus simply "catches" it before it is complete. Regardless of the underlying mechanism, this paired-pulse facilitation of single cardiac RyR channel function is an interesting phenomenon with potential physiological relevance.

Supported by NIH grants R01HL57832 \& R01HL64310

\section{REGULATION OF THE INSP ${ }_{3}$ R FROM BOTH SIDES}

\section{BARBARA E. EHRLICH}

\section{Yale University, New Haven CT USA}

Intracellular calcium signals have distinct temporal and spatial patterns. In this presentation, the effect of regulation of the inositol $(1,4,5)$-trisphosphate receptor $\left(\operatorname{Ins} \mathrm{P}_{3} \mathrm{R}\right)$ will be discussed. The $\operatorname{InsP}_{3} \mathrm{R}$ is regulated by endogenous compounds such as $\mathrm{InsP}_{3}$, calcium and ATP and modulated by associated proteins from both the cytoplasmic and lumenal side of the channel. The functional implications of ligand and cofactor binding to the $\operatorname{InsP}_{3} \mathrm{R}$ was studied using single channel and calcium imaging measurements. Single channel activity was modulated by addition of chromogranin, a low affinity/high capacity $\mathrm{Ca}$ storage protein, to the lumenal side of the channel, as well as by a number of reagents added to the cytoplasmic surface. In calcium imaging studies a regional specificity in signal initiation and propagation was observed. We found that in many cell types the rate of InsP3 production and surface-to-volume effects play minor roles in determining these temporal and spatial patterns. However, the reagents found to modulate single channel activity were important in the generation of specific 
subcellular calcium signaling patterns in intact cells. For example, we disrupted the interaction between chromogranin and the $\operatorname{Ins}_{3} \mathrm{R}$ by adding a 20 amino acid fragment made from the near $\mathrm{N}$-terminal portion on chromogranin B (CGB), which competed with chromogranin for its binding site on the $\operatorname{InsP}_{3} \mathrm{R}$. A peptide with the same amino acids as the CGB fragment, but with a randomized sequence, was used as a control. When monitoring $\mathrm{Ins}_{3} \mathrm{R}$ type $\mathrm{I}$ incorporated into planar lipid bilayers and activated by cytoplasmic $\operatorname{Ins}_{3}$ and luminal chromogranin, addition of the CGB fragment reversed the enhancing effect of chromogranin on channel activity. Moreover, expression of the CGB fragment in the ER of neuronally differentiated PC12 cells attenuated agonistinduced intracellular $\mathrm{Ca}^{2+}$ release. The randomized peptide had no effect on the channel activity or on intracellular $\mathrm{Ca}^{2+}$ signaling. These results show that the $\mathrm{InsP}_{3} \mathrm{R} /$ chromogranin interaction amplifies $\mathrm{Ca}^{2+}$ release from the ER and that chromogranin is an essential component of this intracellular channel signaling complex. Similar functional studies have been done to identify additional critical cytosolic and lumenal cofactors for the InsP $\mathrm{P}_{3} \mathrm{R}$. These functional interactions provide the basis for understanding the consequences of channel modulation for intracellular $\mathrm{Ca}^{2+}$ signaling patterns.

\section{MULTIPLE MESSENGERS AND STORES FOR CALCIUM SIGNALLING}

\section{ANTONY GALIONE \\ Department of Pharmacology, University of Oxford OX1 3QT UK}

The discovery of cyclic adenosine diphosphate ribose (cADPR) and nicotinic acid adenine dinucleotide phosphate (NAADP) as $\mathrm{Ca}^{2+}$ releasing messengers has provided additional insight into how complex $\mathrm{Ca}^{2+}$ signalling patterns are generated. There is mounting evidence that these molecules along with the more established messenger, myo-inositol 1,4,5-trisphosphate (IP3), have a widespread messenger role in shaping $\mathrm{Ca}^{2+}$ signals in many cell types. These molecules have distinct structures and act on specific $\mathrm{Ca}^{2+}$ release mechanisms. Emerging principles are that cADPR enhances the $\mathrm{Ca}^{2+}$ sensitivity of ryanodine receptors (RYRs) to produce prolonged $\mathrm{Ca}^{2+}$ signals through $\mathrm{Ca}^{2+}$-induced $\mathrm{Ca}^{2+}$ release (CICR), while NAADP acts on a novel $\mathrm{Ca}^{2+}$ release mechanism to produce a local trigger $\mathrm{Ca}^{2+}$ signal which can be amplified by CICR by recruiting other $\mathrm{Ca}^{2+}$ release mechanisms. Whilst IP3 and cADPR mobilise $\mathrm{Ca}^{2+}$ from the endoplasmic reticulum (ER), recent evidence from the sea urchin egg suggests that the major NAADP-sensitive $\mathrm{Ca}^{2+}$ stores are reserve granules, acidic lysosomal-related organelles.

\section{NICOTINIC ACID ADENINE DINUCLEOTIDE PHOSPHATE: A NEW SECOND MESSENGER?}

\author{
EDUARDO N. CHINI \\ Department of Anesthesiology, Mayo Clinic and \\ Foundation, Rochester, Minnesota 55905.
}

Nicotinic acid adenine dinucleotide phosphate (NAADP) is one of the most potent stimulators of intracellular $\mathrm{Ca}^{2+}$ release known to date. The role of the NAADP system in physiological processes is being extensively investigated at the present time. Exciting new discoveries in the last 5 years suggest that the NAADP-regulated system may have a significant role in intracellular $\mathrm{Ca}^{2+}$ signaling. The NAADP receptor and its associated $\mathrm{Ca}^{2+}$ pool have been hypothesized to be important in several physiological processes including fertilization, $T$ cell activation, and pancreatic secretion. However, whether NAADP is a new second messenger or a tool for the discovery of a new $\mathrm{Ca}^{2+}$ channel is still an unanswered question. However, recent observations indicate that NAADP may be in fact a new intracellular regulator of the homeostasis of $\mathrm{Ca}^{2+}$.

Over the last decade, intensive research on mechanisms of intracellular calcium regulation has led to the discovery of potential new second messengers and a novel $\mathrm{Ca}^{2+}$ release system. The role of the NAADP system in physiological processes is being extensively investigated at the present time, and the title of this review may imply that we can provide an answer for this question. However, although NAADP displays many characteristics of a signal transduction molecule, in our opinion, we are far from answering whether NAADP is indeed an intracellular messenger.

Several requirements must be fulfilled before NAADP can be considered an intracellular messenger. 1) NAADP levels must be determined in cells. 2) The physiological pathways for the synthesis of NAADP must be defined. 3) The concentration of intracellular NAADP must be regulated by external or internal stimuli. 4) A correlation between stimulated intracellular NAADP levels and $\mathrm{Ca}^{2+}$ release must be established.

Recent discoveries indicate that NAADP may be in fact an intracellular messenger. However, until it is clearly demonstrated other possibilities need to be explored. It is possible that NAADP may not be an intracellular messenger, and, in analogy to ryanodine, NAADP may be a pharmacological, rather than physiological, agonist of a new intracellular $\mathrm{Ca}^{2+}$ channel. However, even if NAADP turns out not to be a physiological agonist, it will lead to the discovery of a new class of intracellular $\mathrm{Ca}^{2+}$ channels with unique properties relevant to cell physiology. Certainly, the future holds new and exciting discoveries in this field. 


\section{SESSION 3:}

\section{REGULATION OF CALCIUM RELEASE CHANNELS (RYR AND INSP3-GATED CHANNELS)}

\section{SUSAN HAMILTON, CHAIR}

Session Chair's Summary: The first speaker in this session was Paul Allen who spoke on the use of chimeras of RYR1 (skeletal) and RYR3 to assess the regions of RYR1 that are involved in mechanical excitationcontraction coupling. These workers found that a 174 AA region between AA4007 and 4181 of RyR1 is the most likely site for 4-CmC binding site. Data were presented to suggest that residues 1,681 to 3,770 of RyR1 played a major role in mechanical excitation-contraction coupling but other regions separated in the primary sequence were also involved in this process.

Colin Taylor then spoke on the regulation of capacitative and non-capacitative entry pathways in vascular smooth muscle cells and their regulation by vasopressin and $5-\mathrm{HT}$. He presented evidence that vasopressin, via arachidonic acid, stimulates cGMP formation while 5-HT is much less effective. He proposed that the different effects of the two hormones on $\mathrm{Ca}^{2+}$ entry results from their differing abilities to stimulate the enzyme DAG lipase, which catalyses release of arachidonic acid from diacylglycerol. He also presented evidence to support the idea that vasopressin stimulates both PLC and DAG lipase, while 5-HT stimulates only PLC.

Roberto Coronado spoke on their studies demonstrating that the beta subunit of the L-type calcium channel plays a direct role in mechanical coupling in skeletal muscle. Their major findings were that both the II-III loop of the alpha 1 subunit and the beta subunit are required for mechanical coupling.

Kurt Beam reported on his studies using FRET to assess interactions in muscle myotubes. They introduced either cyan or yellow fluorescent proteins (ECFP, EYFP) at various sites of the $\alpha_{1 S}$ and beta subunits of the DHPR and at the amino terminus of RyR 1 and measured FRET efficiency using the method of enhanced donor emission after acceptor photobleaching. They found evidence that RyR1 is in close apposition with the amino terminal of beta $_{1 \mathrm{a}}$ and the carboxyl terminal of $\alpha_{1 \mathrm{~s}}$

Hector Valdivia spoke on the regulation of cardiac ryanodine receptors (RyR2) by the E-F hand containing protein, sorcin. They demonstrated that sorcin binds to RyR2 with high affinity and inhibits channel activity, but this modulation was decreased by sorcin phosphorylation. He suggested that sorcin may play an important role in regulating the response of RYR2 to PKA. An extremely intriguing observation was that sorcin levels increase with heart failure, without any change in RYR2 phosphorylation. These workers suggested that sorcin is an important blocker of RyR2 during excitation-contraction coupling and that increased levels of sorcin expression may contribute to decreased $\mathrm{Ca}^{2+}$ release observed in HF cells.

Humbert De Smedt spoke about the regulation of InsP3receptors by calmodulin. His group has identified a $\mathrm{Ca}^{2+}$-independent CaM-binding site in the $\mathrm{N}$-terminal part of the InsP3R. He showed that apoCaM binding to this site decreases affinity of the receptor for InsP3. They also showed that suramin, presumably binding at CaM binding sites, decreases the affinity of the receptor for InsP3. They also investigated the interaction of CaBPs with InsP3Rs and found a calcium-independent interaction between $\mathrm{CaBP}$ and the most $\mathrm{N}$-terminal $\mathrm{CaM}$-binding domain (AA. 49-81) of InsP3R1

\section{STRUCTURE FUNCTION STUDIES OF RYR1}

\author{
PAUL ALLEN \\ Brigham \& Women's Hospital, Boston, MA, USA
}

If for no other reasons than its sheer size and its need for intermolecular interactions, elucidation of the molecular details of how the primary structure of RyR-1 relates to its $\mathrm{Ca}^{2+}$ channel function has been very difficult. It has long been known that activity of RyR 1 is activated by $\mu \mathrm{M}$ cytoplasmic $\mathrm{Ca}^{2+}$, caffeine and 4 Chloro-m-cresol (4CmC) and inhibited by $\mathrm{mM}$ cytoplasmic $\mathrm{Ca}^{2+}$ and $\mathrm{Mg}^{2+}$, yet the mechanism(s) that govern its sensitivity to these divalent cations and compounds is still unknown. Furthermore RyR1, unlike RyR2 and RyR3, displays the unique property of achieving excitation-contraction (E-C) coupling in the absence of extracellular $\mathrm{Ca}^{2+}$, a property depicted as skeletal-type E-C coupling. A mechanical coupling model, in which there is a direct physical interaction between RyR 1 and the dihydropyridine receptor (DHPR) in the plasma membrane, has been proposed to explain this phenomenon. In addition we have previously demonstrated that in addition to the orthograde signal from the DHPR to RyR1, there is also a "retrograde" signal from RyR1 to DHPR that is responsible for enhancement of the $\mathrm{Ca}^{2+}$ channel activity of DHPR. This reciprocal [bi-directional] interaction is appears to be RyR1 specific since native and expressed RyR3 and expressed RyR2 lack the ability to enhance DHPR activity. Several studies attempting to define RyR1 structure-function have been done by others using heterologously expressed recombinant proteins. Because the heterologously expressed recombinant proteins lack functionally important interactions normally existing between the RyR-1 channel protein and key proteins normally present within the junctional SR membrane they have functional properties which are similar to but not identical to the native $\mathrm{Ca}^{2+}$ channel of skeletal SR. Thus, in order to study structure function relationships the recombinant RyR-1 channel protein must be studied in the environmental context of the muscle cell lacking wild type RyR1.

Extensive studies have been focused on the identification of the molecular domains of DHPR and RyR1 involved in such bi-directional signaling exploiting the differences between the skeletal and cardiac DHPR physiology using chimeric DHPRs. From these studies there is compelling evidence suggesting that the $45 \mathrm{AA}$ segment of the putative cytoplasmic loop between the intramembrane segments II and III (II-III loop) of the $\alpha_{1 \text { s }}$ subunit of DHPR is both necessary and sufficient for normal E-C coupling. We have tried to exploit similar differences in the physiologic function of RyR1 and RyR3 to determine the binding site of $4 \mathrm{CmC}$ and the site(s) of interaction between RyR1 and the DHPR by expressing RyR1/RyR3 chimeras in dyspedic myotubes. Using these chimeras we have found a 174 AA region between AA4007 and 4181 of RyR1 that are the likely $4 \mathrm{CmC}$ binding site. However although we first found that exchanging residues 1,681 to 3,770 of RyR 1 for the corresponding residues from RyR3 allowed RyR3 to gain skeletal-type E-C coupling we have more recently shown that the sites of interaction between these two proteins is much more complex and requires regions that are far separated from one another in the "linear" protein sequence. 
REGULATION OF CAPACITATIVE AND NONCAPACITATIVE CA ${ }^{2+}$ ENTRY PATHWAYS IN A7R5 VASCULAR SMOOTH MUSCLE CELLS

\section{COLIN W TAYLOR \\ Department of Pharmacology, Cambridge, UK}

In A7r5 vascular smooth muscle cells, vasopressin stimulates phospholipase $\mathrm{C}$ (PLC) and both the $\mathrm{IP}_{3}$ and the DAG formed then regulate $\mathrm{Ca}^{2+}$ entry pathways. $\mathrm{IP}_{3}$, by emptying intracellular $\mathrm{Ca}^{2+}$ stores, activates capacitative $\mathrm{Ca}^{2+}$ entry (CCE), while arachidonic acid released from DAG both activates non-capacitative $\mathrm{Ca}^{2+}$ entry (NCCE) and inhibits CCE. Using selective inhibitors of each pathway $\left(1 \mu \mathrm{M} \mathrm{Gd}{ }^{3+}\right.$ to inhibit CCE; $30 \mu \mathrm{M}$ LOE 908 to inhibit NCCE), we demonstrate that in the presence of maximal or submaximal concentrations of vasopressin, only the NCCE pathway is active, while CCE is transiently active only after removal of vasopressin. This hormone therefore stimulates the two pathways in a strictly sequential sequence: first NCCE and then CCE. We provide evidence that the effects of arachidonic acid are mediated via activation of nitric oxide synthase 3 (NOS 3 ). The NO produced then directly activates NCCE, and inhibits CCE via its ability to stimulate cGMP formation and thence activation of protein kinase G. Other receptors that also couple to PLC have very different effects to vasopressin on $\mathrm{Ca}^{2+}$ entry pathways. The $\mathrm{Ca}^{2+}$ entry evoked by $5-\mathrm{HT}$ is mediated entirely by CCE, even thought the $\mathrm{Ca}^{2+}$ mobilization is identical to that evoked by vasopressin. We present evidence that vasopressin, via arachidonic acid, stimulates cGMP formation while 5-HT is much less effective. We speculate that the different effects of the two hormones on $\mathrm{Ca}^{2+}$ entry result from their differing abilities to stimulate the enzyme DAG lipase, which catalyses release of arachidonic acid from diacylglycerol. Vasopressin, we propose, stimulates both PLC and DAG lipase, while 5-HT stimulates only the former. In conclusion, two receptors that share an ability to stimulate $\mathrm{PLC}, \mathrm{Ca}^{2+}$ mobilization and $\mathrm{Ca}^{2+}$ entry, nevertheless recruit different $\mathrm{Ca}^{2+}$ entry pathways (and so perhaps different physiological responses).

\section{MOLECULAR DOMAINS OF THE CALCIUM CHANNEL TRIGGERING EXCITATION-CONTRA- CTION COUPLING}

\section{ROBERTO CORONADO, CHRIS A. AHERN, DAVID

Department of Physiology, University of Wisconsin School of Medicine, Madison, WI 53706.

Molecular understanding of the mechanism of excitationcontraction (EC) coupling in skeletal muscle has been made possible by cultured myotube models lacking specific dihydropyridine receptor (DHPR) subunits $\left(\alpha_{1 S}\right.$, $\alpha 2-\delta, \beta 1 \mathrm{a}, \gamma 1)$ and ryanodine receptor isoform 1 (RyR1). Transient expression of missing cDNAs in mutant myotubes leads to a rapid recovery, within days, of various $\mathrm{Ca}^{2+}$ current and EC coupling phenotypes. These myotube models have thus permitted structure-function analysis of EC coupling domains present in the DHPR controlling the opening of RyR1. The purpose of this presentation is to highlight advances made by our laboratory towards understanding the contribution of domains present in $\alpha_{1 \mathrm{~s}}$ and $\beta_{1 \mathrm{a}}$ subunits of the skeletal DHPR to EC coupling signaling. Our main contention is

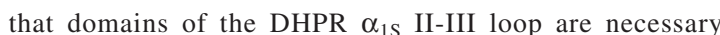
but not sufficient to recapitulate skeletal-type EC coupling. Rather, the functional DHPR unit that controls the EC coupling signal appears to be the $\alpha_{1 S} / \beta_{1 \text { a }}$ pair.

\section{References:}

1. Ahern CA, Arikkath J, Vallejo P, Gurnett CA, Powers PA, Campbell KP, Coronado R (2001) Proc Natl Acad Sci USA 98: 6935-6940

2. Ahern CA, Bhattacharya D, Mortenson L, Coronado R. (2001) Biophys J 81: 3294-3307

3. Sheridan DC, Cheng W, Ahern CA, Mortenson L, Alsammarae D, Vallejo P, Coronado, R.(2003) Biophys J 84: 220-237

4. Ahern CA, Sheridan DC, Cheng W, Mortenson L, Nataraj P, Allen P, De Waard M, Coronado, R.(2003) Biophys J 84: 942-959

\section{ARRANGEMENT OF PROTEINS INVOLVED IN EXCITATION-CONTRACTION COUPLING AS ANALYZED BY FRET}

\section{KURT BEAM \\ College of Veterinary Medicine and Biomedical Sciences, Colorado State University, USA.}

In skeletal muscle, excitation-contraction (EC) coupling proceeds from depolarization of the plasma membrane to the release of calcium from the sarcoplasmic reticulum (SR) in a manner that does not depend upon the entry of external $\mathrm{Ca}^{2+}$. Rather, it appears that conformational changes of the dihydropyridine receptor (DHPR), a voltage-gated calcium channel in the plasma membrane, are coupled to opening of the ryanodine receptor (RyR1) which serves as the calcium release channel in the SR. Morphological evidence for such coupling is provided by freeze fracture images of the plasma membrane at regions of junction with the SR, which reveal that DHPRs are organized into groups of four (tetrads) whose occurrence depends on the presence of RyR1. However, there is currently no clear picture as to the identity of the primary amino acid sequences of the DHPR and RyR1 that may be closely apposed to one another. As one approach to this issue, we have begun to use fluorescence resonant energy transfer (FRET) to assay proximity between specific sites of DHPRs and RyRs in living muscle cells. Specifically, we have introduced either cyan or yellow fluorescent proteins (ECFP, EYFP) at various sites of the $\alpha_{1 \mathrm{~s}}$ and $b$ subunits of the DHPR and at the amino terminus of RyR1. To measure FRET efficiency we have been using the method of enhanced donor emission after acceptor photobleaching. Using this method, we have found that there is substantial FRET in dysgenic myotubes (null for $\alpha_{1 \mathrm{~S}}$ ) co-expressing ECFP- $\alpha_{1 \mathrm{~S}}$ and $\alpha_{1 \mathrm{~S}}$-EYFP, but not in myotubes null for both $\mathrm{a}_{1 \mathrm{~S}}$ and RyR1, suggesting that the DHPRs in tetrads are arranged such that the carboxyl terminus of one $\alpha_{1 \mathrm{~S}}$ is adjacent to the amino terminus of its neighboring $\alpha_{1 \mathrm{~s}}$. We have also examined the FRET efficiency of an ECFP-EYFP (CY) tandem either in free solution or linked to the amino or carboxyl terminals of $\alpha_{1 \mathrm{~S}}$ and $\beta_{1 \mathrm{a}}$ or to the proximal portion of the II-III loop in a two fragment construct $\alpha_{1 \mathrm{~S} \text { (I-II) }} \mathrm{CY}+\alpha_{1 \mathrm{~S} \text { (III-IV). The }}$ FRET efficiency is reduced when the fusion proteins are targeted to junctions, which is consistent with the idea that junctional proteins may restrict the rotational mobility of the CY tandem. For two of the constructs $\left(\mathrm{CY}-\beta_{1 \mathrm{a}}\right.$ and $\left.\alpha_{1 \mathrm{~S}}-\mathrm{CY}\right)$ FRET efficiency is increased when the construct is expressed in dyspedic myotubes (no RyR1) rather than in dysgenic myotubes, suggesting that 
RyR1 may come into close apposition with the amino terminal of $\beta_{1 \mathrm{a}}$ and the carboxyl terminal of $\alpha_{1 \mathrm{~s}}$. Future experiments will examine if the FRET efficiency of the CY reporter changes at one or more of the attachment sites during the process of EC coupling.

\section{MODULATION OF CARDIAC RYANODINE RECEPTORS BY SORCIN, A NOVEL REGULATOR OF EXCITATION-CONTRACTION COUPLING}

\section{EMILY F FARRELL, ANAID ANTARAMIAN, NANCY BENKUSKY, ANDREW J LOKUTA, HÉCTOR H VALDIVIA \\ Department of Physiology, University of Wisconsin Medical School, Madison, WI, USA.}

Sorcin, a $22-\mathrm{kDa} \mathrm{Ca}^{2+}$-binding protein originally identified in multi-drug resistance cells, is widely expressed in mammalian tissues. Its precise cellular role remains unknown, but in cardiac cells, sorcin binds to ryanodine receptors $\left(\right.$ RyR2) with high affinity $\left(K_{D}=480 \mathrm{nM}\right)$ and inhibits channel activity (Lokuta et al. J. Biol. Chem. $272: 25333$, 1997). Phosphorylation of sorcin with the catalytic subunit of protein kinase A (PKA) decreases the ability of sorcin to modulate RyR2. Thus, sorcin is capable of protein-protein interactions with the RyR2, and signaling pathways that increase PKA activity (i.e. $\beta$ adrenergic stimulation) may modulate $\mathrm{Ca}^{2+}$ release from the sarcoplasmic reticulum (SR) by relieving the inhibitory effect of sorcin on RyR2. Here we report that sorcin levels in cardiac homogenates of a fast-paced canine model of heart failure (HF) are increased $39 \pm 15 \%$ with respect to sham-operated control $\operatorname{dogs}(\mathrm{n}=7$ and 9 dogs, respectively), as detected by Western blots. Immunofluorescence labeling and confocal microscopy in single ventricular myocytes of control and HF dogs reveals that sorcin is spatially distributed throughout the cell, with regularly spaced peaks of fluorescence spread at length intervals equal to that of a single sarcomere $(\sim 2 \mathrm{~mm})$, suggesting preferential localization of sorcin to T-tubule/ SR junctions. $\mathrm{Ca}^{2+}$ release from SR vesicles of HF cells is depressed by $32 \pm 7 \%$, but the open probability (Po) of individual, sorcin-free RyR2 reconstituted in lipid bilayers is the same for control and HF groups ( $\mathrm{Po}=0.21 \pm 0.06$ and $0.18 \pm 0.04$ at $p \mathrm{Ca} 4.7 ; 0.02 \pm 0.01$ and $0.03 \pm 0.02$ at $p$ Ca 7.0, respectively). Single RyRs isolated from canine and human HF display no major structural or functional differences when compared to control channels. Addition of rapamycin to HF RyRs increased the frequency of subconductance states, suggesting that FKBP remains associated to RyRs. Further, HF RyRs are phosphorylated by PKA to the same extent as control channels, implying that the channel's structural domains for phosphorylation remain unaltered in HF. Fast solution exchange in the microenvironment of reconstituted channels indicates that sorcin rapidly blocks $(<50 \mathrm{~ms})$ RyR 2 , suggesting that sorcin is capable of harnessing RyR2 activity on a beat-tobeat basis. The privileged and rapid access of sorcin to RyR2 indicate that sorcin is an important blocker of RyR2 during excitation-contraction coupling and that an increased level of sorcin expression, more than intrinsic alterations of the RyR2, may be a critical component of the depressed $\mathrm{Ca}^{2+}$ release observed in HF cells.

Supported by NIH and AHA.

\section{IP ${ }_{3}$-INDUCED Ca ${ }^{2+}$ RELEASE AND CALMODULIN}

\section{NAEL NADIF KASRI\&, H. LLEWELYN \\ RODERICK*, GEERT BULTYNCK\&, KAROLINA \\ SZLUFCIK\&, JAN B. PARYS\&, MARTIN, D. BOOTMAN*, MICHAEL J. BERRIDGE*, GEERT CALLEWAERT\&, LUDWIG MISSIAEN\& AND HUMBERT DE SMEDT\&}

\& Laboratory of Physiology, K.U.Leuven, Belgium, * Laboratory of Molecular Signalling, Babraham Institute, Cambridge, UK

Inositol 1,4,5-trisphosphate receptors (IP3Rs) are known to be regulated by an increasing number of other proteins. IP3Rs have a consensus $\mathrm{Ca}^{2+}$-calmodulin $\left(\mathrm{Ca}^{2+}-\mathrm{CaM}\right)$ binding site of relatively high affinity in their modulator region. In addition we found a $\mathrm{Ca}^{2+}$-independent CaM-binding site of much lower affinity in the N-terminal part of the IP3R [1]. $\mathrm{Ca}^{2+}$ independent $\mathrm{CaM}$ binding to this site significantly decreased the affinity for IP3 [2]. This may provide a tonic regulation of IP3R activity, and could explain the low sensitivity of IP3mediated $\mathrm{Ca}^{2+}$ release in neuronal tissues where $\mathrm{CaM}$ is highly expressed. Two synthetic peptides matching IP3R1 amino acids 49-81 and 106-128, bound CaM independently of $\mathrm{Ca}^{2+}$. These sequences were components of a discontinuous $\mathrm{Ca}^{2+}$-independent CaM-binding domain responsible for the inhibition of IP3 binding and IP3-induced $\mathrm{Ca}^{2+}$ release (IICR). Suramin, a polysulfonated naphtylurea, that has been shown to interact with the CaM-binding sites of the RyR and thereby counteract the effects of $\mathrm{CaM}$, also interacted with the $\mathrm{Ca}^{2+}$-dependent and $\mathrm{Ca}^{2+}$-independent $\mathrm{CaM}$ binding sites on the IP3R. Suramin mimicked the inhibitory effect of $\mathrm{CaM}$ by lowering the affinity for IP3. The data suggest that suramin as well as CaM interrupt an intramolecular interaction between the N-terminal 1-225 AA. of IP3R1 and the IP3-binding core.

IP3Rs were recently demonstrated to be activated independently of IP3 by a family of calmodulin (CaM)-like neuronal calcium-binding proteins (CaBP) [3]. We investigated the interaction of CaBP with IP3Rs, and their functional effects on IICR. We found a calciumindependent interaction between $\mathrm{CaBP}$ and the most $\mathrm{N}$ terminal CaM-binding domain (AA. 49-81) of IP3R1. Using several experimental paradigms we demonstrated a decrease in the sensitivity of IICR. Although similar to $\mathrm{CaM}, \mathrm{CaBP}$ possess unique properties, which may provide another level of IP3R regulation [4].

Neither $\mathrm{CaM}$ nor $\mathrm{CaBP}$ act as $\mathrm{Ca}^{2+}$ sensors for the inhibition of IICR since the $\mathrm{Ca}^{2+}$-independent mutants of these proteins had similar effects. We have however found in some cell types a novel $\mathrm{Ca}^{2+}$ release mechanism that was not blocked by inhibitors of IP3Rs nor RyRs, and that was functioning as a $\mathrm{Ca}^{2+}$-induced $\mathrm{Ca}^{2+}$ release pathway (CICR) with $\mathrm{CaM}$ as the $\mathrm{Ca}^{2+}$ sensor. We could not yet identify the protein responsible for this CICR mechanism but it could represent a TRP-like $\mathrm{Ca}^{2+}$ channel or perhaps a truncated IP3R.

\section{References:}

1. Adkins CE, Morris SA, De Smed, H, Sienaert I, Torok K, Taylor, CW (2000) Biochem J 345 Pt 2: 357-363

2. Sienaert I, Nadif Kasri N, Vanlingen S, Parys JB, Callewaert G, Missiaen L, De Smedt H (2002) Biochem J 365:269-277

3. Yang J, McBride S, Mak DO, Vardi N, Palczewski K, Haeseleer F, Foskett JK (2002) Proc Natl Acad Sci U S A 99: 7711-7716

4. Nadif Kasri N, Sienaert I, Parys JB, Callewaert G, Missiaen L, Jeromin A, De Smedt H. (2003) J Biol Chem 278: 27548-27555 


\section{SESSION 4:}

\section{REGULATION OF CALCIUM RELEASE CHANNELS (RYR AND INSP3-GATED CHANNELS), CONTINUED}

\section{ENRIQUE JAIMOVICH, CHAIR}

Session Chair's Summary: Session 4 of the workshop was the second part of the subject Regulation of Calcium Release Channels (RyR and InsP3-gated channels), and included presentations by Sandor Gyorke, Cecilia Hidalgo and David Yule. As a whole, discussion during this session focused on various aspects of the fine tuning of calcium release channels under physiological conditions and posed several questions for further research in a subject that shows a high degree of progress during recent years.

Sandor Gyorke' presentation was focused on SR intraluminal $\mathrm{Ca}$ signaling in the heart and the role of calsequestrin. He showed evidence of rather dramatic increases in both electrically induced calcium transients and the magnitude of calcium sparks in isolated heart cells in which the cardiac calsequestrin gene was overexpressed. The opposite result was obtained in cells in which calsequestrin levels were reduced by adenoviral-mediated antisense transduction. This, as well as other discussed evidence could provide an explanation for ventricular arrhythmias associated with mutations of calsequestrin.

Cecilia Hidalgo discussed redox regulation of calcium release through RyR channels and described the changes that such channels suffer upon oxidation and reduction when reconstituted in lipid bilayers or when studied in isolated $\mathrm{SR}$ vesicles. She described caffeine-induced calcium oscillations in isolated SR vesicles; both redox agents and free magnesium affected these oscillations. She proposed that alkylation/oxidation of a few highly reactive $\mathrm{SH}$ residues present in RyR enhances channel opening, possibly by shifting the calcium activation curve to the left and decreasing the inhibitory effect of magnesium on CICR.

David Yule's presentation was on regulation of $\mathrm{Ca}^{2+}$ release by InsP3 receptor phosphorylation. Describing experiments in exocrine cells from the pancreas and salivary glands he discussed the functional consequences of phospho-regulation of InsP3 receptors. PKA -mediated phosphorylation of InsP3Rs in pancreatic acinar cells resulted in slowed kinetics of calcium release following photo-release of InsP3. In contrast, activation of PKA in parotid cells resulted in a marked potentiation of calcium release. In pancreatic acinar cells the predominant InsP3R isoform phosphorylated was the type 3 receptor, while the type 2 receptor was markedly phosphorylated in parotid acinar cells. He discussed the possibility that phosphoregulation of InsP3Rs results in subtype-specific effects and may play a role in the specificity of calcium signals by modulating the spatio-temporal profile of the response.
The abstracts for these presentations follow:

\section{SARCOPLASMIC RETICULUM LUMINAL CALCIUM SIGNALING IN THE HEART: THE ROLE OF CALSEQUESTRIN}

\section{SANDOR GYÖRKE, DMITRY TERENTYEV, SERGE VIATCHENKO-KARPINSKI, INNA GYÖRKE, POMPEO VOLPE*, SIMON C. WILLIAMS}

Departments of Physiology and Cell Biology \& Biochemistry, Texas Tech University Health Sciences Center, Lubbock, Texas.

*Dipartimento di Scienze Biomediche Sperimentali, Università di Padova, Padova, Italy.

In the heart, $\mathrm{Ca}$ controls muscle contraction and abnormal $\mathrm{Ca}$ handling has been implicated in a number of pathological states, including heart failure and arrhythmia. Most of the Ca required for contractile activation of cardiac myocytes is derived from the sarcoplasmic reticulum (SR), an intracellular $\mathrm{Ca}$ storage and release site. The $\mathrm{Ca}$ release process is dynamically controlled by both cytosolic and SR luminal $\mathrm{Ca}$ levels and represents the result of coordinated activity of multiple $\mathrm{Ca}$ signalling proteins, including plasmalemmal voltage-dependent $\mathrm{Ca}$ channels and proteins of the SR Ca release channel/ryanodine receptor (RyR) complex. Calsequestrin is a high capacity $\mathrm{Ca}$ binding protein expressed inside the SR. Mutations in the cardiac calsequestrin gene (CSQ2) have been linked to arrhythmias and sudden death inducible by stress and catecholamine infusion. However, the specific role of this protein in heart physiology and the mechanism by which mutations in the $C S Q 2$ gene lead to arrhythmias is currently unknown. We have used an adenoviral-mediated gene transfer strategy to either increase or decrease the levels of CSQ2 in adult rat ventricular myocytes and explored the effects of altered CSQ2 expression on intracellular $\mathrm{Ca}$ handling using $\mathrm{Ca}$ imaging and patch clamp techniques. Three to four- fold overexpression of CSQ2 dramatically increased the magnitude of both cell-averaged electrically-induced $\mathrm{Ca}$ transients and spontaneous Ca sparks in isolated heart cells. Analysis of the rising phase and rate of change of these $\mathrm{Ca}$ signals indicated that their augmented size was due to slowed termination of underlying $\mathrm{Ca}$ release fluxes from the SR. Increased CSQ2 levels also reduced the frequency of repetitive $\mathrm{Ca}$ sparks induced at fixed locations by the RyR activator, Imperotoxin A. Thus, in addition to prolonging active $\mathrm{Ca}$ release, the dynamics of functional recharging of SR Ca stores were also slowed in cells with elevated CSQ2 protein levels. We essentially obtained the opposite results in myocytes in which CSQ2 levels were reduced two to three-fold by adenoviral-mediated antisense transduction. These myocytes displayed shorter $\mathrm{Ca}$ release but accelerated restitution of $\mathrm{Ca}$ release sites. Furthermore, CSQ2-underexpressing myocytes exhibited drastic disturbances in rhythmic $\mathrm{Ca}$ transients and membrane potential with signs of delayed afterdepolarizations (DADs) when undergoing periodic pacing and exposed to isoproterenol. We conclude that CSQ2 is a key determinant of the SR Ca releasing function that acts by governing $\mathrm{Ca}$ release duration and release site refractoriness. CSQ2 appears to exert its effects by acting as a molecular buffer that influences the dynamics of free Ca concentration in the SR luminal space to control the luminal Ca-dependent activity of the RyR channels. The abnormal functional restitution of $\mathrm{Ca}$ release channels in the presence of reduced CSQ2 levels provides a plausible explanation for ventricular arrhythmia associated with mutations of CSQ2. 


\section{REDOX REGULATION OF CALCIUM RELEASE THROUGH RYR CHANNELS}

\section{CECILIA HIDALGO}

Centro FONDAP de Estudios Moleculares de la Célula and Programa de Biología Celular y Molecular, Instituto de Ciencias Biomédicas, Facultad de Medicina, Universidad de Chile, Santiago, Chile

The response to cytoplasmic free $\left[\mathrm{Ca}^{2+}\right]$ of RyR 1 channel is bell-shaped: $\mu \mathrm{M}$ concentrations activate and $\mathrm{mM}$ concentrations inhibit the channel, presumably by occupying the magnesium inhibitory site. We have reported that RyR1 (native and purified) and RyR2 single channels incorporated in lipid bilayers display three different responses to cytoplasmic free $\left[\mathrm{Ca}^{2+}\right]$ that convert among them when changing channel redox state.

To extend these studies to RyR channels in native SR vesicles, we have analyzed the effects of thimerosal, the endogenous redox-active agents $S$-nitrosoglutathione (GSNO) and glutathione disulfide (GSSG)-and the NO donor NOR-3- on calcium release kinetics from triadenriched SR vesicles isolated from rabbit skeletal muscle. We have found that incubation of these vesicles with these agents elicits different responses. GSSG significantly reduces the inhibitory effect of $\mathrm{Mg}^{2+}$ without altering $\mathrm{Ca}^{2+}$ activation of release kinetics whereas NOR-3 enhances $\mathrm{Ca}^{2+}$ activation of release kinetics without altering $\mathrm{Mg}^{2+}$ inhibition. Incubation with GSNO or thimerosal produces both effects; it significantly enhances $\mathrm{Ca}^{2+}$ activation and diminishes the inhibitory effect of $\mathrm{Mg}^{2+}$ on release kinetics. Triad incubation with $\left[{ }^{35} \mathrm{~S}\right]$-GSNO at pCa 5 promoted ${ }^{35} \mathrm{~S}$ incorporation into 2.5 cysteine residues per RyR1 channel monomer; this incorporation decreases significantly at $\mathrm{pCa}$ 9. These novel findings indicate that $S$-nitrosoglutathione supports $S$-glutathionylation as well as the reported $S$ nitrosylation of RyR channels, and suggest that $\mathrm{S}$ glutathionylation of specific cysteine residues can modulate channel inhibition by $\mathrm{Mg}^{2+}$ while S-nitrosylation of different cysteines can modulate the activation of the channel by $\mathrm{Ca}^{2+}$.

In parallel studies, we have measured caffeine-induced calcium release from skeletal SR vesicles actively loaded with calcium. Addition of caffeine ( $4 \mathrm{mM})$ induces only partial and transient calcium release, followed by oscillations. This behavior was observed even in vesicles containing high intravesicular calcium levels, indicating that the transient response to caffeine is not due to luminal calcium depletion. Lowering extravesicular free $\left[\mathrm{Mg}^{+2}\right]$ or pre-incubation of vesicles with GSNO or thimerosal enhanced the initial response to caffeine whereas reduction with GSH had the opposite effects. The oscillatory pattern was also affected by extravesicular free $\left[\mathrm{Mg}^{+2}\right]$ and the above redox agents. We propose that in the constant presence of caffeine, RyR 1 channels undergo spontaneous cycles of opening and closing. Decreasing free $\left[\mathrm{Mg}^{+2}\right]$ or alkylation/oxidation of RyR1 free $\mathrm{SH}$ residues would prolong caffeine-induced channel opening, presumably by decreasing the inhibitory effect of $\mathrm{Mg}^{2+}$ on RyR channel activity.

Supported by FONDAP Project 15010006

REGULATION OF $\mathrm{Ca}^{2+} \mathrm{RELEASE}^{\mathrm{B} Y} \quad \mathrm{INSP}_{3}$ RECEPTOR PHOSPHORYLATION

LARRY E. WAGNER II, STEPHEN V. STRAUB, DAVID A BROWN, JASON I.E. BRUCE AND DAVID I. YULE University of Rochester, School of Medicine and Dentistry, 601 Elmwood Ave, Rochester, NY 14642. USA.

Inositol 1,4,5-trisphosphate receptors $\left(\operatorname{Ins}_{3} \mathrm{R}\right)$ are the major route of intracellular calcium release in eukaryotic cells and thus are pivotal for stimulation of $\mathrm{Ca}^{2+}$ dependent effectors important for the control of numerous physiological processes. Modulation of $\mathrm{Ca}^{2+}$ release through $\operatorname{Ins}_{3} \mathrm{R}$ is thus of general importance for defining the particular spatio-temporal characteristics of $\mathrm{Ca}^{2+}$ signals. While it is widely appreciated that $\mathrm{Ca}^{2+}$ itself is an important regulator of $\operatorname{InsP}_{3} \mathrm{R}$, the receptor is also subject to modulation through numerous inputs, including proteinprotein interactions, binding of adenine nucleotides and phosphorylation by multiple kinases. In this study we have investigated the effects on $\mathrm{Ca}^{2+}$ release of phosphorylation of $\mathrm{Ins}_{3} \mathrm{R}$ by cyclic nucleotide-dependent protein kinases. In exocrine cells from the pancreas, stimulation with the peptide hormones cholecystokinin or bombesin results in rapid phosphorylation of the type-III $\operatorname{Ins}_{3} \mathrm{R}$. This event is dependent on protein kinase $\mathrm{A}$ and alters the kinetics of $\mathrm{Ca}^{2+}$ release, ultimately contributing to the characteristic spatio-temporal signature of the $\mathrm{Ca}^{2+}$ signal initiated by these particular agonists. In contrast, stimulation with the neurotransmitter acetylcholine fails to result in phosphoregulation of $\operatorname{InsP}_{3} \mathrm{R}$ (1-3). In the morphologically and functionally related exocrine cells from the parotid salivary gland pharmacological activation of PKA with forskolin concurrently with a calcium mobilizing stimulus, results in markedly enhanced $\mathrm{Ca}^{2+}$ release. This potentiated $\mathrm{Ca}^{2+}$ release is consistent with phosphoregulation of the type-II Ins $\mathrm{P}_{3} \mathrm{R}$ in parotid acinar cells (4).

To investigate the particular sites of phosphoregulation in an unambiguously homogenous population of homomeric receptors, type- $1 \mathrm{InsP}_{3} \mathrm{R}$ ( $\mathrm{InsP}_{3} \mathrm{R}-\mathrm{I}$ ) were expressed in DT-40 cells devoid of endogenous $\operatorname{Ins}_{3} \mathrm{R}$ (5). In cells expressing the neuronal, $\mathrm{S}_{2}{ }^{+}$splice variant of the $\mathrm{Ins} \mathrm{P}_{3} \mathrm{R}-1, \mathrm{Ca}^{2+}$ release was markedly enhanced when either PKA or PKG was activated $(6,7)$. The sites of phosphorylation were investigated by mutation of serine residues present in two canonical phosphorylation sites present in the protein. Potentiated $\mathrm{Ca}^{2+}$ release was abolished when serine 1755 was mutated to alanine (S1755A) but was unaffected by a similar mutation of serine 1589 (S1589A) (7). These data demonstrate that $\mathrm{S} 1755$ is the functionally important residue for phosphoregulation by PKA and PKG in the neuronal variant of the $\operatorname{InsP}_{3} \mathrm{R}-1$. Activation of PKA also resulted in potentiated $\mathrm{Ca}^{2+}$ release in cells expressing the nonneuronal, S2- splice variant of the $\operatorname{InsP}_{3} \mathrm{R}-1$. However, the PKA-induced potentiation was still evident in S1589A or S1755A InsP ${ }_{3} \mathrm{R}-1$ mutants. The effect was abolished in the double (S1589A/S1755A) mutant, indicating both sites are phosphorylated and contribute to the functional effect. Activation of PKG had no effect on $\mathrm{Ca}^{2+}$ release in cells expressing the $\mathrm{S}_{2}^{-}$variant of $\mathrm{InsP}_{3} \mathrm{R}-1$. Collectively these data indicate that phosphoregulation of $\operatorname{Ins}_{3} \mathrm{R}$ has dramatic effects on $\mathrm{Ca}^{2+}$ release and importantly defines the molecular sites phosphorylated in the major variants of the type-I Ins $\mathrm{P}_{3} \mathrm{R}$ expressed in neuronal and peripheral tissues.

\section{References:}

1. LeBeau, AP, Yule DI, Groblewski, GE, Sneyd J (1999) J Gen Physiol 113: 851-872

2. Giovannucci DR, Groblewski GE, Sneyd J, Yule DI (2000) J Biol Chem 275: 33704-33711

3. Straub SV, Giovannucci DR, Bruce JI, Yule DI (2002) J Biol Chem 277:31949-31956

4. Bruce JI, Shuttleworth TJ, Giovannucci DR., Yule, DI (2002) J Biol Chem 277: 1340-1348

5. Sugawara H, Kurosaki M, Takata M, Kurosaki, T (1997) EMBO J 16:3078-3088

6. Tang, TS, Tu H, Wang Z, Bezprozvanny I (2003) J Neurosci 23: 403-415

7. Wagner LE, Li WH., and Yule, DI. (2003) J Biol Chem 278: 45811-45817 


\title{
SECOND TOPIC:
}

\section{CELLULAR RESPONSES TRIGGERED BY CALCIUM RELEASE}

\section{PLENARY LECTURE: LOCAL AND GLOBAL $\mathrm{Ca}^{2+}$ SIGNALS: PHYSIOLOGY AND PATHOPHYSIOLOGY}

\author{
OLE H. PETERSEN \\ MRC Secretory Control Research Group, The \\ Physiological Laboratory, University of Liverpool, UK
}

The first part of the Plenary Lecture will consist of a general description of local and global $\mathrm{Ca}^{2+}$ signals in pancreatic acinar cells, a discussion of the mechanisms by which they are established and a brief summary of the physiological and pathophysiological roles of these events (Petersen et al. TINS 24, 271-276, 2001;. Cancela \& Petersen Diabetes 51 (supplement 3), S349-S357, 2002; Petersen Cell Calcium 33, 337-344, 2003).

In the second part, I shall focus on recent work defining the action and the mechanism of action of nicotinic acid adenine dinucleotide phosphate (NAADP) on isolated nuclei from pancreatic acinar cells. $\mathrm{Ca}^{2+}$ release from the envelope of these nuclei could be activated by NAADP as well as by IP3 and cyclic ADP-ribose (cADPR). Each of these agents reduced the $\mathrm{Ca}^{2+}$ concentration inside the nuclear envelope and this was associated with a transient rise in the nucleoplasmic $\mathrm{Ca}^{2+}$ concentration. NAADP released $\mathrm{Ca}^{2+}$ from the same thapsigargin-sensitive pool as IP3 and cADPR. The NAADP action was specific since, for example, NADP was ineffective. The $\mathrm{Ca}^{2+}$ release was unaffected by procedures interfering with acidic organelles (bafilomycin, brefeldin, nigericin). Ryanodine blocked the $\mathrm{Ca}^{2+}$ releasing effects of NAADP, cADPR and caffeine, but not IP3. Ruthenium red also blocked the $\mathrm{Ca}^{2+}$ release elicited by NAADP but not by IP3. IP3 receptor blockade did not inhibit the $\mathrm{Ca}^{2+}$ release elicited by NAADP or cADPR. We conclude that the nuclear envelope contains both functional ryanodine and IP3 receptors, which can be activated separately and independently: the ryanodine receptors by either NAADP or cADPR and the IP3 receptors by IP3 (Gerasimenko, Maruyama, Yano, Dolman, Tepikin, Petersen \& Gerasimenko J Cell Biol 2003 $163,271)$. These data indicate that NAADP does not exclusively act to release $\mathrm{Ca}^{2+}$ from acidic pools, as in sea urchin eggs, and are most easily understood by assuming that the NAADP receptor is not itself an ion channel. The characteristics of NAADP- and cADPR-elicited $\mathrm{Ca}^{2+}$ release from the nuclear envelope are essentially identical except that cADPR can still act to release $\mathrm{Ca}^{2+}$ normally when the NAADP receptors have been inactivated by a high NAADP concentration. The simplest explanation is that occupied cADPR and NAADP receptors can both interact with ryanodine receptors to increase their open state probability. 


\section{SESSION 5:}

CELLULAR CALCIUM SIGNALS GENERATED BY CALCIUM RELEASE THROUGH RYR-CHANNELS AND INSP3-GATED CHANNELS

\section{KEVIN FOSKETT, CHAIR}

Session Chair's Summary: Martin Schneider described his imaging studies of $\mathrm{Ca}^{2+}$ sparks in skeletal muscle cells. The time course of each spark can be fitted with the sum of two exponentials, reflecting the kinetics of $\mathrm{Ca}^{2+}$ release followed by termination of release and diffusion and binding of the released $\mathrm{Ca}^{2+}$. The fact that the release events were not exponentially distributed suggests that a non-random process is involved in terminating release, but the mechanism is yet unknown. Using saponin-permeabilized skeletal muscle fibers, he demonstrated that the spontaneous release events had pharmacological sensitivities similar to those of ryanodine receptors. Interestingly, Imperatoxin A induced small but long-lasting events. Schneider argued that these events are due to release through a single modified channel, which indicates that sparks can be accounted for by concerted gating of 2-4 ryanodine receptor release channels. Using the same preparation he also showed results from experiments that explored the role of calmodulin in regulating release activity. Both calmodulin and apocalmodulin increased spark frequency with no effects on the properties of the sparks.

Eduardo Rios described comparative studies in rat and frog muscle fibers to explore the relationship between the distribution of release channels and the properties of calcium release. In frog fibers, release channels can communicate by CICR, which enables propagation of the signal, whereas there are no sparks in rat fibers, with the release channels apparently controlled individually by DHP receptors, such that CICR does not appear to operate. The frog, but not the rat, has parajunctional RyR3, suggesting that they may be involved in CICR in frog fibers. An important question concerns the mechanism, in the absence of CICR, which enables multiple RYR1 in rat fibers to gate concertedly.

David Eisner turned our attention to cardiac myocytes. He emphasized the critical role of sarcoplasmic calcium content on the amount of calcium released during contraction. Calcium overload causes spontaneous waves of release. Homeostasis systems, including $\mathrm{Na}^{+} / \mathrm{Ca}^{2+}$ exchange and $\mathrm{Ca}^{2+}$-feedback on L-type $\mathrm{Ca}^{2+}$ channels, regulates the store content to enable constant $\mathrm{Ca}^{2+}$ amplitudes to be associated with variable release rates. Alternans is associated with alternating beat-to-beat strength of contraction and $\mathrm{Ca}^{2+}$ release amplitude. The normal homeostatic mechanisms that regulate lumenal $\mathrm{Ca}^{2+}$ concentration may be altered, but the mechanisms remain to be deciphered.

Martin Bootman has explored the role of InsP3 receptor release channels in cardiac function. The expression, of the type 2 isoform predominantly, is considerably higher in atrium than ventricle. Field stimulation of myocytes causes $\mathrm{Ca}^{2+}$ to rise only in the sub-sarcolemmal region, due to release from junctional ryanodine receptors, and moderate contractile strength. Non-junctional RyR can be made to respond using caffeine, higher SR calcium loading and mitochondrial $\mathrm{Ca}^{2+}$ uptake inhibition, which results in stronger contractile responses. Bootman suggests that mitochondria form a "firewall" that buffers calcium released from sarcolemmal RyR, preventing calcium from triggering CICR from non-junctional channels. Phospholipase $\mathrm{C}$ activating hormones including endothelin have a positive ionotropic effect by helping to globalize the
$\mathrm{Ca}^{2+}$ signal. In addition, $\mathrm{Ca}^{2+}$ released through $\mathrm{InsP}_{3} \mathrm{R}$ can depolarize the cell and generate arrhythmias.

Enrique Jaimovich discussed $\mathrm{InsP}_{3}$-dependent signaling in skeletal muscle cells. He localized the three $\mathrm{InsP}_{3}$ isoforms to distinct compartments in skeletal muscle, including the nucleus. Isolated muscle nuclei responded to $\mathrm{InsP}_{3}$ with $\mathrm{Ca}^{2+}$ transients. In addition, tetanic stimulation of fibers is associated with a slow-onset calcium rise that is dependent on the DHP receptor as well as PLC, and it was associated with an increase mass of $\operatorname{Ins}_{3}$. He proposed an interesting model in which the DHP receptor may be coupled to phospholipase C. Depolarization of fibers is associated with activation of gene expression. Using microarray analysis, 76 genes had altered expression within hours of high- $\mathrm{K}^{+}$depolarization. Thus, these signaling pathways may couple electrical activity to changes in cellular gene expression.

Susan Wray discussed her work on signaling and contraction of uterine smooth muscle cells. Contraction of smooth muscle is mediated by both Ca-dependent as well as independent mechanisms. Myogenic activity of uterine smooth muscle is regulated by the amount of calcium in the sarcoplasmic reticulum. The mechanism may involve release-activation of plasma membrane $\mathrm{K}^{+}$channels, socalled STOCS. Because the local release events, sparks, are more frequent with enhanced store $\mathrm{Ca}^{2+}$ content, the extent of SR loading helps, by contributing to a refractory period that limits contraction, regulates the excitability. During labor, diminished blood flow to the myometrium causes acidosis, as determined by NMR, which inhibits L-type $\mathrm{Ca}^{2+}$ channels, and therefore can diminish contractility. During problem deliveries, acidification is more prominently observed, which may perturb contraction and exacerbate the situation.

Shmuel Muallem changed the focus, and discussed some ideas regarding the mechanisms that are involved in determining specificity in G-protein signaling. He focused on the homer family of proteins. First, he considered that they may be possible candidates for helping to create signaling complexes that contain phospholipases, G proteins, Ins $\mathrm{P}_{3} \mathrm{R}$ and $\mathrm{Ca}^{2+}$ pumps. Exploiting mouse knockout models, homer did not appear to play this role in the apical membrane of pancreatic acinar cells. Nevertheless, homer appears to be required to promote an association between the $\mathrm{Ins}_{3}$ receptor and the trp- $\mathrm{C} 1^{-}$plasma membrane cation channel, and in so doing regulates the gating activity of trp. Depletion of the ER of calcium modulates the interaction of trp with homer. An enhanced frequency of $\mathrm{Ca}^{2+}$ oscillations was observed in pancreatic acini from homer 2 knock-out mice. Muallem proposes that homer may regulate RGS protein activity to account for this observation.

\section{Abstracts of this session follow:}

LOCAL $\mathrm{Ca}^{2+}$ RELEASE EVENTS IN SKELETAL MUSCLE

\section{MARTIN F. SCHNEIDER, GEORGE G. RODNEY} AND CHRIS W. WARD.

Dept of Biochemistry and Molecular Biology and Interdisciplinary Program in Muscle Biology, University of Maryland School of Medicine, Baltimore, MD, 21201 USA

In muscle, the activity of small functionally coupled groups of ryanodine receptor ( $\mathrm{RYR}$ ) $\mathrm{Ca}^{2+}$ release channels gives rise to localized, discrete elevations in myoplasmic $\left[\mathrm{Ca}^{2+}\right]$, termed $\mathrm{Ca}^{2+}$ sparks. The simultaneous occurrence of large numbers of $\mathrm{Ca}^{2+}$ sparks appears to underlie the 
"macroscopic" $\mathrm{Ca}^{2+}$ transient that occurs during action potential depolarization of frog skeletal muscle fibers. $\mathrm{Ca}^{2+}$ sparks also occur "spontaneously", presumably initiated by CICR ligand activation of $\mathrm{RYR} \mathrm{Ca}^{2+}$ release channels independent of voltage sensor activation. These events can be studied in permeabilized muscle fibers, which provide a convenient preparation for investigating the modulation of RYR function by both physiological and experimental ligands, including peptides and proteins which can enter the permeabilized fiber. Earlier work utilized the permeabilized fiber preparation to investigate very longlasting (seconds duration) $\mathrm{Ca}^{2+}$ release events initiated by the peptide toxin ImperatoxinA (Shtifman et al., 2000), which also produces similarly long duration openings of single RYR channels in lipid bilayers. We also previously characterized the increase in $\mathrm{Ca}^{2+}$ spark frequency with minimal change in average spark properties caused by the addition of the RYR domain peptide DP4 to permeabilized fibers (Shtifman et al., 2001).

Here we used confocal line scan (xt) imaging of permeabilized fibers exposed to fluo- 3 containing internal solution to determine the effects of $\mathrm{CaM}$ and various $\mathrm{CaM}$ mutants on the frequency and properties of $\mathrm{Ca}^{2+}$ sparks. Wild type CaM (0.05-5.0 mM) caused a highly cooperative dose dependent increase in $\mathrm{Ca}^{2+}$ spark frequency (Figure 1). The values of relative spark frequency (f) as a function of $[\mathrm{CaM}]$ were fit by the Hill equation, $\mathrm{f}=\mathrm{F}\left([\mathrm{CaM}]^{\mathrm{n}} /\right.$ $\left.\left(\mathrm{K}^{\mathrm{n}}+[\mathrm{CaM}]^{\mathrm{n}}\right)\right)+\mathrm{C}$, where $\mathrm{f}$ is the normalized event frequency, $F$ is $f_{\max }-f_{\min }, n$ is the Hill coefficient, $K$ is the concentration of $\mathrm{CaM}$ that elicits $50 \%$ of the increase in frequency $\left(\mathrm{EC}_{50}\right)$, and $\mathrm{C}$ is $\mathrm{f}_{\text {min }}$. The $\mathrm{EC}_{50}$ was $1.1 \pm 0.1$ $\mathrm{mM}$ and the Hill coefficient (n) was $4.2 \pm 1.1$. The spatial and temporal properties of calcium sparks were essentially unaffected by $\mathrm{CaM}$. These observations indicate that $\mathrm{CaM}$ highly cooperatively potentiates either the opening rate of the channel(s) responsible for initiation of the sparks or increases the likelihood that an open channel can initiate a spark. In contrast, the constancy of spark properties indicates that $\mathrm{CaM}$ had negligible effect on of the aggregate open time of the channels generating the sparks or the amount of $\mathrm{Ca}^{2+}$ released in a spark.

Both $\mathrm{CaM}(1.0 \mathrm{mM})$ and the non- $\mathrm{Ca}^{2+}$ binding mutant $\mathrm{CaM}_{1234}(1.0 \mathrm{mM})$ increased spark frequency approximately 10 fold, indicating that the potentiation of spark frequency in frog skeletal muscle fibers by $\mathrm{CaM}$ does not require $\mathrm{Ca}^{2+}$ binding to CaM. $(\mathrm{N}+3) \mathrm{CaM}(2 \mathrm{mM})$, which binds RYR with a higher affinity than CaM but does not activate RYR at $\mathrm{nM}\left[\mathrm{Ca}^{2+}\right]$ in $\mathrm{SR}$ vesicles (Xiong et al., JBC, 2002),

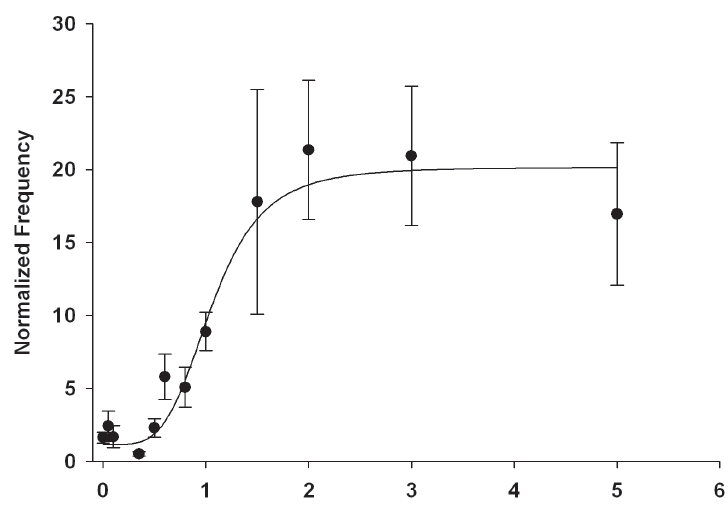

prevented the binding of fluorescently labeled CaM (1 $\mathrm{mM}$ ), had no significant effect on spark frequency and served as a negative control in these studies.

Neither wild-type $\mathrm{CaM}$ nor $\mathrm{CaM}_{1234}$ induced a noticeable alteration in the spatial or temporal properties of $\mathrm{Ca}^{2+}$ sparks. Thus, the aggregate open time of the channels underlying the generation of a $\mathrm{Ca}^{2+}$ spark was the same for sparks promoted by either wild type $\mathrm{CaM}$ or by the non $\mathrm{Ca}^{2+}$ binding $\mathrm{CaM}_{1234}$. Consequently, our data suggest that $\mathrm{CaM}$ acts to promote activation of RYR, but that termination of the $\mathrm{Ca}^{2+}$ sparks activated by $\mathrm{CaM}$ may be through a mechanism that is independent of $\mathrm{Ca}^{2+}$ binding to CaM.

\section{References:}

1. Shtifman A, CW Ward, J Wang, HH Valdivia, MF Schneider (2000). Biophys J 79: 814-827

2. Shtifman A, CW Ward, T Yamamoto, J Wang, B Olbinski, HH Valdivia, N Ikemoto, MF Schneider (2001) J Gen Physiol 119:15-32

3. Xiong LW, RA Newman, GG. Rodney, O Thomas, JZ Zhang, A Persechini, MA Shea, SL Hamilton. (2002) J Biol Chem 277: 40862-40870

\section{CONTROL OF DUAL ISOFORMS OF $\mathrm{Ca}^{2+}$ RELEASE CHANNELS IN MUSCLE}

\section{EDUARDO RÍOS}

Rush University, Section of Cellular Signaling.

The membrane systems that control $\mathrm{Ca}^{2+}$ release in amphibians and mammals differ in the morphology of its organelles, and in the nature and arrangement of its RyR channel isoforms. The time course of $\mathrm{Ca}^{2+}$ release flux is also different, as are the morphology and control of $\mathrm{Ca}^{2+}$ sparks. Unlike the frog, rat $\mathrm{Ca}^{2+}$ sparks are infrequent and not elicited by low voltage pulse depolarization. They are also wider and more rapidly rising than their frog counterparts. Spark promotion by cytosolic $\mathrm{Ca}^{2+}$, explored by solution switching and laser uncaging, requires increase of $\mathrm{Ca}^{2+}$ within the SR, as confirmed by imaging of an SRtrapped ratiometric dye. Large increases in CaSR lead in the frog to $\mathrm{Ca}^{2+}$ sparks that propagate over several microns at $\sim 200 \mu \mathrm{m} / \mathrm{s}$ (a speed consistent with $\mathrm{Ca}^{2+}$-mediated activation, "CICR"). Rat sparks instead do not propagate. In both the frog and the rat a reduction in cytosolic $\left[\mathrm{Mg}^{2+}\right]$ increases spark frequency, presumably upon relieving inhibition at two sites on the cytosolic face of the RyR channel. Unexpectedly in the rat, $\left[\mathrm{Mg}^{2+}\right]$ reduction below 1 $\mathrm{mM}$, which should enable the RyR's $\mathrm{Ca}^{2+}$ specific "CICR site", caused no further increase in spark frequency.

Spatially propagating sparks and their enhancement by submM $\mathrm{Mg}^{2+}$ are hallmarks of CICR. Their absence in the rat suggests that CICR requires RyR3 or parajunctional channel clusters, present only in the frog (Felder \& Franzini-Armstrong, 2002). These and other aspects of $\mathrm{Ca}^{2+}$ release indicate little or no role of CICR in mammalian muscle. The multiple RyR1 channels that open concertedly during a spark in the mammal must be synchronized by another very effective mechanism.

Thanks to G. Brum, G. Pizarro, J. Zhou, B. Launikonis, N. Shirokova, A. González, M. Stern, P. Cheng, and the Uruguayan and US taxpayers.

Figure 1: Dose-dependent effect of $\mathrm{CaM}$ on spontaneous $\mathrm{Ca}^{2+}$ spark frequency. 
CONTROL AND MISCONTROL OF THE CARDIAC CALCIUM TRANSIENT

\section{D.A. EISNER, M.E. DÍAZ, S.C. O'NEILL \& A.W. TRAFFORD}

Unit of Cardiac Physiology, University of Manchester, 1.524 Stopford Building, Oxford Rd, Manchester M13 9PT.

Most of the calcium that activates cardiac contraction comes from the sarcoplasmic reticulum (SR). Release is triggered by the entry of calcium into the cell via the Ltype $\mathrm{Ca}$ channel leading to opening of the ryanodine receptor (RyR). This process is known as $\mathrm{Ca}$ induced $\mathrm{Ca}$ release (CICR). The amount of Ca released depends on the Ca content of the SR; an increase of SR content increases the amount released. Stable contraction of the heart therefore depends on control of SR content [1]. We will review evidence showing that control of SR content depends on the effects of Ca release on surface membrane Ca fluxes. Specifically an increase of SR content increases SR Ca release and this (1) increases Ca efflux from the cell on $\mathrm{Na}-\mathrm{Ca}$ exchange and (2) decreases $\mathrm{Ca}$ entry into the cell via the L-type $\mathrm{Ca}$ current. Both of these effects will decrease cell and thence SR Ca content [2]. This simple homeostatic mechanism has many consequences. For example it predicts that manoeuvres which increase the open probability of the RyR will have no maintained effect on the amplitude of the systolic $\mathrm{Ca}$ transient. Experimentally we find that such an increase of open probability results in a transient increase of the $\mathrm{Ca}$ transient accompanied by a decrease of SR Ca content [3].

Under some clinical conditions the cardiac output shows "alternans". At a cellular level this is seen as alternate large and small systolic $\mathrm{Ca}$ transients ${ }^{4}$. We are investigating the hypothesis that this alternation is due to breakdown of the homeostatic mechanism described above. We find that, under alternating conditions there is an increase in the steepness of the relationship between SR Ca content and $\mathrm{Ca}$ efflux from the cell. The factors responsible for this will be described.

\section{References:}

1. Eisner DA, Choi HS, Díaz ME, O'Neill SC, Trafford AW (2000). Circ Res 87: 1087-1094.

2. Trafford AW, Díaz ME, Negretti N, Eisner DA (1997) Circ Res 81: 477-484

3. Trafford AW, Díaz ME, Sibbring GC, Eisner DA (2000) J Physiol (Lond ).; 522: 259-270.

4. Díaz ME, Eisner DA, O’Neill SC (2002) Circ Res 91: 585-593.

THE SPATIAL PROPERTIES OF CALCIUM TRANSIENTS IN RAT ATRIAL MYOCYTES

\section{LAUREN MACKENZIE, H. LLEWELYN RODERICK,} MICHAEL J. BERRIDGE AND MARTIN D. BOOTMAN Laboratory of Molecular Signalling, The Babraham Institute, Babraham Hall, Babraham, Cambridge, CB2 4AT, UK.

Calcium is a versatile intracellular messenger that encodes information in frequency, amplitude, and subcellular distribution. We examined how the ultrastructure of rat atrial myocytes constrains action potential-evoked calcium responses and their ability to promote cellular contraction. Myocytes were stimulated with $40 \mathrm{~V}$ pulses ( $2 \mathrm{~ms}$ duration) using two field electrodes $(0.5 \mathrm{~cm}$ from the cell) at $1 \mathrm{~Hz}$, and calcium changes were monitored using laser scanning confocal microscopy (NORAN Oz, Bicester, UK) of Fluo4-loaded cells.
Under control conditions, only $10 \%(n=120$ cells $)$ of atrial cardiac myocytes examined showed homogenous global calcium transients following electrical stimulation. In the majority of cells calcium transients originated in subsarcolemmal locations, and gave rise to a sharply-defined ring of elevated calcium. Despite functional ryanodine receptors being expressed at regular $(\sim 2 \mu \mathrm{m})$ intervals throughout the cells, the subsarcolemmal calcium signal did not spread in a regenerative manner to the cellular interior. Rather, there was only a diminishing inward diffusion of calcium. The averaged subsarcolemmal calcium response was $1656 \pm 219 \mathrm{nM}$ and took $38 \pm 3 \mathrm{~ms}$ to reach peak ( $n=5$ cells), whilst the calcium rise in the central region of the atrial cells was typically $400 \pm 63 \mathrm{nM}$ and was maximal after $91 \pm 7 \mathrm{~ms}(n=5$ cells $)$.

Immunostaining atrial myocytes revealed that L-type voltage-operated calcium channels were exclusively located around on the sarcolemma around the outside of the cells $(n=30$ cells $)$. Therefore, in atrial myocytes excitation-contraction coupling takes place in subsarcolemmal regions where L-type voltage-operated calcium channels and ryanodine receptors are co-localised. Treating atrial cells with cyclopiazonic acid $(10 \mu \mathrm{M})$ or antimycin $(20 \mu \mathrm{M})+$ oligomycin $(20 \mu \mathrm{M})$, to inhibit sarcoplasmic reticulum calcium ATPases and mitochondrial calcium sequestration respectively, allowed the subsarcolemmal calcium signal to propagate regeneratively into the central regions of atrial cells $(n=30$ cells). Calcium ATPases and mitochondria therefore form a functional firewall in atrial myocytes, which limits the calcium signals during normal excitation-contraction coupling to the subsarcolemmal sites. Positive inotropic agents such as endothelin-1 $(100 \mathrm{nM})$ and the b-adrenergic agonist isoproterenol $(1 \mu \mathrm{M})$ also induced globalisation of action potential-evoked calcium signals $(n=20$ cells $)$. The functional consequence of globalising calcium signals was a significant increase in the contractility of the cells. For example, with endothelin-1 the twitch amplitude increased by $585 \pm 52 \%(n=8)$. We therefore suggest that atrial myocytes have two functionally distinct populations of ryanodine receptors. The subsarcolemmal population is recruited during each action potential, but produces only a spatially limited calcium signal that triggers modest contraction. The central non-junctional ryanodine receptors represent an inotropic reserve, but are located behind a calcium ATPase and mitochondrial firewall. Physiological inotropes can activate this second population of ryanodine receptors to enhance the contractility of the cells.

\section{IP $_{3}$ DEPENDENT CALCIUM SIGNALS IN SKELETAL MUSCLE CELLS}

\section{ENRIQUE JAIMOVICH, JOSÉ MIGUEL ELTIT, CESAR CÁRDENAS, JOSÉ L. LIBERONA, NEVENKA JURETIC \& JORGE HIDALGO.}

Centro de Estudios Moleculares de la Célula, ICBM, Facultad de Medicina, Universidad de Chile

Recently, we have described an inositol 1,4,5-trisphosphate $\left(\mathrm{IP}_{3}\right)$ signaling system in cultured rodent skeletal muscle, triggered by membrane depolarization and affecting gene transcription (Jaimovich et al., 2000, Powell et al., 2001). Neonatal rat primary muscle cultures (animals were humanely killed) were used to study fluorescence calcium signals after loading with fluo-3 and both biochemical measurements, immunocytochemical studies and Western blots were performed on cells before and after depolarizing protocols. When myotubes were exposed to tetanic electrical stimulation and the fluorescence calcium signal 
was monitored, the expected calcium signal sensitive to ryanodine and associated to the E-C coupling was seen during stimulation. A few seconds after the stimulus ended, a long lasting second calcium signal, refractory to ryanodine was evident. The onset kinetics of this slow signal was slightly modified in nominally calcium-free medium, as was by both the frequency and number of pulses during tetanus. The role of the action potential was evidenced since, in the presence of TTX, the signal was abolished. The role of the L-type, voltage dependent calcium channel or dihydropyridine receptor (DHPR) as voltage sensor for this signal (Araya et al., 2003) was assessed by treatment with agonist and antagonist dihydropyridines (Bay K 8644 and nifedipine) showing an enhanced and inhibitory response respectively. When the dysgenic GLT cell line was used, the signal was absent. Transfection of these cells with the $\alpha_{1 \text { s }}$ subunit, restored the slow signal. The $\mathrm{IP}_{3}$ mass increase induced by electrical pulses was previous in time to the slow calcium signal. Both $\mathrm{IP}_{3} \mathrm{R}$ blocker and PLC inhibitor (xestospongin $\mathrm{C}$ and U73122) dramatically inhibited the slow calcium response. Immunocytochemical studies show that all three types of $\mathrm{IP}_{3}$ receptors type 1 , type 2 and type 3 are present in muscle cells. Using hypotonic shock combined with mechanical disruption, we obtained a fraction of purified nuclei from muscle cell lines as well as from rat primary myotubes. Nuclei look intact and clean to both optical and electron microscopy. In order to discard endoplasmic reticulum contaminants two specific markers (triadin and calsequestrin) were tested and they were both absent from nuclear samples. Immunofluorescence studies localized the $\mathrm{IP}_{3}$ receptor type 1 in the nuclear envelope, whereas IP3 receptor type 3 was found in the nuclear matrix. Nuclear calcium loading was confirmed by confocal imaging. $\mathrm{IP}_{3}$ induced calcium oscillations in nuclei loaded with fluo-3AM. On the other hand, a steady calcium increase in nuclei from dyspedic (1B5) cells that lack ryanodine receptors, was evident in the presence of $\mathrm{IP}_{3}$. Calcium signaling was inhibited by xestospongin $\mathrm{C}$, a specific inhibitor of $\mathrm{IP}_{3}$ receptors. These results confirm that nuclear calcium signals present in muscle cells are mediated by nuclear $\mathrm{IP}_{3}$ receptors and that there is a distinct calcium release component that originates in the nucleus from muscle cells. We have shown that $\mathrm{K}^{+}$-induced depolarization of rat myotubes elicits a transient increase in the early genes cfos, c-jun and egr-1 mRNA levels and we can link such increase to nuclear calcium signals (Carrasco et al., 2003). We performed microarray studies to identify genes regulated by membrane potential changes; we found 76 genes whose expression changed at least 2 fold up or down related to non-depolarized conditions. Among the changes detected, a number of genes were differentially expressed (7) or repressed (2) as early as $2 \mathrm{hr}$. after depolarization. Significant changes were found for genes involved in metabolism, signal transduction and stress response.

Our results agree with a general pattern of intracellular signaling that involves DHPR as voltage sensor, nuclear calcium increase and translocation of PKCa to the nucleus. Subsequent events include CREB phosphorylation and early gene mRNA expression.

Financed by FONDAP 15010006

\section{References:}

1. Jaimovich E, Reyes R, Liberona JL, Powell JA (2000). Am J Physiol (Cell Physiol) 278: C998-C1010

2. Powell JA, Carrasco, MA, Adams DS, Drouet, B, Rios, J. Müller, M., Estrada, M, Jaimovich, E (2001). J Cell Sci 2001 114: 3673-3683

3. Araya R, Liberona JL, Cárdenas JC, Riveros N, Estrada M, Powell JA, Carrasco, MA, Jaimovich. (2003). J. Gen Physiol 121: 3-16
4. Carrasco MA, Riveros N, Ríos J, Müller M, Torres F, Pineda J, Lantadilla S, Jaimovich E (2003). Am J Physiol (Cell Physiol) 284: C1438-C1447

\section{CALCIUM SIGNALS AND SMOOTH MUSCLE FUNCTION}

SUSAN WRAY

Physiology Department, University of Liverpool, Liverpool L69 3BX, UK.

Smooth muscle is present in a wide variety of tissues and our health is critically dependent upon its correct functioning; e.g. consider, hypertension, pre-term labour, and asthma. Smooth muscle contraction occurs predominantly in phasic smooth muscles due to an increase in intracellular [Ca], but changes in contraction can also occur by modulation of the $\mathrm{Ca}$ pathway to force i.e. in a $\mathrm{Ca}$ independent manner. As the pathways between $\mathrm{Ca}$ and force are complex, there are many possible loci for modulation, and this is currently an area of much research interest.

In my presentation I will focus on uterine smooth muscle to highlight what we know and don't know about Ca signalling (1). I will discuss the role of Ca entry and SR Ca release. The available data point to an inhibitory role of SR released $\mathrm{Ca}$ on contractions (2). We have directly examined SR Ca content, simultaneously with cytoplasmic $\mathrm{Ca}$, and find a decrease in luminal $\mathrm{Ca}$ stimulates activity (3). We have hypothesized that this is due to the SR releasing $\mathrm{Ca}$ that activates $\mathrm{K}$ channels on the surface membrane and similar effects have been well documented in vascular smooth muscle(4). Recent work has investigated in more detail the link between excitability and local $\mathrm{Ca}$ signals in smooth muscle. Data will be presented to show how increased $\mathrm{Ca}$ spark activity after SR loading, due to tissue stimulation, can profoundly modulate the refractory period. Brief mention will also be made of how membrane microdomains, lipid rafts, present mechanisms to help identify and separate the hundreds of signals impinging on the cell membrane and their transduction into $\mathrm{Ca}$ signals (5).

Ultimately the goal of our students is to better understand the causes of abnormal uterine function. More than half of all preterm infants will die or be severely damaged. Difficult labours can lead to emergency caesarean section and fetal distress. I will discuss some recent clinical findings relating to $\mathrm{Ca}$ signalling and difficult labours.

\section{References}

1. Wray S, Jones K, Kupittayanant S, Matthew AJG, Monir-Bishty E, Noble K et al.(2003) Journal of the Society for Gynecologic Investigation 10: 252-264

2. Kupittayanant S, Luckas MJM, Wray S.(2002) Br J Obstet Gynaec 109(3): 289-96

3. Shmigol AV, Eisner DA, Wray SJ (2001) J Physiol London 531(3): 707-13

4. Wellman GC, Nathan DJ, Saundry CM, Perez G, Bonev AD, Penar PL et al.(2002). Stroke 33: 802-8.

5. Babiychuck EB, Monastyrskaya K, Burkhard FC, Wray S, Draeger A (2002) FASEB J 16: 1177-84.

\section{HOMER PROTEINS IN $\mathrm{Ca}^{2+}$ SIGNALING}

\section{SHMUEL MUALLEM}

Homers are scaffolding proteins that bind $G$ protein coupled receptors, $\mathrm{IP}_{3}$ receptors, Ryanodine receptors and TRP channels. Their role in $\mathrm{Ca}^{2+}$ signaling was studied 
using a combination of biochemical and physiological assays. Deletion of all Homer proteins had no apparent effect on the localization of $\mathrm{IP}_{3}$ receptors and other signaling proteins, suggesting that Homers to not play a significant role in localization of $\mathrm{Ca}^{2+}$ signaling proteins in cellular microdomains. Characterization of $\mathrm{Ca}^{2+}$ signaling in pancreatic acinar cells from Homer $2^{-/}$and Homer $3^{--}$ mice showed that Homer 3 has no discernable role in $\mathrm{Ca}^{2+}$ signaling in these cells. By contrast, Homer 2 functions to tune the intensity of $\mathrm{Ca}^{2+}$ signaling by GPCRs to regulate the frequency of $\left[\mathrm{Ca}^{2+}\right]_{i}$ oscillations. Thus, deletion of Homer 2 increased stimulus intensity by increasing the potency for agonists acting on various GPCRs to activate PLC $\beta$ and evoke $\mathrm{Ca}^{2+}$ release and oscillations. This was due to reduced effectiveness of RGS proteins to inhibit $\mathrm{Ca}^{2+}$ signaling in vivo. Accordingly, Homer 2 preferentially bound to PLC $\beta$ in pancreatic acini and brain extracts and stimulated GAP activity of RGS4 and of PLC $\beta$ in an in vitro. Thus, Homer 2 within $\mathrm{Ca}^{2+}$ signaling complexes tunes signal intensity generated by GPCRs and in this way the characteristics of $\left[\mathrm{Ca}^{2+}\right]_{i}$ oscillations.

Deletion of Homer 1 had no effect on effect on RGS proteins or PLC $\beta$ GAP or PIP2 hydrolytic activity. On the other hand, deletion of Homer 1 increased spontaneous $\mathrm{Ca}^{2+}$ influx. Several TRPC channels were implicated in mediating receptor and store-dependent $\mathrm{Ca}^{2+}$ influx and all TRPC channels have a Homer binging ligand. Therefore, the role of Homers in regulating the activity of TRPC family members function was examined. Biochemical assays indicated that Homers facilitate a physical association between TRPC1 and the IP3R that is required for the channel to respond to stimulating signals. The TRPC1-Homer-IP3R complex is dynamic and its disassembly parallels TRPC1 channel activation. Homer's action depends on its ability to crosslink, and is blocked by its immediate early gene form, H1a. Accordingly, infusion of $\mathrm{H} 1 \mathrm{a}$ into cells activated $\mathrm{Ca}^{2+}$ influx. Since $\mathrm{H} 1 \mathrm{a}$ is transcriptionally regulated by cellular activity, this mechanism can effect both short and long-term regulation of TRPC1 function. These findings point to the diverse roles of Homer proteins in $\mathrm{Ca}^{2+}$ signaling and suggest that the major role of Homers is to control the intensity of the $\mathrm{Ca}^{2+}$ signal by regulating the function of proteins within the $\mathrm{Ca}^{2+}$ signaling complex. 


\section{SESSION 6:}

\section{MITOCHONDRIAL AND STORE-OPERATED CALCIUM SIGNALS}

\section{ERNESTO CARAFOLI, CHAIR}

Session Chair's Summary: Session 6 dealt with two topics. The first was the handling of $\mathrm{Ca}^{2+}$ by mitochondria, which was discussed by R. Rizzuto and S. Garcia-Sancho with emphasis on the heterogeneity of $\mathrm{Ca}^{2+}$ pools in the cell and on the ability of mitochondria to respond to $\mathrm{Ca}$ hotspots generated in their vicinity. Secretion and apoptosis were prominent in the discussion. The second topic was the mechanism of $\mathrm{Ca}^{2+}$ influx promoted by the emptying of the cellular $\mathrm{Ca}^{2+}$ stores. J. Putney concentrated on the role of TRPC family of plasma membrane cation channels, specifically on TRPC 3 . R. Boland also discussed TRPC 3 and its relationship to the activation of $\mathrm{Ca}^{2+}$ influx by $1-25$ $(\mathrm{OH})$ Vitamin D. I. Pessah extended the discussion to TRPC1 and to another mechanism of $\mathrm{Ca}^{2+}$ entry in skeletal myotubes which can become activated in the absence of the store depletion

Abstracts for these presentations follow:

\section{MITOCHONDRIAL Ca ${ }^{2+}$ HOMEOSTASIS: MOLECULAR DETERMINANTS AND FUNCTIONAL ROLE}

\section{ROSARIO RIZZUTO, PAOLO PINTON, GYORGY SZABADKAI, MOUNIA CHAMI, MARIUSZ WIECKOWSKI, MICHELANGELO CAMPANELLA, ANNA SIMONI, KATIUSCIA BIANCHI, ANDREA PRANDINI AND ALESSANDRO RIMESSI.}

Dept. Experimental and Diagnostic Medicine, Section of General Pathology, University of Ferrara, Via Borsari 46, 44100 Ferrara, Italy. Email: rosario.rizzuto@unife.it

In this presentation, I will discuss the principles of mitochondrial $\mathrm{Ca}^{2+}$ homeostasis. I will show how, upon physiological stimulation, mitochondria undergo a major rise in $\left[\mathrm{Ca}^{2+}\right]_{\mathrm{m}}$, well in the range of the $\mathrm{Ca}^{2+}$ sensitivity of the matrix dehydrogenases, in many cell types (e.g. HeLa and $\mathrm{CHO}$ lines and primary cultures of different embryological origin, such as myocytes and neurons). In particular, attention will be focused on the mechanisms that allows the low-affinity transporters of mitochondria to rapidly accumulate $\mathrm{Ca}^{2+}$, despite the low amplitude of the $\left[\mathrm{Ca}^{2+}\right]_{\mathrm{c}}$ rises, i.e. the close apposition of mitochondria to the ER, the main pool of agonist-releasable $\mathrm{Ca}^{2+}$. Thus, upon opening of IP3-gated channels, they are able to sense not the average $\left[\mathrm{Ca}^{2+}\right]_{\mathrm{c}}$ rise, but rather the much higher concentration occurring in the proximity of the open channels. In other words, mitochondria appear to participate in calcium signalling because they sense, and decode, a microdomain, the amplitude and occurrence of which is higher of bulk $\left[\mathrm{Ca}^{2+}\right]_{\mathrm{c}}$.

I will then address the functional significance of this process, that spans from the activation of organelle metabolism to the modulation of cytoplasmic $\mathrm{Ca}^{2+}$ signals and, in the course of apoptosis, to the alteration of organelle morphology and release of pro-apoptotic factors. Finally, I will present the search and functional analysis of molecules (ion channels, docking proteins, master genes, etc.) that could participate and/or modulate this physiological process. After showing a primary role of the channel VDAC of the outer mitochondrial membrane in allowing the fast transfer of $\mathrm{Ca}^{2+}$ to mitochondria, I will focus on the regulatory mechanisms. I will show the effect of the cAMP/CREB mediated pathway converging on the activation of the transcription co-activator PGC-1. This pathway is activated in skeletal muscle, but also in other cell types, during adaptive thermogenesis and other stress conditions. In PGC-1 overexpressing cells, the mitochondrial volume is increased, and a number of mitochondrial proteins (including respiratory complexes and metabolic enzymes, but also uncoupling proteins) is upregulated. Under those conditions, agonist-dependent $\mathrm{Ca}^{2+}$ signals are drastically reduced, while cytoplasmic $\mathrm{Ca}^{2+}$ signalling is unaffected. These data indicate that mitochondrial $\mathrm{Ca}^{2+}$ uptake in physiological and pathological conditions is modulated by the convergence through time of different signalling pathways.

\section{References:}

1. Rizzuto R, Pinton P, Carrington W, Fay F S, Fogarty KE, Lifshitz, LM, Tuft RA, Pozzan, T (1998) Science 280: $1763-1766$

2. Pinton P, Ferrari D, Magalhaes P, Schulze-Osthoff, K, Di Virgilio, F, Pozzan, T, Rizzuto R (2000) J Cell Biol 148: $857-862$

3. Pinton P, Ferrari D, Rapizzi E, Di Virgilio F, Pozzan T, Rizzuto R (2001) EMBO J. 20: 2690- 2701

4. Rapizzi E., Pinton P, Szabadkai G, Wieckowski MR, Vandecasteele G, Baird G, Tuft RA, Fogarty KE, Rizzuto R (2002) J Cell Biol 159: 613-624

\section{THE CONTRIBUTION OF MITOCHONDRIA TO THE GENESIS OF THE CALCIUM SIGNAL IN EXCITABLE CELLS}

\section{JAVIER GARCÍA-SANCHO}

Instituto de Biologia y Genetica Molecular (IBGM), Universidad de Valladolid \& CSIC, Valladolid, Spain

Research on $\mathrm{Ca}^{2+}$ signaling is evolving from the global (cellular) to the local (subcellular) environment, where changes of $\left[\mathrm{Ca}^{2+}\right]$ inside organelles play also a prominent role. Mitochondria do not accumulate $\mathrm{Ca}^{2+}$ in resting cells but they transiently take up large amounts of $\mathrm{Ca}^{2+}$ during cell activation. This may contribute to shape $\mathrm{Ca}^{2+}$ signaling and neurotransmitter release, regulate respiration and ATP synthesis or trigger apoptosis. Accurate measurements of $\left[\mathrm{Ca}^{2+}\right]$ inside organella are essential for a comprehensive

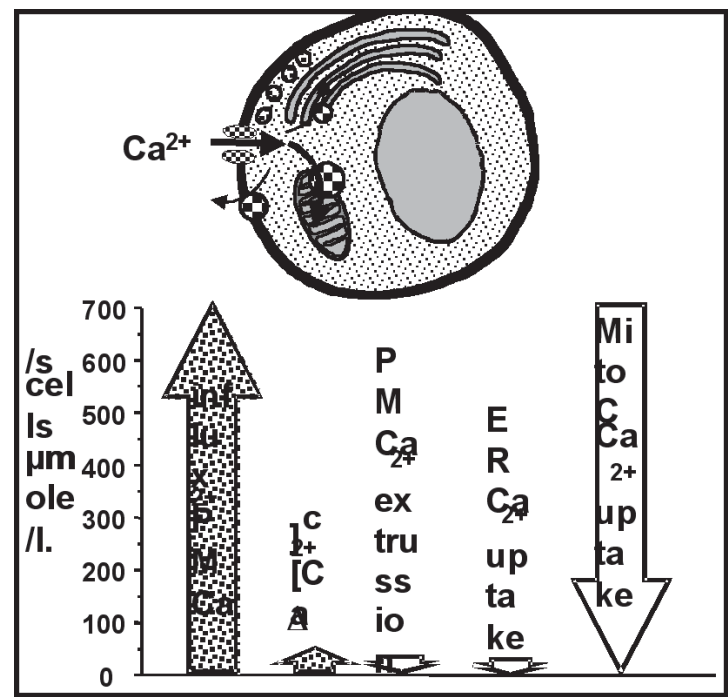


analysis of the $\mathrm{Ca}^{2+}$ redistribution that follows cell stimulation. On the other hand, $\left[\mathrm{Ca}^{2+}\right]$ inside organella regulates by itself important physiological functions. Aequorin, a $\mathrm{Ca}^{2+}$-sensitive photoprotein, can be directed to a defined cellular location by adding specific targeting sequences. Here we combine superb selectivity of targeted aequorin, the high expression induced by a viral vector and the high sensitivity provided by a photon-counting camera to resolve changes of mitochondrial $\left[\mathrm{Ca}^{2+}\right]$ at the singlecell level. Adrenal chromaffin and anterior pituitary cells were used as models for excitable cells.

On activation of plasma membrane voltage-gated $\mathrm{Ca}^{2+}$ channels, mitochondria took up large amounts of calcium through the mitochondrial $\mathrm{Ca}^{2+}$ uniporter. Results are consistent with the generation of cytosolic high-Ca ${ }^{2+}$ (about 50 microM) subplasmalemmal domains adequate for triggering exocytosis. At the cell core, a smaller increase of cytosolic $\mathrm{Ca}^{2+}$, adequate for recruitment of the reserve pool of secretory vesicles to the plasma membrane, is produced. Most of the entering $\mathrm{Ca}^{2+}$ load is taken up by a mitochondrial pool, M1, closer to the plasma membrane. The increase of mitochondrial $\left[\mathrm{Ca}^{2+}\right]$ stimulates respiration in these mitochondria, thus providing local support for the exocytotic process. Relaxation of the $\left[\mathrm{Ca}^{2+}\right] \mathrm{c}$ transient is due to $\mathrm{Ca}^{2+}$ extrusion through the plasma membrane. At this stage mitochondria release $\mathrm{Ca}^{2+}$ to the cytosol through the $\mathrm{Na}^{+} / \mathrm{Ca}^{2+}$ exchanger, thus maintaining $\left[\mathrm{Ca}^{2+}\right] \mathrm{c}$ discretely increased, specially at core regions of the cell,

\section{The cytosolic $\mathrm{Ca}^{2+}$ oscillations are amplified by mitochondria and dampened in nucleus}
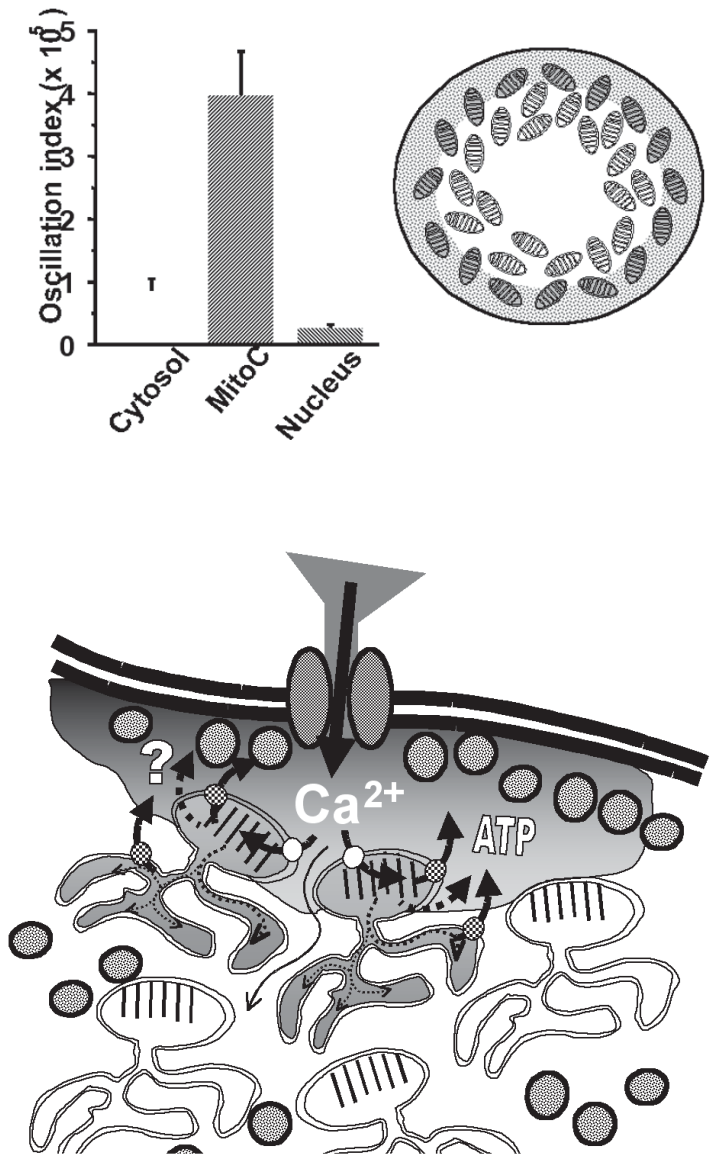

for periods of time that overlast the duration of the stimulus.

Anterior pituitary cells exhibit spontaneous electric activity and cytosolic $\mathrm{Ca}^{2+}$ oscillations that are responsible for basal secretion of pituitary hormones and are modulated by hypophysiotrophic factors. Aequorin reported spontaneous $\left[\mathrm{Ca}^{2+}\right]$ oscillations in bulk cytosol, nucleus and mitochondria. Interestingly, a fraction of mitochondria underwent much larger $\mathrm{Ca}^{2+}$ oscillations, which were driven by local cytosolic high- $\left[\mathrm{Ca}^{2+}\right]$ domains generated by the spontaneous electric activity. These oscillations of mitochondrial $\left[\mathrm{Ca}^{2+}\right]$ were large enough to stimulate respiration, providing the basis for local tune-up of mitochondrial function by the $\mathrm{Ca}^{2+}$ signal.

Subplasmalemmal mitochondria take up $\mathrm{Ca}^{2+}$ and stop the progress of the $\mathrm{Ca}^{2+}$ wave. The increase of $\mathrm{Ca}^{2+}$ inside mitochondria stimulates respiration thus providing locally more ATP for exocytosis support (and perhaps other messengers? Mitochondria keeps a "memory" of the recent history: respiration remains high until $\left[\mathrm{Ca}^{2+}\right]_{\mathrm{M}}$ decreases again to resting level.

\section{TRPCS AND MECHANISMS OF CALCIUM ENTRY}

JAMES W. PUTNEY, JR

National Institute of Environmental Health Sciences, Research Triangle Park, NC 27709 and Laboratory of Physiology, University of Oxford, Oxford OX1 3PT, UK

Virtually all cell types utilize mechanisms to mobilize and control cytoplasmic calcium, which in turn regulates diverse cellular responses such as contraction, secretion, cell growth and differentiation. A common mechanism whereby hormones and neurotransmitters generate cytoplasmic $\mathrm{Ca}^{2+}$ signals is through the generation of $\mathrm{Ca}^{2+}$ releasing messengers, such as the phosphoinositidase $\mathrm{C}$ product, inositol 1,4,5-trisphosphate $\left(\mathrm{IP}_{3}\right) . \mathrm{IP}_{3}$ binds to specific receptors on the endoplasmic reticulum causing the release of sequestered $\mathrm{Ca}^{2+}$. The drop in $\mathrm{Ca}^{2+}$ within the endoplasmic reticulum then signals to the plasma membrane activating $\mathrm{Ca}^{2+}$-permeable channels, a process known as capacitative $\mathrm{Ca}^{2+}$ entry or store-operated $\mathrm{Ca}^{2+}$ entry. In addition, in some cell types, receptor activation is coupled to plasma membrane $\mathrm{Ca}^{2+}$-permeable channels by other mechanisms, independent of the depletion of $\mathrm{Ca}^{2+}$ stores. In order to understand the signaling mechanisms underlying both capacitative and non-capacitative $\mathrm{Ca}^{2+}$ entry, the identity of the channel molecules is needed. Candidates for these ion channels are members of the TRPC family of cation channels which are known to be activated by phospholipase C-coupled receptors. We have focused on the regulation of a specific member of the TRPC family, TRPC3, to determine the mechanism of its regulation by surface membrane receptors and its possible role in capacitative $\mathrm{Ca}^{2+}$ entry.

When expressed either transiently or stably in the epithelial cell line, HEK293, TRPC3 produced non-selective cation channels which could be activated by phospholipase Ccoupled agonists, but not by store depletion with thapsigargin. These channels could not be activated by dialysis of the cytoplasm with $\mathrm{IP}_{3}$, and blockade of $\mathrm{IP}_{3}$ receptors with heparin did not affect the activation of TRPC 3 by agonists. On the other hand, TRPC 3 could be efficiently activated by a synthetic diacylglycerol, OAG, or by drugs which block the metabolism of endogenous diacylglycerols. When expressed in the avian Blymphocyte line, DT40, two different patterns of activation were observed, depending on the level of expression. With low levels of expression, TRPC3 formed store-operated 
channels, the activation of which was at least partially independent of $\mathrm{IP}_{3}$ receptors. At higher levels of expression, TRPC3 formed receptor-operated, non-storeoperated channels. These channels could be activated by $\mathrm{OAG}$ and could be activated by agonist in cells lacking $\mathrm{IP}_{3}$ receptors.

Thus, TRPC 3 appears capable of forming two different types of $\mathrm{Ca}^{2+}$-permeable channels, regulated in very distinct ways, depending on the level of expression of the protein.

\section{TRPC3-LIKE PROTEIN AND VITAMIN D RECEPTOR MEDIATE $1 \alpha, 25(\mathrm{OH})_{2} \mathrm{D}_{3}$-INDUCED STORE OPERATED CALCIUM INFLUX IN MUSCLE AND BONE CELLS}

RICARDO BOLAND.

Departamento de Biología, Bioquímica y Farmacia, Universidad Nacional del Sur. San Juan 670, (8000) Bahía Blanca, Argentina. e-mail: rboland@criba.edu.ar

In chick skeletal muscle and in rat osteoblast-like cells (ROS 17/2.8), $1 \alpha, 25$-dihydroxy-vitamin- $\mathrm{D}_{3}\left[1 \alpha, 25(\mathrm{OH})_{2} \mathrm{D}_{3}\right]$ stimulates release of $\mathrm{Ca}^{2+}$ from inner stores and extracellular cation influx through both voltage-dependent and capacitative $\mathrm{Ca}^{2+}$ entry (CCE; SOC) channels. We investigated the involvement of TRPC proteins in CCE induced by $1 \alpha, 25(\mathrm{OH})_{2} \mathrm{D}_{3}$. Two fragments were amplified by RT-PCR, exhibiting 94-100\% sequence homology with human TRPC3. Northern and Western blots employing TRPC3-probes and anti-TRPC3 antibodies, respectively, confirmed endogenous expression of a TRPC3-like protein. Both cell types transfected with anti-TRPC3 antisense oligodeoxynucleotides showed reduced $\mathrm{CCE}$ and $\mathrm{Mn}^{2+}$ entry in response to either thapsigargin or $1 \alpha, 25(\mathrm{OH})_{2} \mathrm{D}_{3}$. In muscle cells, anti-VDR antisense inhibited hormone stimulation of $\mathrm{Ca}^{2+}$ and $\mathrm{Mn}^{2+}$ influx and coimmunoprecipitation of TRPC 3 and VDR was observed, suggesting an association between both proteins and a functional role of the receptor in $1 \alpha, 25(\mathrm{OH})_{2} \mathrm{D}_{3}$ activation of CCE. In agreement with these observations, the VDR rapidly translocated from the nucleus to the plasma membranes after short treatment of muscle cells with $1 \alpha, 25(\mathrm{OH})_{2} \mathrm{D}_{3}$. This novel steroid hormone-induced reverse translocation of the receptor could be abolished by tyrosine kinase inhibitors. In addition, by using specific antagonists and antisense oligodeoxynucleotides for calmodulin (CAM), evidence was

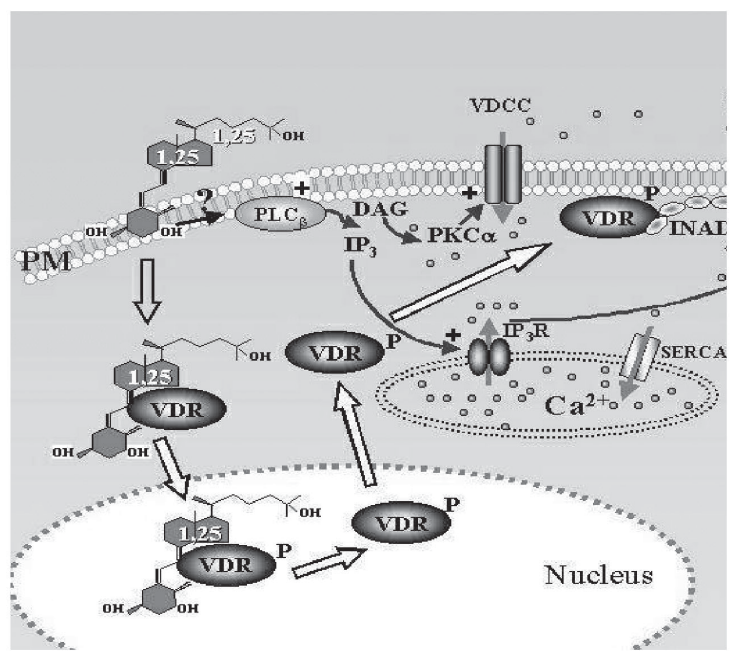

obtained indicating that CAM is involved in SOC influx modulated by $1 \alpha, 25(\mathrm{OH})_{2} \mathrm{D}_{3}$. In osteoblasts, two PCR fragments showing high homology with human INAD-like sequences were obtained. Northern blot and antisense functional assays further suggested the presense of a INADlike protein and its involvement in CCE regulation by the hormone. Therefore, we propose that an endogenous TRPC 3 protein mediates $1 \alpha, 25(\mathrm{OH})_{2} \mathrm{D}_{3}$ modulation of CCE in muscle and osteoblastic cells, which seems to implicate VDR-TRPC3 association and the participation of a INADlike scaffold protein.

\section{EXCITATION-SOC ENTRY COUPLING IN SKELETAL MYOTUBES}

\section{ISAAC N. PESSAH}

Department of Molecular Biosciences and Center for Children's Environmental Health and Disease Prevention, University of California Davis, Davis, California 95616, USA

Store operated calcium entry (SOCE) occurs in diverse cell types in response to depletion of $\mathrm{Ca}^{2+}$ within the endoplasmic/sarcoplasmic reticulum (ER/SR), and functions both to refill these stores and to shape cytoplasmic $\mathrm{Ca}^{2+}$ transients. Here we report that in addition to conventional SOCE, skeletal myotubes display a physiological mechanism that we term excitation-SOCE coupling. Unlike conventional SOCE, excitation-SOCE coupling is initiated by membrane depolarization and can be triggered in the absence of $\mathrm{Ca}^{2+}$ store depletion. Like excitation-contraction (E-C) coupling, excitation-SOCE coupling is absent in both dysgenic myotubes that lack the dihydropyridine receptor (DHPR), and dyspedic myotubes that lack the skeletal muscle type ryanodine receptor (RyR1), and is independent of the DHPR L-type $\mathrm{Ca}^{2+}$ current. Concentrations of ryanodine sufficient to lock RyR1 in an inactivated state greatly enhance excitationSOCE coupling triggered by depolarization, underscoring the importance of conformation on this process. Recent studies using heterologous expression and/or skinned fibers have led to the hypothesis that conventional SOCE involves conformational coupling between ryanodine or IP3 receptors and the store operated calcium channels (SOCC). Using co-immunoprecipation studies, we have identified TRPC 1 and TRPC 3 as possible candidate SOCCs participating in excitation-SOCE coupling. In addition to demonstrating the existence of a new pathway of $\mathrm{Ca}^{2+}$ entry, our results now demonstrate that such conformational coupling appears to occur in intact myotubes, whereby depolarization-induced conformational changes of the DHPR and RyR1 couple to SOCC and thus aid in the rapid refilling of stores depleted during E-C coupling. 


\section{THIRD TOPIC:}

\section{CELLULAR CALCIUM SIGNALING}

\section{SESSION 7:}

\section{CELLULAR CALCIUM SIGNALING DOMAINS}

\section{CECILIA HIDALGO, CHAIR}

Session Chair's Summary: Session 7 of the workshop included presentation by Pedro Verdugo, Patricia Camacho, Jordi Molgó, Patrick Delmas, Ian Parker, Alex Verkhratsky and David Friel. Speakers addressed calcium release signals in different physiological conditions, stimulating many inspired discussions on how different cells generate calcium release signals to effect different functions.

Pedro Verdugo presented a detailed theoretical discussion on the parameters that govern polymer expansion, and how these parameters are affected by polymer structure, including crosslinking among individual polymer molecules. He then presented results showing how polymer expansion occurs during secretion in secretory granules. He discussed how $\mathrm{pH}$ and calcium affect polymer expansion, and he discussed the reversibility of the polymer expansion process.

Patricia Camacho discussed how calreticulin expression inhibits InsP3-induced calcium oscillations in oocytes. She presented results showing that ERp57, a lumenal oxidoreductase ER protein, mediates the inhibitory effect of calreticulin on calcium oscillations. She showed that ERp57 is specifically recruited to the ER by either calreticulin or calnexin, where it promotes the formation of protein disulfide bonds.

Jordi Molgó focused his talk on the presence of InsP3 receptors in skeletal muscle satellite cells, and he proposed that these receptors might participate in skeletal muscle plasticity. He discussed as well the localization of InsP3 receptors in neuromuscular junctions, and he presented experiments showing that InsP3 rich regions colocalize with regions that generate calcium signals following $\mathrm{K}^{+}$ depolarization.

The talk given by Patrick Delmas centered on the role of polycystins 1 and 2 ( $\mathrm{PC} 1$ and $\mathrm{PC} 2$ ) in the formation of functional $\mathrm{ER} /$ plasma membrane complexes. He showed that $\mathrm{PC} 1$, a cell surface receptor, on the one hand controls the gating of PC2, an ER calcium permeable ion channel, and on the other it interacts with a $G$ protein. He proposed that through the formation of this multi-protein complex PC1 regulates ER calcium release through a bimodal mechanism involving $\mathrm{PC} 2$ and $\mathrm{G}$ proteins.

Ian Parker presented imaging results showing local calcium signaling microdomains around the mouth of a voltagegated calcium channel expressed in oocytes. He showed that depolarization elicited the appearance of local and transient calcium signals ("sparklets") and he discussed the experimental evidence that favors the proposal that each sparklet represents the opening of a single calcium channel. The talk given by Alexei Verkhratsky centered on the properties of intracellular calcium stores in neurons. He presented data showing that stores contain RyR-channels as well as InsP3-gated channels and the SERCA pump. He also showed that calcium entry through voltage-gated calcium channels promoted a decrease of lumen calcium concentration that was due to CICR mediated by activation of RyR channels.

The last talk in this session was presented by David Friel, who discussed contributions to calcium signals from calcium entry and from store calcium release in neurons. By measuring luminal calcium he presented results showing how calcium entry signals of different magnitudes result in calcium uptake into the stores or in calcium release. He analyzed the quantitative properties of pumpmediated and RyR-channel mediated calcium fluxes as a function of cytoplasmic calcium concentration. He proposed a model whereby the generation of small cytoplasmic calcium signals (such as those produced by low ryanodine concentrations) activate calcium loading in the ER instead of calcium release.

\section{Abstracts follow: \\ CALCIUM/PROTON SIGNALING IN SECRETION: CROSSTALK, REDUNDANCY, OR COMPLEMENTATION?}

\section{PEDRO VERDUGO, IVÁN QUESADA, AND WEI- CHUN CHIN}

Dept of Bioengineering, Friday Harbor Laboratories, University of Washington, San Juan Island, WA 98250, USA.

Activation of InsP3-receptor channels on the granular membrane can turn secretory granules into $\mathrm{Ca}^{2+}$ oscillators that deliver periodic trains of $\mathrm{Ca}^{2+}$ release to the cytosol (Nature, 395: 908-912, 1998; Biophys. J. 80: 2133-2139, 2001). More recently we further demonstrated that InsP3 can turn mast cell granules into proton oscillators (Biophys. J. 85: 963-970,2003). Intralumenal $\left[\mathrm{H}^{+}\right]$oscillations are ATP-independent, result from $\mathrm{H}^{+} / \mathrm{K}^{+}$exchange in the heparin matrix, and produce corresponding perigranular $\mathrm{pH}$ oscillations that have the same frequency and are in-phase with intralumenal $\left[\mathrm{H}^{+}\right]$but out-of-phase with the corresponding perigranular $\left[\mathrm{Ca}^{2+}\right]$ oscillations.

The search for how specificity is encoded in intracellular signal transduction remains one of the most interesting and challenging topics in cell biology. The association of proton release with InsP3-induced $\mathrm{Ca}^{2+}$ signals, their similar periodic nature, and the sensitivity of important exocytic proteins to the joint action of $\mathrm{Ca}^{2+}$ and $\mathrm{pH}$ strongly suggest that granules might broadcast a combined $\mathrm{Ca}^{2+} / \mathrm{H}^{+}$intracellular signal. Although both $\mathrm{Ca}^{2+}$ and $\mathrm{H}^{+}$ can readily induce conformational changes, switching on/ off functional conformations in proteins or other polyions present in the cell, the broad effect of these cations can decrease their specificity. The assignment of their combination in signaling could represent a heuristic model of conditional signaling. The granule periodically scans a broad range of $\mathrm{Ca}^{2+} / \mathrm{H}^{+}$combinations that could tune into specific activation conditions unambiguously targeting sensor/effector proteins like calmodulin, annexins or syncollin that are crucial for exocytosis and require specific combinations of $\left[\mathrm{Ca}^{2+}\right]$ "and" $\mathrm{pH}$ for their action.

\section{ER CHAPERONES MODULATE INTRACELLULAR $\mathrm{Ca}^{2+}$ OSCILLATIONS}

\section{YUN LI AND PATRICIA CAMACHO}

University of Texas Health Science Center at San Antonio. 7703 Floyd Curl Drive, San Antonio Texas, 78229-3900

Calcium homeostasis in the endoplasmic reticulum (ER) plays a key role in the functions of the organelle such as glycoprotein folding. Calreticulin (CRT) and calnexin (CLNX) are lectin chaperones involved in folding and 
quality control. In previous studies in our laboratory using the heterologous Xenopus oocyte expression system, we have explored the role that these chaperones play in the modulation of $\mathrm{Ca}^{2+}$ signaling in the ER. Expression of CRT or CLNX in Xenopus oocytes inhibits $\mathrm{Ca}^{2+}$ oscillations in oocytes activated by IP3, and when coexpressed with the $\mathrm{Ca}^{2+}$ ATPase, SERCA $2 \mathrm{~b}$. We have determined that the $\mathrm{COOH}$ terminus of the pump is necessary for the CRT or CLNX effect and have also found that cytosolic phosphorylation of CLNX controls an interaction of CLNX with SERCA $2 b$ to inhibit $\mathrm{Ca}^{2+}$ oscillations. In this talk I will concentrate in dsemonstrating that the inhibitory effect of CRT on $\mathrm{Ca}^{2+}$ oscillations involves another key component of the organelle, namely ERp57. The later is the thiol-dependent oxidoreductase, ERp57, in the same family of PDI. CRT or CLNX specifically recruit ERp57 during protein folding to promote intra- or inter-molecular disulfide bonds.

At the $\mathrm{COOH}$ terminus of SERCA2b there is a glycosylation motif facing the lumen of the ER. Furthermore, in the longest ER luminal loop of this pump (Loop 4), there are two conserved cysteines, which I'll demonstrate are targets for ERp57 catalytic activity. Using confocal $\mathrm{Ca}^{2+}$ imaging in the Xenopus oocyte preparation we demonstrate that co-expression ERp57 with SERCA $2 b$ inhibits $\mathrm{Ca}^{2+}$ oscillations. In contrast, mutagenesis of the relevant luminal cysteine residues causes the opposite effect i.e, increasing the frequency of $\mathrm{Ca}^{2+}$ oscillations. The inhibition of $\mathrm{Ca}^{2+}$ waves correlates with catalytic enzyme activity of ERp57 as demonstrated by mutagenesis of thioredoxin motifs in the enzyme. A specific physical interaction between ERp57 and the Loop 4 is found to be $\mathrm{Ca}^{2+}$ dependent and favored at luminal concentrations approaching $300 \mathrm{mM}$. Furthermore, CRT is required to recruit ERp57 to the Loop 4. Although the ERp57 reductase activity measured in vitro is not $\mathrm{Ca}^{2+}$ dependent, modulation of thiol groups in the pump shows $\mathrm{Ca}^{2+}$ modulation, conferred by the $\mathrm{Ca}^{2+}$ dependent binding of ERp57 to the Loop 4. The effects of ERp57 and CRT are specific for SERCA $2 b$ as they do no occur with the alternative splice variant of the SERCA 2 gene, the $\mathrm{Ca}^{2+}$ ATPase expressed in the heart (SERCA 2a). Dominantnegative experiments involving overexpression of various domains of CRT that interfere with lectin binding or with binding to ERp57, contribute to implicate the necessary role of CRT in inhibition of $\mathrm{Ca}^{2+}$ oscillations. These results suggest that ERp57 in complex with CRT maintains ER $\mathrm{Ca}^{2+}$ homeostasis by interaction with the Loop 4 of SERCA $2 \mathrm{~b}$ and provide a more refined model of how this chaperone modulates ER $\mathrm{Ca}^{2+}$ signaling.

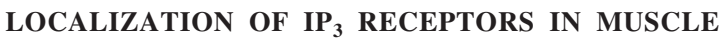
SATELLITE CELLS, AND COMPONENTS OF THE MOUSE NEUROMUSCULAR JUNCTION

\section{JORDI MOLGÓ ${ }^{1}$, JEANNE A. POWELL ${ }^{2}$, DANY S. ADAMS $^{2}$, CESARE COLASANTE ${ }^{1}$, AND ENRIQUE JAIMOVICH ${ }^{3}$ \\ ${ }^{1}$ Laboratoire de Neurobiologie Cellulaire et Moléculaire, U.P.R. 9040, C.N.R.S., Institut Fédératif de Neurobiologie Alfred Fessard, 91198-Gif sur Yvette cedex, France, ${ }^{2}$ Department of Biological Sciences, Smith College, Northampton, MA 01063, USA, and ${ }^{3}$ Centro de Estudios Moleculares de la Célula, Instituto de Ciencias Biomédicas, Facultad de Medicina, Universidad de Chile, Casilla 70005, Santiago 6530499, Chile}

Growth, stabilization and regeneration of skeletal muscle depends on many elements, such as growth, neurotrophic and gliotrophic factors and electrical activity of muscle. Strenuous activity and/or tissue damage can cause hypertrophy of muscle, due to the activation, multiplication and fusion of muscle satellite cells with myofibers. Satellite cell activation also plays a role in muscle growth following exercise, probably without muscle damage. The reaction of satellite cells to such muscle activity would probably not involve factors triggered by damage (e.g. growth factors), but could relate to muscle depolarization. Little is known concerning signal transduction pathways involved in muscle growth in response to activity. In the present study performed on mature rodent skeletal muscle, using immunocytology and confocal microscopy, we have found a high level of inositol 1,4,5trisphosphate receptor $\left(\mathrm{IP}_{3} \mathrm{R}\right)$-staining in satellite cells identified by their position, morphology and immunolabeling with satellite cell specific antibodies such as desmin and $\mathrm{N}$ CAM. By recording depolarization-triggered calcium transients, in cells, identified as satellite cells, we propose an $\mathrm{IP}_{3}$ mediated pathway.

At the neuromuscular junction (NMJ) three elements are instrumental in the development and stabilization of nervemuscle associations: (i) the presynaptic motor nerve endings, (ii) the subsynaptic nuclei of the muscle fiber, and (iii) the perisynaptic Schwann cells. IP $_{3} \mathrm{Rs}$ are also localized to postsynaptic components of the neuromuscular junction (NMJ), in areas surrounding the nuclei of the motor endplate, and in perisynaptic Schwann cells, and localized close to nicotinic acetylcholine receptors of the endplate gutters. $\mathrm{Ca}^{2+}$ imaging experiments show calcium release at the motor endplate upon $\mathrm{K}^{+}$depolarization precisely in these $\mathrm{IP}_{3} \mathrm{R}$ rich regions. We suggest that electrical activity stimulates $\mathrm{IP}_{3}$-associated $\mathrm{Ca}^{2+}$ signals that may be involved in gene regulation in satellite cells and in elements of the NMJ, contributing both to muscle fiber growth and stabilization of the NMJ.

This work was made possible by an ECOS Sud-CONICYT (C99B03) exchange program and was supported in part by grant \# 15010006 from FONDAP (to E.J.), by grants from the Association Française contre les Myopathies (to J.M) and a grant from the Blakeslee Fund of Smith College (J.A.P.).

\section{SIGNALING MICRODOMAINS LINKING MEMBRANE RECEPTORS TO $\mathrm{Ca}^{2+}$ STORES}

\section{PATRICK DELMAS}

Intégration des Informations Sensorielles (UMR 6150), CNRS

IFR Jean Roche, Faculté de Médecine, Bd. Pierre Dramard, 13916 Marseille, France

Email: delmas.p@jean-roche.univ-mrs.fr

Polycystin-2 (PC2), a $\mathrm{Ca}^{2+}$ permeable cation channel belonging to the TRP channel superfamily and polycystin-1 (PC1), an orphan membrane receptor of largely unknown function, are thought to be part of a common signaling complex. Loss of function of this polycystin complex causes severe, potentially lethal, kidney disorders and multiple extrarenal -including brain- disease phenotypes. Here, we demonstrate that PC1 and PC2 form functionally associated 'subunits' of a heteromultimeric signaling complex that functions either as a $\mathrm{Ca}^{2+}$-permeable cation channel or as a G-protein-coupled receptor. Within these complexes, PC1 acts as a cell surface receptor that controls the gating of the PC2 channel via a structural rearrangement of its cytosolic tail. Evidence will be also presented that suggest that polycystin complex functions as an endoplasmic $\mathrm{Ca}^{2+}$ release channel. Thus, PC1 acts as a prototypical membrane receptor that concordantly regulates 
$\mathrm{Ca}^{2+}$ transport via PC2 channels and G-proteins, a bimodal mechanism that may account for the multifunctional roles of polycystin proteins in fundamental cellular processes of various cell types.

\section{IMAGING SINGLE-CHANNEL $\mathrm{Ca}^{2+}$ MICRODOMAINS}

\section{IAN PARKER AND ANGELO DEMURO}

Department of Neurobiology and Behavior, University of California, Irvine CA92697

The microdomains of $\mathrm{Ca}^{2+}$ in the cytosol around the mouth of open $\mathrm{Ca}^{2+}$ channels are the basic 'building blocks' from which cellular $\mathrm{Ca}^{2+}$ signals are constructed. Moreover, the kinetics of local $\left[\mathrm{Ca}^{2+}\right]$ closely reflect channel gating, so their measurement holds promise as an alternative to electrophysiological patch-clamp recording as a means to study single channel behavior. We have thus explored the development of optical techniques capable of imaging single-channel $\mathrm{Ca}^{2+}$ signals with good spatial and temporal resolution.

To demonstrate the practicability of this approach, we used a model system whereby $\mathrm{N}$-type voltage-gated channels are expressed in Xenopus oocytes. Recording of nearmembrane fluorescence signals from the $\mathrm{Ca}^{2+}$ indicator fluo-4 dextran by confocal and total internal reflection (TIR) microscopy reveal localized, stochastic transients ('sparklets') during depolarizations to voltages that activate N-type channels (Fig. 1). Several lines of evidence indicate that the sparklets reflect openings of single N-type channels: they are absent in control oocytes; their fluorescence magnitudes correspond to expected singlechannel currents; they show stochastic kinetics with durations and inactivation properties consistent with patch clamp data; and the voltage-dependence of their occurrence and magnitude match those expected for voltage-gated plasma membrane $\mathrm{Ca}^{2+}$ channels. The spatial spread of the fluorescence during a sparklet has a width (FWHM) of about $0.7 \mathrm{~mm}$, but because this measure includes both optical blurring (PSF $\sim 0.3 \mathrm{~mm}$ ) and diffusion of $\mathrm{Ca}^{2+}$ bound indicator, the distribution of free $\mathrm{Ca}^{2+}$ ions is likely to be much more restricted. N-type channels appear to be anchored in the oocyte membrane, since the positions of sparklets remain essentially fixed over periods of a few minutes. Because of this, we could follow the simultaneous activity of multiple (ca 100) channels over time to reveal differences in gating properties of channels within a restricted membrane area.

These data will aid in interpretation of presumptive optical signals ('blips' and 'quarks') thought to arise from single intracellular $\mathrm{Ca}^{2+}$ release channels. Moreover, optical imaging techniques hold great promise as an alternative to patch-clamp recording for single-channel studies of $\mathrm{Ca}^{2+}$ permeable channels. In comparison to patch-clamping, optical approaches are less invasive, provide spatial information regarding channel location and mobility, and permit simultaneous, independent monitoring of multiple channels.
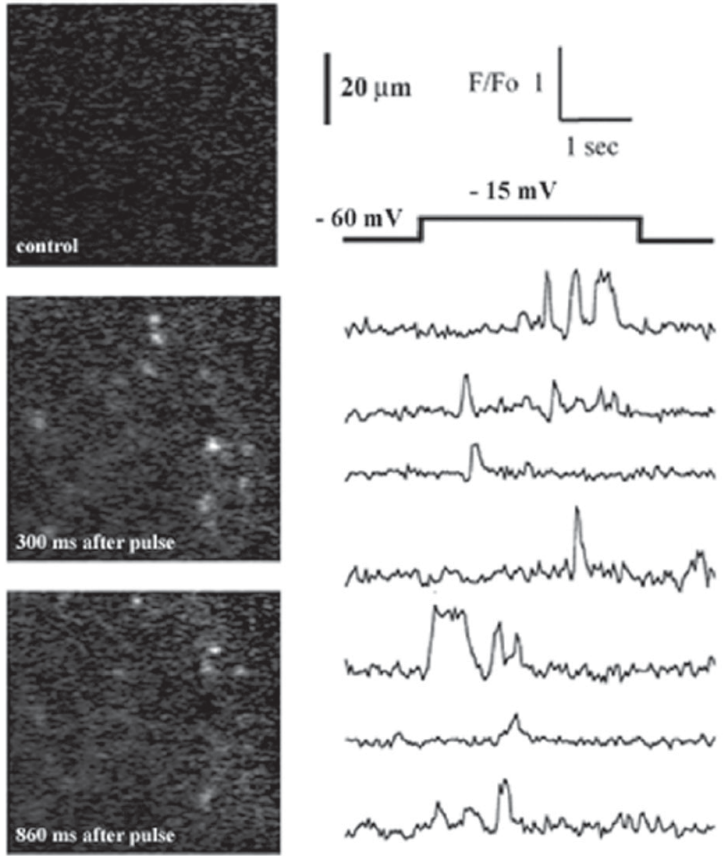

Fig. 1. Imaging $\mathrm{Ca}^{2+}$ influx through single $\mathrm{N}$-type $\mathrm{Ca}^{2+}$ channels by total internal reflection fluorescence microscopy. Images at left show near-membrane fluo-4 fluorescence signals from a $70 \times 70 \mathrm{~mm}$ region of an oocyte before stimulation and at different times after depolarizing to $-15 \mathrm{mV}$ to activate $\mathrm{N}$-type channels. Traces at right show corresponding fluorescence records measured simultaneously from several small regions of interest centered on channels. 


\section{INTRA-ER CALCIUM DYNAMICS IN NERVE CELLS}

\section{ALEXEI VERKHRATSKY \\ The University of Manchester, School of Biological Sciences, 1.124 Stopford Building, Oxford Road, Manchester M13 9PT}

The endoplasmic reticulum (ER) is an intracellular organelle of fundamental importance, which is present in all types of eucariotic cells. The ER lumen is densely packed with numerous enzymatic systems that allow protein synthesis in the rough endoplasmic reticulum and correct posttranslational "folding" of these proteins. Any malfunctions in the latter process result in accumulation of unfolded proteins, which in turn activates several signalling systems aimed at appropriate compensatory responses. At the same time the ER is recognised as an important component of a different signalling system, that is the cytosolic calcium signalling cascade. Within a framework of this cascade the endoplasmic reticulum serves as a rapidly exchanging $\mathrm{Ca}^{2+}$ store, able to release $\mathrm{Ca}^{2+}$ ions upon appropriate physiological stimulation. In order for the endoplasmic reticulum to work as a dynamic $\mathrm{Ca}^{2+}$ store, a high concentration of free $\mathrm{Ca}^{2+}$ has to be maintained within its lumen, where $\left[\mathrm{Ca}^{2+}\right]$ varies between $0.2-1 \mathrm{mM}$. Simultaneously, high intraluminal free $\mathrm{Ca}^{2+}$ concentration appears to be a key factor determining the activity of synthesis and processing of proteins within the endoplasmic reticulum, and disruption of endoplasmic reticulum $\mathrm{Ca}^{2+}$ homeostasis triggers endoplasmic reticulum stress response. The importance of the endoplasmic reticulum as a dynamic calcium pool in nerve cells was first appreciated in the late 80-s and early 90-s when several groups reported stimulation-induced cytosolic $\mathrm{Ca}^{2+}$ signals recorded from cultured neurones, which were not affected by $\mathrm{Ca}^{2+}$ removal from the extracellular media. These $\left[\mathrm{Ca}^{2+}\right]_{\mathrm{i}}$ signals were triggered by either caffeine (potent activator of RyRs) or by neurotransmitters (glutamate or ATP) stimulating metabotropic (i.e. $\mathrm{InsP}_{3}$ producing) receptors.

By imaging free $\mathrm{Ca}^{2+}$ concentration within the ER lumen $\left(\left[\mathrm{Ca}^{2+}\right]_{\mathrm{L}}\right)$ of cultured peripheral (dorsal rot ganglia) and central (hippocampus) neurones employing low-affinity $\mathrm{Ca}^{2+}$ dyes we succeeded in real-time visualisation of $\left[\mathrm{Ca}^{2+}\right]_{\mathrm{L}}$ dynamics in response to physiological and pharmacological stimulation.

In a study of cultured rat DRG neurones we deployed the patch-clamp whole-cell technique to record membrane currents in parallel with simultaneous video-imaging of both $\left[\mathrm{Ca}^{2+}\right]_{\mathrm{L}}$ and calcium concentration in cytosol $\left(\left[\mathrm{Ca}^{2+}\right]_{\mathrm{i}}\right)$ using low (Mag-Fura-2) and high (Fluo-3) affinity $\mathrm{Ca}^{2+}$ sensitive fluorescent probes $\mathrm{Ca}^{2+}$ entry through voltagegated calcium channels induced transient decrease in $\left[\mathrm{Ca}^{2+}\right]_{\mathrm{L}}$. This $\left[\mathrm{Ca}^{2+}\right]_{\mathrm{L}}$ response was inhibited by $50 \mathrm{mM}$ ryanodine and potentiated by $1 \mathrm{mM}$ of caffeine, indicating that it was directly associated with the calcium-induced calcium release (CICR) triggered.

The InsP $_{3}$-induced $\mathrm{Ca}^{2+}$ release was investigated in saponin-permeabilised DRG neurones pre-loaded with Mag-Fura-2. The permeabilisation effectively removed the cytosolic portion of the dye allowing direct $\left[\mathrm{Ca}^{2+}\right]_{\mathrm{L}}$ monitoring in response to InsP $\mathrm{P}_{3}$ application. We found that both $\mathrm{Ca}^{2+}$ release mechanisms, the RyR-mediated and the Ins $\mathrm{P}_{3} \mathrm{R}$-mediated share the same $\mathrm{Ca}^{2+}$ pool, further substantiating the idea of one continuous $\mathrm{ER} \mathrm{Ca}^{2+}$ store.

\section{INTERPLAY BETWEEN ER Ca ${ }^{2+}$ UPTAKE AND RELEASE FLUXES IN NEURONS AND ITS IMPACT ON $\left[\mathrm{Ca}^{2+}\right]$ DYNAMICS}

\section{DAVID FRIEL (USA)}

In neurons, depolarizing stimuli open voltage-gated $\mathrm{Ca}^{2+}$ channels, leading to $\mathrm{Ca}^{2+}$ entry and a rise in the cytoplasmic free $\mathrm{Ca}^{2+}$ concentration $\left(\left[\mathrm{Ca}^{2+}\right]_{\mathrm{i}}\right)$. Studies in a variety of cells have shown that $\left[\mathrm{Ca}^{2+}\right]_{\mathrm{i}}$ responses evoked by such stimuli are influenced by multiple factors, including $\mathrm{Ca}^{2+}$ entry and extrusion across the plasma membrane, $\mathrm{Ca}^{2+}$ uptake and release from internal stores, and $\mathrm{Ca}^{2+}$ binding to endogenous and exogenous buffers. Contributions to $\left[\mathrm{Ca}^{2+}\right]_{\mathrm{i}}$ signaling from the endoplasmic reticulum (ER) are particularly interesting because the ER expresses $\mathrm{Ca}^{2+}$ release channels that render its $\mathrm{Ca}^{2+}$ permeability sensitive to $\left[\mathrm{Ca}^{2+}\right]_{i}$, setting the stage for $\mathrm{Ca}^{2+}$ induced $\mathrm{Ca}^{2+}$ release. We examined how the ER contributes to depolarization-evoked $\left[\mathrm{Ca}^{2+}\right]_{\mathrm{i}}$ responses using sympathetic neurons as model cells and electron probe microanalysis to measure the total intraluminal $\mathrm{Ca}$ concentration $\left([\mathrm{Ca}]_{\mathrm{ER}}\right)$. We found that the ER can either accumulate or release net $\mathrm{Ca}^{2+}$ in response to stimulation, depending on properties of the stimulus-evoked $\left[\mathrm{Ca}^{2+}\right]_{\mathrm{i}}$ elevation. Weak depolarizing stimuli $\left(\mathrm{V}_{\mathrm{m}} \sim-35 \mathrm{mV}\right)$ that raise $\left[\mathrm{Ca}^{2+}\right]_{\mathrm{i}}$ from a resting level of $50-100 \mathrm{nM}$ to $\sim 300 \mathrm{nM}$ lead to net $\mathrm{Ca}^{2+}$ uptake, stronger depolarizations $\left(\mathrm{V}_{\mathrm{m}} \sim-20\right.$ $\mathrm{mV})$ that raise $\left[\mathrm{Ca}^{2+}\right]$ to somewhat higher levels $(400-600$ $\mathrm{nM})$ lead to little or no net ER $\mathrm{Ca}^{2+}$ transport, and stimuli that raise $\left[\mathrm{Ca}^{2+}\right]_{\mathrm{i}}$ to $\sim 1 \mathrm{mM}$ cause net $\mathrm{Ca}^{2+}$ release. We investigated the basis for this biphasic $\left[\mathrm{Ca}^{+2}\right]_{\mathrm{i}}$-dependence of net $\mathrm{ER} \mathrm{Ca}^{2+}$ transport. Since changes in the intraluminal calcium concentration depend on the relative rates of $\mathrm{Ca}^{2+}$ uptake and release via different transport pathways, we hypothesized that the biphasic $\left[\mathrm{Ca}^{2+}\right]_{\mathrm{i}}$-dependence of stimulus-evoked changes in $[\mathrm{Ca}]_{\mathrm{ER}}$ result from differences in the $\left[\mathrm{Ca}^{2+}\right]_{\mathrm{i}}$-dependencies of ER $\mathrm{Ca}^{2+}$ uptake and release rates. To test this idea, we examined the $\left[\mathrm{Ca}^{2+}\right]_{\mathrm{i}^{-}}$ dependence of the rates of $\mathrm{Ca}^{2+}$ uptake via SERCAs $\left(\mathrm{J}_{\text {SERCA }}\right)$ and of passive $\mathrm{Ca}^{2+}$ release by the ER $\left(\mathrm{J}_{\text {Release }}\right)$. We found that $J_{\text {SERCA }}$ increases with $\left[\mathrm{Ca}^{2+}\right]_{i}$, while $J_{\text {Release }}$ depends on both the driving force for $\mathrm{Ca}^{2+}$ release and the $\mathrm{Ca}^{2+}$ permeability of the ER $\left(\mathrm{P}_{\mathrm{ER}}\right)$. Moreover, $\mathrm{P}_{\mathrm{ER}}$ depends on $\left[\mathrm{Ca}^{2+}\right]_{\mathrm{i}}$ in a way that is highly sensitive to caffeine and ryanodine, suggesting that it is influenced by the activity of ryanodine-sensitive $\mathrm{Ca}^{2+}$ release channels. The quantitative properties of $\mathrm{J}_{\mathrm{SERCA}}$ and $\mathrm{P}_{\mathrm{ER}}$ provide an explanation for the biphasic $\left[\mathrm{Ca}^{2+}\right]_{\mathrm{i}}$-dependence of evoked changes in $[\mathrm{Ca}]_{\mathrm{ER}}$. At low $\left[\mathrm{Ca}^{2+}\right]_{\mathrm{i}}, \mathrm{J}_{\mathrm{SERCA}}$ increases more steeply with $\left[\mathrm{Ca}^{2+}\right]_{\mathrm{i}}$ than does $\mathrm{J}_{\text {Release }}$, leading to net $\mathrm{Ca}^{2+}$ uptake, while at high $\left[\mathrm{Ca}^{2+}\right]_{\mathrm{i}}$ the reverse is true, accounting for net $\mathrm{Ca}^{2+}$ release. Our findings also provide a simple explanation for the paradoxical observation that ryanodine enhances ER $\mathrm{Ca}^{2+}$ accumulation during weak stimulation: by preventing the $\left[\mathrm{Ca}^{2+}\right]_{\mathrm{i}}$-dependent increase in $\mathrm{P}_{\mathrm{ER}}$ that normally occurs at low $\left[\mathrm{Ca}^{2+}\right]_{\mathrm{i}}$ during weak stimulation, ryanodine increases the imbalance between $\mathrm{J}_{\mathrm{SERCA}}$ and $\mathrm{J}_{\text {Release }}$ increasing the rate of $\mathrm{ER} \mathrm{Ca}^{2+}$ accumulation. These results illustrate the value of obtaining quantitative characterizations of $\mathrm{Ca}^{2+}$ transport systems in intact cells, and demonstrate that in addition to different spatial signaling domains, there are $\mathrm{Ca}^{2+}$ concentration 'domains' within which cells show distinctive patterns of signaling. 


\section{SESSION 8:}

\section{NUCLEAR CALCIUM SIGNALS AND CALCIUM- DEPENDENT GENE EXPRESSION}

\section{OLE PETERSEN, CHAIR}

Session Chair's Summary: Two invited talks were given in the last session on nuclear calcium signaling and gene expression session. The first, by Angelica Carrasco dealt with skeletal muscle cells. Following on from the talk of Enrique Jaimovich earlier in the meeting, who had demonstrated InsP3-receptor mediated $\mathrm{Ca}^{2+}$ signals in nuclei from skeletal muscle cells elicited by membrane depolarization, she demonstrated that these cells respond to depolarization by phosphorylation of the MAP kinases ERKs $1 / 2$ and the transcription factor CREB, as well as by increased c-fos, c-jun and egr-1 mRNA levels. All these effects seem to be initiated by InsP3-receptor mediated $\mathrm{Ca}^{2+}$ signals. Dr. Carrasco also presented evidence indicating that the $\mathrm{Ca}^{2+}$-dependent $\mathrm{PKC}$ isoform $\mathrm{PKC}$ alpha is specifically involved in CREB phosphorylation.

The second talk was given by Jim Lechleiter from UTHSCSA in San Antonio, Texas, who discussed the possibility that cytosolic $\mathrm{Ca}^{2+}$ oscillations, evoked by extracellular ATP, might protect astrocytes from oxidative stress. He reported that those cells that exhibited repetitive $\mathrm{Ca}^{2+}$ release were more resistant to oxidant stress than those that did not have $\mathrm{Ca}^{2+}$ oscillations. This was related to enhanced ATP production in cells with $\mathrm{Ca}^{2+}$ oscillations.

\section{These abstracts follow:}

\section{SIGNAL TRANSDUCTION AND GENE EXPRESSION REGULATED BY CALCIUM RELEASE FROM INTERNAL STORES IN EXCITABLE CELLS}

\section{MARIA ANGÉLICA CARRASCO \\ CEMC and ICBM, Facultad de Medicina, Universidad de Chile}

In skeletal muscle cells, calcium release from internal stores induced by depolarization, involves a fast component mediated by ryanodine receptor (RYR) activation, and a slow one, which is mediated by IP3 receptor (IP3R) activation (E. Jaimovich et al., this Workshop). We have undertaken a study on the regulation by calcium of signaling cascades involved in gene expression in primary skeletal muscle cells which present these well defined calcium signals. We have looked at the MAP kinases ERKs $1 / 2$, the transcription factor CREB, and the early genes $c$ fos, $c$-jun, and egr-1, which respond to depolarization in our model.

The stimulation by depolarization of ERK and CREB phosphorylation, and the mRNA increase in early genes, does not require extracellular calcium. Instead, the stimulation is dependent on calcium from intracellular stores, specifically, from the IP3-dependent slow calcium transient. We have found that inhibitors of the IP3Rmediated calcium release, significantly decrease the stimulation induced by depolarization of the three elements. Inhibition of the RYR-mediated calcium release, meanwhile, has no effect. Supporting these results, there is ERK activation in depolarized dyspedic skeletal cells, cells that do not express RYR and in which the calcium release depends only on the IP3 system. In addition, a pharmacological study of the kinases involved in depolarization-induced CREB phosphorylation, has shown that ERK and PKC are the main kinases involved. Very interestingly, it was determined that a calcium-dependent PKC isoform, PKC $\alpha$, is involved in CREB phosphorylation. The activation of $\mathrm{PKC} \alpha$, determined by its translocation to the nucleus in an immunocytochemical study, occurs with kinetics compatible with CREB phosphorylation, and is blocked by several compounds that inhibit the IP3R-mediated calcium increase. These data suggest an IP3R-calcium dependent signaling pathway for excitation-transcription coupling in muscle cells.

In neurons, extracellular calcium plays an important role in the regulation of gene expression, and growing evidence indicates that calcium from intracellular stores is also involved. In particular, calcium release from the endoplasmic reticulum (ER) is known to contribute to the distinct calcium signals generated after neuronal activation. Since RyR present in neuronal ER are activated by oxidation (C. Hidalgo, this Workshop), we have initiated a study on redox modification of RyR and gene expression. We have studied the activation of CREB and ERK in a neuronal cell line (N2a) and in hippocampal neurons in culture exposed to $\mathrm{H}_{2} \mathrm{O}_{2}$. In both cultures the incubation with $\mathrm{H}_{2} \mathrm{O}_{2}$ results in increased phosphorylation of CREB and ERK1/2, which is significantly inhibited by $50 \mu \mathrm{M}$ ryanodine. These results suggest that redox activation of RyR-mediated $\mathrm{Ca}^{2+}$ release from intracellular stores might play a role in the modulation of $\mathrm{Ca}^{2}$-dependent gene expression in neurons.

Supported by FONDAP Center for Molecular Studies of the Cell 15010006 and FONDECYT 1030988.

\section{$\mathrm{Ca}^{2+}$ OSCILLATIONS PROTECT ASTROCYTES FROM OXIDATIVE STRESS}

\section{UPADHYAY, G., MULLER, L, WU, J, LIN, D.T. AND LECHLEITER, J. \\ Department of Cellular and Structural Biology, UTHSCSA, San Antonio, TX}

Astrocytes protect neurons by providing metabolic support and by buffering neurotransmitters and ions. Neuronal protection is an energy dependent process that can be initiated by neurotransmitter stimulation of astrocytes that generates inositol 1,4,5 trisphosphate $\left(\mathrm{IP}_{3}\right)$. This in turn releases intracellular $\mathrm{Ca}^{2+}$, which increases mitochondrial $\mathrm{Ca}^{2+}$ and consequently, ATP production. The natural production and accumulation of reactive oxygen species during mitochondrial respiration has been suggested to contribute to the aging process. Here, we examined the effects of age related oxidative stress on $\mathrm{Ca}^{2+}$ homeostasis in primary cultures of astrocytes from young ( 4 months) and old mice (28 months). The purinergic ligand ATP was used to induce $\mathrm{IP}_{3}$-mediated $\mathrm{Ca}^{2+}$ release. $\mathrm{Ca}^{2+}$ was imaged with confocal and two-photon microscopy using the $\mathrm{Ca}^{2+}$ indicator Oregon Green -1 AM and Fura-2 AM, respectively. We found that a significantly higher number of cells from older animals responded to ATP when compared to cells from younger animals. Of those cells that did respond, a tidal (non-oscillating) $\mathrm{Ca}^{2+}$ response was observed in the same fraction of cells from both groups. However, the cell cultures from older animals contained significantly higher numbers of oscillating $\mathrm{Ca}^{2+}$ responses. These findings are particularly interesting since it is known that oscillating $\mathrm{Ca}^{2+}$ is more efficient at stimulating ATP production in mitochondria than tidal $\mathrm{Ca}^{2+}$ release. Next, we tested whether astrocytes with $\mathrm{Ca}^{2+}$ oscillations exhibited increased resistance to oxidant stress. Briefly, primary cultures of astroctyes from young and old mice were stimulated with ATP for 10 minutes and then continually exposed to tert-butyl hydroperoxide $(\mathrm{tBuOOH})$. 
Consistent with this hypothesis, we found that those cells which exhibited $\mathrm{Ca}^{2+}$ release were much more resistant to oxidant stress. In a separate series of experiments, we determined that ATP production was increased when astrocytes from middle aged mice (6-9 months old) were treated with Pasteurella multocida Toxin (PMT), a reagent which induces $\mathrm{IP}_{3}$ mediated $\mathrm{Ca}^{2+}$ release. Taken together, these data suggest that $\mathrm{Ca}^{2+}$ oscillations in astrocytes are protective against oxidant stress and that this protection may be due to increased ATP production.

This work is supported by PO1 AG19316-01. 


\section{POSTER SESSIONS}




\section{PROGRAM OF POSTER SESSIONS}

\section{POSTER SESSION 1}

1.- NF-kB ACTIVATION IN DEPOLARIZED SKELETAL MUSCLE CELLS

Valdés J.A., Lavandero S., Jaimovich E., and M.A. Carrasco.

2.- $\mathrm{H}_{2} \mathrm{O}_{2}$ ACTIVATES CALCIUM-DEPENDENT SIGNAL TRANSDUCTION PATHWAYS IN CULTURED RAT SKELETAL MUSCLE CELLS

Leiva A., Carrasco M.A., Estrada M., Ríos J., Silva M. and E. Jaimovich.

3.- ENDOTHELIAL DYSFUNCTION IN UMBILICAL VEIN ENDOTHELIAL CELLS FROM FOETUS WITH INTRAUTERINE GROWTH RESTRICTION IS RELATED TO CHRONIC HYPOXIA

Casanello P. and L. Sobrevia.

4.- CALCIUM RELEASE MEDIATED BY REDOXACTIVATED RYANODINE RECEPTORS (RyR) INDUCES CREB AND ERK1/2 PHOSPHORYLATION IN HIPPOCAMPAL AND N2a NEURONS

Kemmerling, U. Carrasco, M.A. and C. Hidalgo.

5.- LIPID SIGNALING AND PKC INVOLVEMENT IN Trypanosoma cruzi METACYCLOGENESIS

Belaunzarán M. L., Wainszelbaum M. J., Lammel E. M., Gimenez G., Aloise M. M., Florin-Christensen J. and I. Elvira.

6.- CERAMIDE INCREASES CYTOPLASMIC $\mathrm{Ca}^{2+}$ CONCENTRATION IN JURKAT T CELLS BY $\mathrm{IP}_{3}-$ INDUCED CALCIUM RELEASE AND A STOREOPERATED CALCIUM CHANNEL

Colina C., Flores A., Castillo C., DiPolo R. and .G. Benaim.

7.- CORRELATION BETWEEN RNA SYNTHESIS AND THE $\mathrm{Ca}^{2+}$ FILLED STATE OF THE NUCLEAR ENVELOPE STORE

Benech J. C.; Escande C. and J. R. Sotelo

8.- MODULATION OF $\mathrm{IP}_{3}$-EVOKED $\mathrm{Ca}^{2+}$ PUFFS BY ENDOGENOUS $\mathrm{Ca}^{2+}$ BINDING PROTEINS

Dargan S. L, Beat Schwaller B. and I. Parker.

9.- MODIFICATION OF CALCIUM DEPENDENCE OF RAT BRAIN RYANODINE RECEPTOR CHANNELS BY ATP AND SH OXIDATION

Finkelstein J., Hidalgo C. and R. Bull.

10.- SLOW CALCIUM SIGNALS AFTER TETANIC ELECTRICAL STIMULATION IN SKELETAL MYOTUBES

Eltit J. M., Liberona J. L., Jaimovich E. and J. Hidalgo.

11.- THE ROLE OF CALSEQUESTRIN, TRIADIN, AND JUNCTIN IN CONFERRING CARDIAC RYANODINE RECEPTOR RESPONSIVENESS TO LUMINAL CALCIUM

Gyorke I., Hester N., Jones L.R. and S. Gyorke.

12.- $\mathrm{Ca}^{2+}$ STORE REFILLING DETERMINES SLOW INHIBITION OF STORE OPERATED CALCIUM ENTRY IN MAMMALIAN SKELETAL MUSCLE

Castillo A., Figueroa L. and A. González.
13.- IGF-I AND INSULIN INDUCE DIFFERENT INTRACELLULAR CALCIUM SIGNALS IN SKELETAL MUSCLE CELLS

Espinosa A., Estrada M. and E. Jaimovich.

14.- $\mathrm{Ca}^{2+}, \mathrm{Mg}^{2+}$ AND REDOX MODULATION OF RYR CALCIUM RELEASE CHANNELS FROM RAT BRAIN CORTEX

Humeres A. and C. Hidalgo.

15.- EFFECT OF ETHANOL ON CALCIUM SIGNALLING IN MOUSE PANCREATIC ACINAR CELLS

Criddle D.N., Raraty M.G.T., Neoptolemos J.P., Tepikin A., Petersen O. H. and R. Sutton.

16.- ALLOSTERIC CHANGES IN THE INSP ${ }_{3} R$ RECEPTOR AND ATP MODULATION

Fraiman D. and S. Ponce Dawson. 


\section{POSTER SESSION 2}

1.- RyR EXPRESSION LEVELS AND CAFFEINE SENSITIVITY IN 1B5 MYOTUBES

Perez C. F., Lopez J. R. and P. D. Allen.

2.- CD38/CYCLIC ADP-RIBOSE SIGNALING IN INTRACELLULAR CALCIUM REGULATION IN AIRWAY SMOOTH MUSCLE

Deshpande D.A., Milla C., Walseth T.F., Lund F.E. and M.S. Kannan.

3.- INHIBITION OF INOSITOL 1,4,5-TRISPHOSPHATE (INSP ${ }_{3}$ )-INDUCED CALCIUM RELEASE (IICR) BY NEURONAL CALCIUM BINDING PROTEINS (CABP)

Holmes A. M., Bootman M. D., Kasri N. N., DeSmedt H. and H.L. Roderick.

4.- MODULATION OF RYANODINE RECEPTORS (RYRs) CHANNELS BY DIHYDROPYRIDINE RECEPTOR (DHPR) PEPTIDE A (PepA)

Porta M., Nani A., Ramos-Franco J., Fill M., Ikemoto N. and J.A. Copello.

5.- DOES $\mathrm{Ca}^{2+}$ PARTICIPATE IN NFkB ACTIVATION INDUCED BY HYPEROSMOTIC STRESS?

Eisner V., Quiroga C., Criollo A., Ibarra C., Cea P., Chiong M., Díaz-Araya G. and S. Lavandero.

6.- IGF-1 INDUCES IP ${ }_{3}$-DEPENDENT INCREASES IN BOTH NUCLEAR AND CYTOSOLIC CALCIUM IN RAT CARDIAC MYOCYTES

Ibarra C., Estrada M., Carrasco L., Chiong M., Jaimovich E. and S. Lavandero.

7.- MODULATION OF CAFFEINE ACTION ON SINGLE RYANODINE RECEPTOR (RyR2) CHANNELS BY ENDOGENOUS AGENTS

Porta M., Diaz-Sylvester P.L., Nani A., Perez C., Mejía Alvarez R., Escobar A., Fleischer S., Fill M. and J. A. Copello

8.- ROLE OF STORE OPERATED CHANNELS IN TESTOSTERONE-INDUCED INTRACELLULAR CALCIUM OSCILLATIONS IN MYOTUBES

Estrada M. and E. Jaimovich.

9.- MOLECULAR INTERACTIONS AND ACTIVITY OF THE TYPE-1 INOSITOL 1,4,5-TRISPHOSPHATE RECEPTOR: EFFECTS OF SH-REAGENTS AND OF $\mathrm{Ca}^{2+}$ Parys J.B., Szlufcik K., Bultynck G., Nadif Kasri N., Vermassen E., Callewaert G., De Smedt H. and L. Missiaen.

10.- RYANODOL: A PROBE FOR RYANODINE RECEPTOR MEDIATED CALCIUM RELEASE

Ramos-Franco J., Nani A., Copello J.A., Gomez A.M. and M. Fill.

11.- DIFFERENTIAL GENE EXPRESSION IN SKELETAL MUSCLE CELLS AFTER K+-DEPOLARIZATION

Juretic N., Gangi L., Munroe D., Jaimovich E. and N. Riveros.

12.- TACHYCARDIA INCREASES RYR2 PROTEIN CONTENT IN THE HEART

Sánchez G., Macho P., Doménech R. and P. Donoso.

13.- SPECIFIC ENHANCEMENT OF IP $_{3}$-MEDIATED $\mathrm{Ca}^{2+}$ SIGNALING IN MOUSE CORTICAL NEURONS EXPRESSING AN ALZHEIMER'S-LINKED MUTATION IN PRESENILIN-1

Stutzmann G. E., LaFerla F. M. and I. Parker.
14. - PARTICIPATION OF TRPC3/6 PROTEINS AND THE VITAMIN D RECEPTOR (VDR) IN STORE OPERATED CALCIUM ENTRY (SOCE) INDUCED BY $1 \alpha, 25(\mathrm{OH})_{2}$-VITAMIN $\mathrm{D}_{3}$ IN SKELETAL MUSCLE CELLS

Katz S., Santillán G., and R. Boland*.

15.- DIVERGENT EFFECTS OF PKA-MEDIATED PHOSPHORYLATION ON HOMOTETRAMERIC INOSITOL 1,4,5-TRISPHOSPHATE RECEPTORS Straub S. V., Wagner L. E. and D. I. Yule.

16.- ABNORMAL CALCIUM RELEASE CHANNEL/ RYANODINE RECEPTOR PHOSPHORYLATION MAY CONTRIBUTE TO SARCOPLASMIC RETICULUM DYSFUNCTION IN MYOCARDIAL STUNNING

Valdivia C.R., Hegge J.O., Mentzer, Jr. R.M. and H. H. Valdivia. 


\section{POSTER SESSION 3}

1.- MEMBRANE $\mathrm{IP}_{3}$ RECEPTOR-DEPENDENT $\mathrm{Ca}^{2+}$ INFLUX IS AUGMENTED BY PROTEIN KINASE A IN THE SYNERGISM OF THE CILIARY BEAT FREQUENCY INCREASE INDUCED BY ATP AND ADENOSINE

Barrera N. P., Torres S., Morales B. and M. Villalón.

2.- NONGENOMIC ALDOSTERONE ACTION ON INTRACELLULAR CALCIUM AND VASCULAR TONE IN ARTERIAL VESSELS

Michea L. and E. T. Marusic.

3.- THE EFFECT OF INTRALUMINAL $\mathrm{Ca}^{2+}$ OF THE ENDOPLASMIC RETICULUM (ER) ON $\mathrm{CA}^{2+} \mathrm{HOT}$ SPOTS IN SYMPATHETIC GANGLION NEURONS

Z Cseresnyes

4.- MULTICOLOR IMAGING OF $\mathrm{Ca}^{2+}$ PUFFS AND ENDOPLASMIC RETICULUM MORPHOLOGY IN THE XENOPUS EGG

Boulware M. J. and J. S. Marchant

5.- IRON-GENERATED REACTIVE OXYGEN SPECIES MODULATE THE ACTIVATION AND LOCALIZATION OF ERK1/2 IN PC12 CELLS

Muñoz P. C., Hidalgo C. and M. T. Núñez.

6.- XESTOSPONGINS ARE NOT SERCA INHIBITORS, RATHER THEIR HYDROXYLATED DERIVATIVES ARE ALLOSTERIC RYR AGONISTS

Ta T. N., Feng W., Molinski T. F. and I. N. Pessah

7.- REDOX MODULATION OF FKBP12 BINDING TO RYANODINE RECEPTORS/Ca ${ }^{2+}$ RELEASE CHANNELS FROM MAMMALIAN SKELETAL MUSCLE

Aracena, P., Tang, W., Hamilton, S. L. and C. Hidalgo.

8.- NADPH OXIDASE GENERATES REACTIVE OXYGEN SPECIES AFTER DEPOLARIZATION OF RAT SKELETAL MUSCLE CELLS

Peña M., Estrada M., Espinosa A., Hidalgo C. and E. Jaimovich

9.- $\mathrm{Ca}^{2+}$ SIGNALING PATHWAYS IN THE ANTIAPOPTOTIC ACTION OF IGF-1 ON CULTURED CARDIAC MYOCYTES

Rocco P., Ibarra C., Foncea R., Cea P., Maldonado C., Chiong M., Quest A. and S. Lavandero.

10.- MULTIFUNCTIONAL CELLS IN HUMAN PITUITARY ADENOMAS: IMPLICATIONS FOR PARADOXICAL SECRETION AND TUMORIGENESIS

Senovilla L., Núñez L., De Campos J.M., De Luis D.A., Romero E., García-Sancho J., Villalobos C. and A. Sánchez.

11.- TESTOSTERONE INDUCES RAPID $\mathrm{Ca}^{2+}$ INCREASES INDEPENDENT OF INTRACELLULAR ANDROGEN RECEPTOR ON CARDIAC MYOCYTES

Vicencio J.M., Estrada M., Chiong M., Jaimovich E. and S. Lavandero.

12.- LIPID RAFTS ISOLATED FROM SKELETAL MUSCLE TRIAD VESICLES CONTAIN CAVEOLIN-3 AND L-TYPE CALCIUM CHANNELS

Barrientos G., Quest A. F. and C. Hidalgo.
13.- ON THE ROLE OF P2X RECEPTORS AND CONNEXIN COMPOSED CHANNELS DURING MYOGENESIS

Araya, R and J. C. Sáez.

14.- CALCIUM IMAGING AND TYROSINE KINASE PHOSPHORYLATION CHANGES IN DIFFERENT MAMMALIAN SKELETAL MUSCLE CELL LINES IN RESPONSE TO $1,25(\mathrm{OH})_{2}$-VITAMIN $\mathrm{D}_{3}$

Buitrago, C., Estrada, M., Boland, R. and E. Jaimovich.

15.- CARBACHOL INDUCED CALCIUM SIGNALING IN TRYPANOSOMA CRUZI EPIMASTIGOTES VIA A $\mathrm{NA}^{+} / \mathrm{H}^{+}$EXCHANGER ACTIVATION

Bonansea S.; Bollo M. and E. Machado-Domenech.

16.- MEMBRANE DEPOLARIZATION INDUCES PHOSPHORYLATION OF CAMP-RESPONSE ELEMENT-BINDING PROTEIN VIA A CALCIUM AND PROTEIN KINASE C ALPHA DEPENDENT PATHWAY IN SKELETAL MUSCLE CELLS

Cárdenas C., Müller M., Jaimovich E., Perez F., Buchuk D., Quest A.F.G, and M. A. Carrasco. 


\section{ABSTRACTS}

\section{SESSION 1}

\section{1.- NF-kB ACTIVATION IN DEPOLARIZED SKELETAL MUSCLE CELLS}

\#VALDÉS J.A., *§LAVANDERO S., *\#JAIMOVICH E. AND *\#M.A. CARRASCO

${ }^{*}$ CEMC, \#ICBM, Fac. Medicina, § Fac. Ciencias Químicas, U. de Chile.

Nuclear factor kappa B (NF-kB) is a transcription factor involved in many cellular responses. In skeletal muscle cells, NF-kB is activated by stable transfected calcineurin, a calcium-dependent phosphatase involved in gene expression regulation in muscle hypertrophy and fibre phenotypes. NF-kB represents a group of structurally related and evolutionary conserved proteins, the dimer p50/ p65 is considered the prototype of NF-kB family. Calcium signals play an important role in NF-kB activation, through the regulation of its translocation to the nucleus.

Calcium release in depolarized skeletal muscle cells is a complex event involving at least two components. A fast calcium transient is mediated by ryanodine receptors and associated to contraction. A slower component is associated to $\mathrm{IP}_{3}$ receptors, and participates in regulation of gene expression. Here we investigated NF-kB activation in depolarized rat skeletal muscle cells in primary culture in relation to its calcium dependence, and the possible participation of calcineurin

High potassium-induced depolarization of muscle cells transfected with a NF-kB-luciferase reporter vector resulted in enhancement of transcription. This effect was inhibited by slow calcium component inhibitors (2APB or BAPTA-AM) and by cyclosporin A (calcineurin activity inhibitor). These preliminary results indicate that our model is adequate to study calcium signaling involved in $\mathrm{NF}-\mathrm{kB}$ activation.

Supported by FONDAP Center for Molecular Studies of the Cell 15010006 and FONDECYT 1030988

2.- $\mathrm{H}_{2} \mathrm{O}_{2}$ ACTIVATES CALCIUM-DEPENDENT SIGNAL TRANSDUCTION PATHWAYS IN CULTURED RAT SKELETAL MUSCLE CELLS

*LEIVA A., \#CARRASCO M.A., \#ESTRADA M., \#RÍOS J., \#SILVA M. AND \#E. JAIMOVICH.

*Centro de Investigaciones Biomédicas "Victoria de Girón" (CIBIOMED). \#Centro de Estudios Moleculares de la Célula, ICBM, Fac. Medicina, Universidad de Chile.

Reactive oxygen species (ROS) are generated intracellularly as byproducts of normal aerobic metabolism, or as second messengers in various signal transduction pathways. ROS are generated during exercise, and their role as physiological components of signaling pathways in skeletal muscle is an open question. In this work, we have studied the effect of $\mathrm{H}_{2} \mathrm{O}_{2}$ on calcium signaling and on transcription factors activation, in cultured rat skeletal muscle cells.

50-1000 mM $\mathrm{H}_{2} \mathrm{O}_{2}$ did not affect skeletal muscle cells viability. Experiments were performed with 100 or $200 \mathrm{mM}$ peroxide. $\mathrm{H}_{2} \mathrm{O}_{2}$ induced intracellular calcium transients 1-2 minutes after the oxidant addition, as determined by epifluorescent microscopy. This response remained in $\mathrm{Ca} 2+-$ free medium, was not affected by $\mathrm{IP}_{3}$-mediated pathways inhibitors, but it was blocked by $25 \mathrm{mM}$ ryanodine, condition that inhibits the ryanodine receptors. On the other hand, $\mathrm{H}_{2} \mathrm{O}_{2}$ transiently increased both ERK $1 / 2$ and CREB phosphorylation, measured by Western blotting, with maximum levels at 5 - 10 minutes of exposure. $\mathrm{H}_{2} \mathrm{O}_{2}$ also induced an increase in c-fos and c-jun mRNA, determined by semi-quantitative RT-PCR. Both CREB phosphorylation and early genes up-regulation were also decreased by inhibitory ryanodine concentrations. These results indicate that $\mathrm{H}_{2} \mathrm{O}_{2}$ might have a role in skeletal muscle cells signaling pathways, and suggest that calcium release through ryanodine receptors would mediate these effects. Supported by FONDAP 15010006.

\section{3.- ENDOTHELIAL DYSFUNCTION IN UMBILICAL VEIN ENDOTHELIAL CELLS FROM FOETUS WITH INTRAUTERINE GROWTH RESTRICTION IS RELATED TO CHRONIC HYPOXIA}

\section{1,2 CASANELLO P. AND ${ }^{1}$ L. SOBREVIA.}

${ }^{1}$ Cellular and Molecular Physiology Laboratory (CMPL), Department of Obstetrics and Gynaecology \& Medical Research Centre (CIM), School of Medicine, Faculty of Medicine, Pontificia Universidad Católica de Chile, PO Box 114-D, Santiago, Chile. ${ }^{2}$ Department of Obstetrics and Gynaecology, Faculty of Medicine, Universidad de Concepción, PO Box 160-C, Concepción, Chile. (pcasane@med.puc.cl).

Intrauterine growth restriction (IUGR) is associated with chronic foetal hypoxia, altered foetal development and adult vascular disorders. In pregnancies complicated by IUGR both the uteroplacental and fetoplacental circulation resistance are increased. Endothelial regulation of fetoplacental vascular tone becomes abnormal. We have studied the effect of hypoxia on the activity, expression and regulation of the L-arginine/nitric oxide (NO) pathway in human umbilical vein endothelial cells (HUVEC) from normal and IUGR pregnancies. L-arginine transport and NO synthesis are reduced, an effect associated with membrane depolarisation. L-arginine transport is trans-stimulated (8-9 fold) by L-lysine in both normal and IUGR HUVECs. In IUGR as well as normal HUVECs under hypoxia, lower levels of mRNA for hCAT-1, hCAT-2B, and calciumcalmodulin dependent endothelial NO synthase (eNOS) were quantitated (Real-time PCR). The NO donor SNAP reverted the effect of hypoxia and IUGR on L-arginine transport, NO synthesis and membrane depolarisation. cDNA microarray experiments suggest the involvement of PKC, ERK1/2, soluble guanylate cyclase and Sp1 in hypoxia and IUGR. Thus, the L-arginine/NO pathway alterations could be crucial in the pathophysiology involved in the aetiology of IUGR in human pregnancies associated to foetal hypoxia. Supported by FONDECYT (1030781, 7030004, 1030607, 7030109) \& DIUC (201.084.003-1).

4.- CALCIUM RELEASE MEDIATED BY REDOXACTIVATED RYANODINE RECEPTORS (RyR) INDUCES CREB AND ERK1/2 PHOSPHORYLATION IN HIPPOCAMPAL AND N2a NEURONS

*\#KEMMERLING, U. *CARRASCO, M.A. AND *C. HIDALGO.

*CEMC, ICBM, Fac. Medicina, U. de Chile \#Fac. Cs de la Salud, U. de Talca

Nerve cell function is modulated by reactive oxygen species (ROS) and by activation of $\mathrm{Ca}^{2+}$-dependent gene 
expression. The regulation of neuronal gene expression by calcium is a complex phenomenon regulated by nuclear and cytoplasmic mechanisms, which decode the calcium signal in terms of temporal and spatial properties. Calcium release from the endoplasmic reticulum (ER) contributes to the distinct calcium signals generated after neuronal activation. Ryanodine receptors (RyR) are calcium release channels present in neuronal ER that are highly susceptible to redox modification. The channel activity is controlled by channel redox state: oxidation enhances channel activity and reduction has the opposite effect.

To investigate whether redox activated RyR channels promote activation of transcription factors like CREB or the ERK MAP kinases, which are involved in gene expression, we have initiated a study on the activation these proteins by $\mathrm{H}_{2} \mathrm{O}_{2}$ in a neuronal cell line (N2a) and in hippocampal neurons in culture. To detect P-CREB and total CREB, or P-ERK and total ERK, cell lysates were resolved on $10 \%$ SDS PAGE minigels, transferred to PDVF membranes, and immunoblotted with polyclonal antibodies. Immunoreactive proteins were visualized by enhanced chemiluminescence. Cell cultures incubated with $\mathrm{H}_{2} \mathrm{O}_{2}$ $(100-400 \mu \mathrm{M})$ for up to 30 minutes displayed increased phosphorylation of CREB and ERK1/2, which was significantly inhibited by $50 \mu \mathrm{M}$ ryanodine. These results suggest that redox activation of RyR-mediated $\mathrm{Ca}^{2+}$ release from intracellular stores might play a role in the modulation of $\mathrm{Ca}^{2+}$-dependent gene expression.

Supported by FONDAP Center for Molecular Studies of the Cell 15010006.

\section{5.- LIPID SIGNALING AND PKC INVOLVEMENT IN TRYPANOSOMA CRUZI METACYCLOGENESIS}

\section{BELAUNZARÁN M. L., WAINSZELBAUM M. J., LAMMEL E. M., GIMÉNEZ G., ALOISE M. M., FLORIN-CHRISTENSEN J. AND I. ELVIRA.}

Dept. of Microbiology, School of Medicine, University of Buenos Aires, Argentina.

e-mail: paradife@fmed.uba.ar

Trypanosoma cruzi, protozoan agent of Chagas'disease, develops a complex life cycle, including an hematophagus insect vector, Triatoma infestans and a mammalian host. In the vector's intestinal tract, epimastigote differentiation to the infectious metacyclic form (metacyclogenesis) depends on a network of multiple signaling molecules. Among the lipidic components of $T$. infestans intestinal extracts (IE), we found free fatty acids (FFA), mainly Oleic Acid (OA) in concentrations of about $300 \mathrm{mM}$, with metacyclogenic effect. In this work we show a strong increase in Diacylglycerol (DG) biosynthesis in labeled epimastigotes with $\left[1-{ }^{14} \mathrm{C}\right]$ oleate stimulated with IE. DG function as a second messenger, regulating protein kinase $\mathrm{C}(\mathrm{PKC})$ in eukaryotic cells, is widely accepted

We studied protein phosphorylation in epimastigotes stimulated by IE and oleoyl-acyl-glycerol (OAG). We found that both agents induce similar phosphorylation patterns, with bands of Mr 180, 120 and 26 characteristically labeled. These bands are phosphorylated by exposure to $300 \mathrm{mM}$ $\mathrm{OA}$, that also induced a transient $\mathrm{Ca}^{2+}$ signal.

We conclude that PKC stimulation plays a key role in metacyclogenesis of T.cruzi, and that the FFA of the IE can account at least partially for this effect. FFA are a novel signal inducing metacyclogenesis, acting through a pathway involving DG biosynthesis, transient $\mathrm{Ca}^{2+}$ signal and $\mathrm{PKC}$ activation.

Supported by: UBA, CONICET and UNDP/WORLD BANK/WHO

\section{6.- CERAMIDE INCREASES CYTOPLASMIC $\mathrm{Ca}^{2+}$ CONCENTRATION IN JURKAT T CELLS BY IP ${ }_{3}-$ INDUCED CALCIUM RELEASE AND A STORE- OPERATED CALCIUM CHANNEL}

\section{COLINA C..$^{1,3}$, FLORES A.1,3, CASTILLO C..$^{3}$, DIPOLO R. ${ }^{2}$ AND .G. BENAIM ${ }^{1,3}$.}

${ }^{1}$ Instituto de Biología Experimental, Facultad de Ciencias. U.C.V. Apartado 47114, ${ }^{2}$ Centro de Bioquímica y Biofísica, IVIC and ${ }^{3}$ Instituto de Estudios Avanzados (IDEA), Caracas, Venezuela.

e-mail: ccprisco@cantv.net

An increase in the cytoplasmic $\mathrm{Ca} 2+$ concentration $[\mathrm{Ca} 2+]_{\mathrm{i}}$ is an essential signal on $\mathrm{T}$ lymphocytes. The goal of this work is to demonstrate the effect of different sphingolipids on the intracellular calcium concentration $\left([\mathrm{Ca} 2+]_{\mathrm{i}}\right)$ in Jurkat $\mathrm{T}$ cells. Here we show that ceramide increases the $[\mathrm{Ca} 2+]_{\mathrm{i}}$. The effect of ceramide appeared to occur by an increment of $\mathrm{IP}_{3}$ and subsequent activation of a capacitative $\mathrm{Ca} 2+$ entry, as it is similar to that obtained by addition of $\mathrm{OKT}_{3}$. This is also supported by the fact that thapsigargin addition, previous to ceramide, abolished its effect. The capacitative calcium entry observed after ceramide addition was abolished by the $\mathrm{I}_{\text {crac }}$ inhibitor, 2aminoethyldiphenyl-borate (2-APB). It is noteworthy that after the addition of ceramide in the absence of calcium, the $[\mathrm{Ca} 2+]_{i}$ level achieved after the recovery from the initial $\mathrm{Ca} 2+$ rise was lower than the basal $[\mathrm{Ca} 2+]_{\mathrm{i}}$ measured before the addition of the sphingolipid. This effect is probably due to the reported stimulation of the plasma membrane calcium pump by ceramide [Colina et al. (2002) Biochem. J. 362:247]. Addition of ceramine, a nonhydrolizable analogue of ceramide, reproduced its effect, ruling out that the observed results are consequence of the conversion of ceramide to sphingosine. Ceramide-1phosphate, appeared to be more potent than ceramide on the elevation of $[\mathrm{Ca} 2+]_{i}$. The effect of ceramide on $\mathrm{Ca} 2+$ entry was corroborated by the use of patch-clamp in wholecell configuration. The general characteristic of the capacitative calcium channel observed are similar to that reported for $\mathrm{I}_{\text {crac }}$.

Acknowledgments: This work was supported by grants from FONACIT (S1-99000058 to G.B. and G-2001000637 to G.B and R.D.) and C.D.C.H.- U.C.V. (03-33-4798-2000 to G.B.).

\section{7.- CORRELATION BETWEEN RNA SYNTHESIS AND THE $\mathrm{Ca}^{2+}$ FILLED STATE OF THE NUCLEAR ENVELOPE STORE}

\section{BENECH J. C. ${ }^{(1,2)}$; ESCANDE C..$^{(1,2)}$ AND J. R. SOTELO $^{(1)}$}

${ }^{1}$ Laboratorio de Proteínas y Ácidos Nucleicos, Instituto de Investigaciones Biológicas Clemente Estable. 22Área Biofísica, Departamento BMC, Facultad de Veterinaria, Universidad de la República. Montevideo, Uruguay.

RNA synthesis and ATP dependent ${ }^{45} \mathrm{Ca}^{2+}$ uptake were measured simultaneously using the same isolated nuclear fraction of rat liver nuclei. Maximal level of RNA synthesis was obtained in the presence of $1 \mathrm{mM}$ free $\mathrm{Ca}^{2+}$ concentration and physiological ATP (1 mM ATP). Under this condition isolated nuclei were able to accumulate ${ }^{45} \mathrm{Ca}^{2+}$ in an ATP dependent way, normal nuclei.

ATP dependent ${ }^{45} \mathrm{Ca}^{2+}$ uptake was prevented or inhibited using different strategies (modified nuclei) like: a) directly eliminating $\mathrm{Ca}^{2+}$ from the reaction medium (1 mM EGTA); b) lowering the ATP concentration 3 times relative to the reported $\mathrm{Km}$ for ATP of SERCA nuclear $\mathrm{Ca}^{2+}$ pump; c) 
altering permeability of nuclear envelope membranes to $\mathrm{Ca}^{2+}\left(\mathrm{Ca}^{2+}\right.$ ionophores $)$ and $\left.\mathrm{d}\right)$ directly inhibiting nuclear $\mathrm{Ca}^{2+}$ pump (thapsigargin, $\mathrm{I}_{4} \mathrm{PSP}$ ).

RNA synthesis level in modified nuclei was always lower than the synthesis determined in "normal nuclei".

In the presence of the $\mathrm{Ca}^{2+}$ ionophore ionomycin, RNA synthesis was greater at $500 \mathrm{~nm}$ free $\mathrm{Ca}^{2+}$ concentration compared with $\mathrm{Ca}^{2+}$ free medium (1 mM EGTA). However, even in that condition (500 $\mathrm{nm}$ free $\mathrm{Ca}^{2+}$ concentration), RNA synthesis rate was lower than the synthesis obtained with "normal nuclei".

On the whole, these results suggest the existence of 2 components of the $\mathrm{Ca}^{2+}$ effect on RNA synthesis: 1) a direct effect of nucleoplasmic $\mathrm{Ca}^{2+}$ concentration; 2) an effect of $\mathrm{Ca}^{2+}$ gradient actively created by nuclear $\mathrm{Ca}^{2+}$ pump.

Our results suggest a correlation between RNA synthesis and the $\mathrm{Ca}^{2+}$ filled state of the nuclear envelope store.

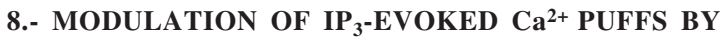 ENDOGENOUS $\mathrm{Ca}^{2+}$ BINDING PROTEINS}

\section{DARGAN S. L ${ }^{1}$, BEAT SCHWALLER B. ${ }^{2}$ AND I. PARKER ${ }^{1}$.}

${ }^{1}$ Department of Neurobiology \& Behavior, University of California, Irvine, CA 92697. ${ }^{2}$ Division of Histology, Department of Medicine, University of Fribourg, Switzerland.

$\mathrm{Ca}^{2+}$ binding proteins (CaBPs) show cell specific expression in many cell types, yet the physiological basis underlying such expression patterns still remains unclear. Cytosolic CaBPs likely modulate the spatiotemporal properties of $\mathrm{IP}_{3}$-evoked $\mathrm{Ca}^{2+}$ signals, via their actions on the successive cycles of diffusion and $\mathrm{Ca}^{2+}$ induced $\mathrm{Ca}^{2+}$ release responsible for recruiting local $\mathrm{Ca}^{2+}$ release events (puffs) into global $\mathrm{Ca}^{2+}$ waves. We investigated this hypothesis using confocal line-scan microscopy together with photo-release of $\mathrm{IP}_{3}$ to image intracellular $\mathrm{Ca}^{2+}$ signals in Xenopus oocytes. We have recently shown that $\mathrm{Ca}^{2+}$ buffers with 'slow' binding kinetics (EGTA and Parvalbumin) speed $\mathrm{Ca}^{2+}$ signals, in complete contrast to 'fast' buffers (BAPTA and Calretinin), which essentially slow $\mathrm{IP}_{3}$-evoked $\mathrm{Ca}^{2+}$ responses, promoting 'globalization' of spatially uniform $\mathrm{Ca}^{2+}$ signals. These effects likely arise via changes in $\mathrm{Ca}^{2+}$ feedback at $\mathrm{IP}_{3}$ receptors since $\mathrm{Ca}^{2+}$ signals evoked by influx through voltage gated channels are little affected. Here we present data showing that EGTA, parvalbumin and calretinin, but not BAPTA, can promote the appearance of $\mathrm{Ca}^{2+}$ puffs, evoked by low $\left[\mathrm{IP}_{3}\right]$. $\mathrm{IP}_{3}$-evoked $\mathrm{Ca}^{2+}$ puffs were more restricted in space and time in the presence of the 'slow' $\mathrm{CaBP}$ (parvalbumin), compared with those evoked by similar $\left[\mathrm{IP}_{3}\right]$ in the presence of a 'fast' $\mathrm{CaBP}$ (calretinin). Here we present a detailed spatial and temporal analysis, comparing the spatial and temporal properties of $\mathrm{Ca}^{2+}$ puffs in the presence of two endogenous CaBPs, parvalbumin and calretinin. The ability of CaBPs to shape both global and local intracellular $\mathrm{Ca}^{2+}$ signals likely has significant physiological implications.

Supported by NIH GM 48071 and 78598.

\section{9.- MODIFICATION OF CALCIUM DEPENDENCE OF RAT BRAIN RYANODINE RECEPTOR CHANNELS BY ATP AND SH OXIDATION}

\section{FINKELSTEIN J., HIDALGO C. AND R. BULL.}

Centro FONDAP de Estudios Moleculares de la Célula (CEMC) and ICBM, Facultad de Medicina, Universidad de Chile, Santiago, Chile.

Ryanodine receptor (RyR) channels are tetramers that allow the release of calcium from sarco/endoplasmic reticulum to the cytoplasm. Single RyR channels from rat brain cortex incorporated into bilayers display three different responses to cytoplasmic free calcium concentration depending on their redox state: low, moderate, and high Po. The response to calcium is biphasic: micromolar concentrations activate the channel and millimolar concentrations inhibit the channel except for high Po channels (Marengo et al, Biophys J 74: 1263,1998). We studied the calcium dependence of RyR channels with different redox state in presence or absence of ATP. ATP modified the calcium response, increasing apparent affinity for calcium activation and decreasing affinity for calcium inhibition. $3 \mathrm{mM}$ ATP decreased Ka of low Po channels from 50 to $10 \mu \mathrm{M}$ and increased $\mathrm{Ki}$ from 3 to $70 \mu \mathrm{M}$. Ka of moderate Po channels was reduced by 3 $\mathrm{mM}$ ATP from 11 to $1.5 \mu \mathrm{M}$ and whereas $\mathrm{Ki}$ was increased $(80 \mu \mathrm{M}$ to $>1 \mathrm{mM})$. ATP decreased $\mathrm{Ka}$ of high Po channels from 1 to $0.1 \mu \mathrm{M}$. These results indicate that both the concentration of ATP and the redox state of SH groups determine the response of RyR channels to cytoplasmic calcium concentration. This modulation can underlie changes in the sensitivity of the calcium induced calcium release process that participates in neuronal plasticity. Supported by FONDAP grant 15010006

\section{0.- SLOW CALCIUM SIGNALS AFTER TETANIC ELECTRICAL STIMULATION IN SKELETAL MYOTUBES}

\section{ELTIT J. M., LIBERONA J. L., JAIMOVICH E. AND J. HIDALGO.}

Centro FONDAP de Estudios Moleculares de la Célula (CEMC) and ICBM, Facultad de Medicina, Universidad de Chile, Santiago, Chile.

Myotubes kept in primary culture were exposed to tetanic electrical stimulation and the fluorescence calcium signal was monitored. During stimulation, the expected calcium signal sensitive to ryanodine and associated to the E-C coupling was seen. A few seconds after the stimulus ended, a long lasting second calcium signal, refractory to ryanodine was evident. The onset kinetics of this slow signal was slightly modified in nominally calcium-free medium, as was by both the frequency and number of pulses during tetanus. The role of the action potential was evidenced since, in the presence of TTX, the signal was abolished. The role of the dihydropyridine receptor (DHPR) as a voltage sensor for this signal was assessed by treatment with agonist and antagonist dihydropyridines (Bay K 8644 and nifedipine) showing an enhanced and inhibitory response respectively. When the dysgenic GLT cell line, which lacks the $\mathrm{a} 1_{\mathrm{S}}$ subunit of the DHPR, was used, the signal was absent. Transfection of these cells with the $\mathrm{a} 1_{\mathrm{S}}$ subunit, restored the slow signal. The $\mathrm{IP}_{3}$ mass increase induced by electrical pulses was previous in time to the slow calcium signal. Both $\mathrm{IP}_{3} \mathrm{R}$ blocker and PLC inhibitor (xestospongin $\mathrm{C}$ and U73122) dramatically inhibited the slow calcium response. Long lasting, slow 
calcium signals appear to be a physiological response to action potential-induced tetanic stimulation in muscle cells. Financed by FONDAP 15010006, CONICYT PREDOCTORAL FELLOWSHIP (JME).

11.- THE ROLE OF CALSEQUESTRIN, TRIADIN, AND JUNCTIN IN CONFERRING CARDIAC RYANODINE RECEPTOR RESPONSIVENESS TO LUMINAL CALCIUM

\section{GYORKE I., HESTER N., JONES L.R.* AND S. GYORKE.}

Department of Physiology, Texas Tech University Health Sciences Center, Lubbock, Texas 79430-6551 *Department of Medicine, Krannert Institute of Cardiology, Indianapolis, Indiana.

Calcium [Ca] inside the SR is an important regulator of the RyR Ca release channel activity. However, little is known about the molecular basis of RyR modulation by luminal $\mathrm{Ca}$. In this study, we investigated the potential role of the auxiliary cardiac proteins calsequestrin (CSQ), triadin 1 , and junctin as luminal calcium sensors for the cardiac RyR. We performed recordings of single RyRs incorporated into lipid bilayers in the presence of $\mathrm{MgATP}$ using $\mathrm{Cs}^{+}$as the charge carrier. Raising luminal [Ca] from $20 \mathrm{mM}$ to $5 \mathrm{mM}$ increased the open channel probability $\left(\mathrm{P}_{\mathrm{o}}\right)$ in native, but not in purified RyRs. Adding CSQ to the luminal side of the purified channels produced no significant changes in the $\mathrm{P}_{\mathrm{o}}$, nor did it restore the ability of RyRs to respond to luminal $\mathrm{Ca}$. When triadin 1 and junctin were added to the luminal side of purified channels, RyR $\mathrm{P}_{\mathrm{o}}$ increased significantly; however, the channels still remained unresponsive to changes in luminal [Ca]. In RyRs re-associated with triadin 1 and junctin, adding luminal CSQ produced a significant decrease in activity. Following re-association with all three proteins, RyRs responded to rises of luminal Ca by increasing their $\mathrm{P}_{\mathrm{o}}$. These results suggest that a complex of CSQ, triadin 1 , and junctin confer RyR luminal Ca sensitivity. CSQ apparently serves as a luminal $\mathrm{Ca}$ sensor that inhibits the channel at low luminal [Ca], while triadin 1 and/or junctin may be required to mediate interactions of CSQ with RyR.

\section{2.- $\mathrm{Ca}^{2+}$ STORE REFILLING DETERMINES SLOW INHIBITION OF STORE OPERATED CALCIUM ENTRY IN MAMMALIAN SKELETAL MUSCLE}

CASTillo A., FigUeroA L. AND A. GONZÁlez.

Instituto Venezolano de Investigaciones Científicas (IVIC). Caracas. VENEZUELA.

This work describes for the first time the activation and inhibition kinetic of the store operated calcium entry (SOCE) and the role of the sarcoplasmic reticulum (SR) calcium pump in adult mammalian skeletal muscle. Flexor digitorum brevis fibers (FDB) were isolated from adult mice and exposed to conditions that deplete the SR. A temporal SR depletion caused by repetitive depolarizations, chlorocresol (CMC) and, cyclopiazonic acid (CPA) induced a bell shape calcium entry that raised the $\left[\mathrm{Ca}^{2+}\right] \mathrm{i} 27.09 \pm 4.35 \mathrm{nM}$ from the resting value $112 \pm 10 \mathrm{~s}(\mathrm{n}=22)$. In the other hand, any mechanism that kept the SR depleted (like thapsigargin, continuous CPA, or CMC) triggered a calcium entry pathway that lasted $325 \pm 23 \mathrm{~s}$ and the $\left[\mathrm{Ca}^{2+}\right]_{\mathrm{i}}$ raised to $129.50 \pm 13.05 \mathrm{nM}$ from the resting level $(n=28)$. Then, a prolonged depletion triggered an increase in $\left[\mathrm{Ca}^{2+}\right]_{\mathrm{i}}$ to higher values and for longer time than when the SR is transiently depleted $(\mathrm{p}<0.001)$. Our results, in skeletal muscle, showed that calcium store depletion was the paradigm for SOCE activation and how the SR was depleted was not relevant. Also, we found that SOCE slow inhibition was not caused by $\left[\mathrm{Ca}^{2+}\right]_{\mathrm{i}}$ but by the SR content. Our novel results suggest that the SR calcium pump, SERCA, plays an important role in SOCE slow inhibition.

Financed by IVIC.

\section{3.- IGF-I AND INSULIN INDUCE DIFFERENT INTRACELLULAR CALCIUM SIGNALS IN SKELETAL MUSCLE CELLS}

ESPINOSA A., ESTRADA M. AND E. JAIMOVICH.

Centro FONDAP de Estudios Moleculares de la Célula (CEMC) and ICBM, Facultad de Medicina, Universidad de Chile, Santiago, Chile.

IGF-1 and insulin are related hormones, which produce different effects in the skeletal muscle. We studied the effect of these hormones on intracellular $\mathrm{Ca}^{2+}$ in primary cultured myotubes. The fluorescent dye Fluo-3 AM was used for temporal and spatial characterization of $\mathrm{Ca}^{2+}$ signals. IGF-1 induced a fast and transient $\mathrm{Ca}^{2+}$ increase, reaching a fluorescence peak $6 \mathrm{~s}$ after stimulus, to return to basal values after $60 \mathrm{~s}$. The response was dependent on IGF-1 receptor because both genistein and AG538 blocked the $\mathrm{Ca}^{2+}$ increase. IGF-1 induced an $\mathrm{IP}_{3}$ increase that reached a maximum value $15 \mathrm{~s}$ after stimuli, returning to basal value after $50 \mathrm{~s}$. The $\mathrm{Ca}^{2+}$ signal was blocked by inhibitors of the $\mathrm{IP}_{3}$ pathway. On the other hand, insulin produced a fast $(<1$ sec) and transient $\mathrm{Ca}^{2+}$ increase lasting less than $10 \mathrm{~s}$. Insulin-induced $\mathrm{Ca}^{2+}$ increase was blocked in $\mathrm{Ca}^{2+}$ free medium and by either nifedipine or ryanodine. To confirm the results obtained with pharmacological inhibitors on IGF1 and insulin-induced $\mathrm{Ca} 2+$ signals we used several muscle cell lines. In the normal NLT cell line, the calcium signals induced by both hormones resemble those of primary myotubes. GLT cells, lacking a1 subunit of DHPR, respond to IGF-1 with a $\mathrm{Ca}^{2+}$ increase but not to insulin, while GLTa1 (GLT cells transfected with a1 subunit of DHPR) do respond to both hormones. Moreover, in dyspedic muscle cells, lacking ryanodine receptors, the response to IGF-1 is similar to that of NLT cells however they show no insulininduced calcium increase. Moreover, G protein inhibitors, PTX and GDPbS, only slightly modified the response to IGF-1, but the insulin-induced $\mathrm{Ca}^{2+}$ increase was blocked. Both the kinetics of the IGF-1 induced signals and the differences between cell lines suggest cross reactivity of IGF-1 and insulin with both receptors. A model to explain the different mechanisms for calcium release produced by IGF-1 and insulin is postulated. The different intracellular $\mathrm{Ca}^{2+}$ patterns produced by IGF-1 and insulin, may help to understand the early action mechanisms for these hormones in skeletal muscle cells.

Financed by FONDAP 15010006

\section{4.- $\mathrm{Ca}^{2+}, \mathrm{Mg}^{2+}$ AND REDOX MODULATION OF RYR CALCIUM RELEASE CHANNELS FROM RAT BRAIN CORTEX}

\section{HUMERES A. AND C. HIDALGO.}

Centro FONDAP de Estudios Moleculares de la Célula (CEMC) and ICBM, Facultad de Medicina, Universidad de Chile, Santiago, Chile.

Several reports indicate that synaptic plasticity in neurons involves CICR mediated by ryanodine receptor (RyR) channels or IP3 receptor channels. In this work, we studied the effects of $\mathrm{Ca}^{2+}, \mathrm{Mg}^{2+}$ and redox agents on the activity of 
RyR channels present in endoplasmic reticulum vesicles isolated from rat cortex brain. By Western blot assays with specific antibodies we identified the RyR2 isoform (cardiac isoform) as the major RyR component; a faint band corresponding RyR3 was also detected. The effects of $\mathrm{Ca}^{2+}$ and $\mathrm{Mg} 2+$ on $\left[{ }^{3} \mathrm{H}\right]$-Ryanodine binding were studied. The calcium dependence was bell shaped, with stimulation from 0.1 to $10 \mathrm{mM}\left[\mathrm{Ca}^{2+}\right]$, maximal binding from 10 to $100 \mathrm{mM}$ and inhibition from $100 \mathrm{mM}$ to $10 \mathrm{mM}\left[\mathrm{Ca}^{2+}\right]$. In the presence of $10 \mathrm{mM}\left[\mathrm{Ca}^{2+}\right]$, increasing free $\left[\mathrm{Mg}^{2+}\right]$ from 0 to $1 \mathrm{mM}$ produced a significant inhibition of $\left[{ }^{3} \mathrm{H}\right]$-Ryanodine binding. Pre-treatment with the reducing agent DTT enhanced the inhibitory effect of $\mathrm{Mg}^{2+}$ on $\left[{ }^{3} \mathrm{H}\right.$ ]-Ryanodine binding while pre-treatment with the $\mathrm{SH}$ alkylating agent thimerosal decreased this inhibition when compared to native vesicles. These results indicate that $\mathrm{Ca}^{2+}$ activates and $\mathrm{Mg} 2+$ inhibits in vitro the activity of RyR calcium release channels in neurons and that the inhibitory effect of $\mathrm{Mg}^{2+}$ is controlled by $\mathrm{RyR}$ channel redox state. If $\mathrm{RyR}$ channels behaved in vivo as in vitro, these results implicate that changes in cellular redox state may affect RyRmediated CICR in neurons in vivo.

Supported by FONDECYT 8980009 and by FONDAP 15010006.

\section{5.- EFFECT OF ETHANOL ON CALCIUM SIGNALLING IN MOUSE PANCREATIC ACINAR CELLS}

CRIDDLE D.N.*, RARATY M.G.T.\$, NEOPTOLEMOS J.P.§, TEPIKIN A.*, PETERSEN OH* AND R. SUTTONミ.

Medical Research Council Secretory Control Research Group, *Physiological Laboratory and §Department of Surgery, University of Liverpool, UK

Excessive alcohol consumption is a principal cause of the common human disease acute pancreatitis, but the mechanism of damage is unknown. We have previously shown a critical role for prolonged, abnormal calcium elevations of cytosolic calcium $\left(\left[\mathrm{Ca}^{2+}\right]_{\mathrm{i}}\right)$ in acute pancreatitis (Raraty et al., 2000) and have now investigated the effect of ethanol on $\left[\mathrm{Ca}^{2+}\right]_{\mathrm{i}}$ in mouse isolated pancreatic cells using microfluorimetry with fura 2-AM.

Ethanol at $10 \mathrm{mM}$ was without effect $(n=15)$, but at 50 $850 \mathrm{mM}$ induced increasing changes in $\left[\mathrm{Ca}^{2+}\right]_{\mathrm{i}}$. In most cells a small, sustained increase in $\left[\mathrm{Ca}^{2+}\right]_{\mathrm{i}}$ of $\sim 100 \mathrm{nM}$ was produced that was immediately reversible upon washout. In a minority of cells a rapid, transient rise of $\left[\mathrm{Ca}^{2+}\right]_{\mathrm{i}}$ $(532.8 \pm 29.6 \mathrm{nM}$ with $850 \mathrm{mM} ; n=45)$ occurred before the sustained rise, the probability of which rose with increasing ethanol concentrations ( 2 of 15 cells $(13 \%)$ at $50 \mathrm{mM} ; 15$ of 72 cells $(20 \%)$ at $500 \mathrm{mM} ; 84$ of 261 cells $(32 \%)$ at $850 \mathrm{mM})$. At $850 \mathrm{mM}$ ethanol, the sustained rise in $\left[\mathrm{Ca}^{2+}\right]_{\mathrm{i}}$ was reversed in 14 of 53 cells $(26.4 \%)$ when extracellular calcium was removed. Depletion of intracellular stores with thapsigargin (TPG; $2 \mu \mathrm{M})$ under calcium-free conditions abolished ethanol-induced elevations of $\left[\mathrm{Ca}^{2+}\right]_{\mathrm{i}}(n=11)$. Ethanol, however, produced a slow depletion of TPGsensitive stores, such that after $20 \mathrm{mins}$ application of $850 \mathrm{mM}$ ethanol the rise in $\left[\mathrm{Ca}^{2+}\right]_{\mathrm{i}}$ elicited by $2 \mu \mathrm{M}$ TPG was $145.4 \pm 35.0 \mathrm{nM}(n=12)$, compared to $498.4 \pm 46.6 \mathrm{nM}$ in controls without ethanol $(n=16)$.

Our data show that high concentrations of ethanol elicit only modest increases of acinar $\left[\mathrm{Ca}^{2+}\right]_{\mathrm{i}}$, an effect that would seem unlikely to account for alcohol-induced acute pancreatitis.

\section{6.- ALLOSTERIC CHANGES IN THE INSP ${ }_{3}$ R RECEPTOR AND ATP MODULATION}

FRAIMAN D. AND S. PONCE DAWSON.

Departamento de Física, Facultad de Ciencias Exactas y Naturales, Universidad de Buenos Aires, Buenos Aires, Argentina

The $\mathrm{InsP}_{3}$ receptor $\left(\mathrm{InsP}_{3} \mathrm{R}\right)$ is a ligand-gated calcium channel that is modulated by $\operatorname{InsP}_{3}, \mathrm{Ca}^{2+}$ and ATP. In this work, based on two well known observations (AdA vs. Ins $\mathrm{P}_{3}$ and mean open times dependence on $\left.\left[\mathrm{Ca}^{2+}\right]_{c}\right)$, we show that the $\operatorname{Ins}_{3} \mathrm{R}$ must be modeled by an allosteric mechanism and propose a mechanism for ATP modulation. In any protein there exists a separation between ligand binding to a stereospecific binding site, and a structural transition (conformational change). For ligand channels it is clear that both processes exist; the fact that the receptor binds a particular ligand does not imply that the receptor will change its conformation immediately. Rather, the ligand promotes the conformational change, but this takes some time to occur, when it happens. If the change in conformation occurs fast enough, we may be tempted to assume that the channel switches conformation upon ligand binding. This is implicit in the DeYoung-Keizer model and in most theoretical models of the $\operatorname{Ins}_{3} \mathrm{R}$. The implications of this "fast jumping" assumption are very dangerous, because we will not have a good representation of the single channel function mechanism, and will not be able to understand macroscopic events as puffs or waves. 


\section{SESSION 2}

\section{1.- RyR EXPRESSION LEVELS AND CAFFEINE SENSITIVITY IN $1 B 5$ MYOTUBES}

\section{PÉREZ C. F., LÓPEZ J. R. AND P. D. ALLEN.}

Department of Anesthesiology, Brigham and Women's Hospital, Harvard Medical School, Boston, MA

Dyspedic myotubes transduced with RyR1 and RyR3 virions display very different sensitivity to caffeine in vitro. Since viral infection systems can provide high infection efficiency and at high MOI cells could be infected with multiple particles, it is possible that this might result in overexpression of the cDNAs delivered. Whether variations in the level of expression of RyRs can account for the differential pharmacological properties observed between RyR1 and RyR3 is unknown. In this work we approach this question by infecting dyspedic 1B5 myotubes with an increasing number of virion particles $(\mathrm{MOI}=0.2$, $0.4,1.0$ and 2.0) carrying either RyR1 or RyR3 and analyzed their caffeine sensitivity, immunostaining pattern, protein expression by western blot, $\left[{ }^{3} \mathrm{H}\right]$-ryanodine binding analysis and resting free $\mathrm{Ca}^{2+}$ concentration. Our results showed that increasing MOI resulted in increased number of myotubes expressing receptors and augmented levels of receptor/mg of protein. Caffeine dose responses (0.1-40 $\mathrm{mM}$ ), assayed in Fluo-4 loaded cells, showed that myotubes expressing higher level of RyR3, but not RyR1, displayed a small but significantly increased caffeine sensitivity. Interestingly, at $\mathrm{MOI}=2.0$ myotubes expressing RyR3, but not RyR1, showed augmented level of resting free $\mathrm{Ca}^{2+}$ compared to cells expressing RyR3 transduced at a lower MOI. Although, we saw no changes in FKBP-12, triadin or calsequestrin expression, down regulation of SERCA-1 pump was detected as RyRs expression increased in cells expressing both RyR1 or RyR3. These results demonstrate that, although the level of expression of RyRs when cells are infected at high MOI can induce slight shift to the left of RyR3's caffeine $E_{50}$ this is not seen in RyR1 expressing cells. Thus over expression cannot explain the differences in caffeine sensitivity observed between RyR1 and RyR3. Instead, our data also suggest that in addition to a differential isoform specific caffeine sensitivity between RyR1 and RyR3 that an increased myoplasmic resting free $\mathrm{Ca}^{2+}$ seems to account for the shift in RyR3's caffeine $\mathrm{EC}_{50}$ at high MOI.

\section{2.- CD38/CYCLIC ADP-RIBOSE SIGNALING IN INTRACELLULAR CALCIUM REGULATION IN AIRWAY SMOOTH MUSCLE}

\section{DESHPANDE D.A., MILLA C., WALSETH T.F., LUND F.E. AND M.S. KANNAN.}

University of Minnesota, MN and Trudeau Institute, NY, USA.

Cyclic ADP-ribose (cADPR) contributes to agonist induced elevation of intracellular calcium $\left(\left[\mathrm{Ca}^{2+}\right]_{\mathrm{i}}\right)$ in airway smooth muscle (ASM) cells. CD38, a bifunctional membrane bound protein constitutively expressed on ASM cells, is responsible for the synthesis and degradation of cADPR. Chronic inflammatory diseases such as asthma are characterized by airway hyperresponsiveness (AHR) and the T helper 2 cytokine IL-13 has a central role in this process. Cytokines induce functional changes in ASM characterized by altered responses to contractile and relaxant agents. We determined the contribution of CD38/ cADPR-mediated calcium signaling in ASM cells to the IL- 13-induced AHR. ASM contraction and responsiveness regulate airway tone. The contribution of cADPR-mediated calcium release in AHR and physiological regulation of respiration is not known. We determined the role of the major ADP-ribosyl cyclase, CD38, in airway responsiveness using $\mathrm{CD} 38$ deficient $(\mathrm{CD} 38 \mathrm{KO})$ mice.

Exposure of ASM cells to IL-13 caused increased CD38 expression and augmented $\left[\mathrm{Ca}^{2+}\right]_{\mathrm{i}}$ responses to agonists, which were inhibited by a cADPR antagonist. Cytokinemediated augmented $\left[\mathrm{Ca}^{2+}\right]_{i}$ responses were attenuated in ASM cells stably transfected with anti-sense CD38. In CD38 KO mice, methacholine-induced changes in lung resistance and dynamic compliance were lower compared to wild type controls. The $\left[\mathrm{Ca}^{2+}\right]_{\mathrm{i}}$ responses to acetylcholine and endothelin-1 were lower in ASM cells isolated from CD38 KO mice compared to controls. The cADPR antagonist attenuated intracellular calcium responses only in control cells. Lungs obtained from CD38 KO mice had no ADP-ribosyl cyclase activity, indicating CD38 as the primary source for cADPR synthesis. CD38/ cADPR signaling contributes to airway responsiveness and airway tone through its effects on agonist-induced intracellular calcium responses in ASM cells under physiological and pathophysiological conditions.

\section{3.- INHIBITION OF INOSITOL 1,4,5-TRISPHOSPHATE (INSP ${ }_{3}$ )-INDUCED CALCIUM RELEASE (IICR) BY NEURONAL CALCIUM BINDING PROTEINS (CABP)}

\section{HOLMES A. M.*, BOOTMAN M. D.*, KASRI N. N.§, DESMEDT H.§, RODERICK H. L.*}

*Laboratory of Molecular Signalling, Babraham Institute, Cambridge. §Laboratorium voor Fysiologie, K. U. Leuven, Leuven, Belgium.

It was recently demonstrated that $\mathrm{CaBP} 1$ functionally interacted with $\mathrm{InsP}_{3} \mathrm{Rs}$ in a calcium dependent manner providing a novel mechanism for their activation [1]. CaBPs have approximately $50 \%$ homology with the prototypical $\mathrm{EF}-$ hand $\mathrm{Ca}^{2+}$-binding protein calmodulin $(\mathrm{CaM})$. Using a combination of techniques, we have investigated the role of $\mathrm{CaBPs}$ in regulating $\mathrm{InsP}_{3} \mathrm{Rs}$ in mammalian cell lines.

$\mathrm{CaBPs}$ interact with the calcium-independent binding region of calmodulin within the $\mathrm{N}$-terminus of the Ins $\mathrm{P}_{3} \mathrm{R}$, and we demonstrate that this interaction occurred independently of calcium. Video imaging of COS7 cells overexpressing YFP-tagged CaBPs revealed that $\mathrm{CaBP}$ could inhibit calcium release from internal stores in response to purinergic agonist (ATP; 0.5 to 100 $\mu \mathrm{M})$. This inhibition of IICR was calcium independent since expression of a CaBP mutant in which the three EF hand calcium binding regions were non-functional had the same effect as the wild type protein. Mutation of the consensus site for myristoylation in CaBP (G2A) revealed that $\mathrm{CaBP}$ function was also not dependent on its myristoylation and hence membrane targeting. Phosphorylation of $\mathrm{CaBP}$ at S120, part of the consensus site for phosphorylation by CK2, decreases its potency in inhibiting calcium release. To investigate the mechanism by which $\mathrm{CaBP}$ mediates its effect we performed an Ins $_{3}$ binding assay using both the purified recombinant Ins $\mathrm{P}_{3} \mathrm{R}$ ligand binding domain as well as the full-length receptor. In these studies we demonstrated that $\mathrm{CaBP}$ inhibited $\mathrm{InsP}_{3}$ binding to the $\operatorname{InsP}_{3} \mathrm{R}$ in a calcium independent manner.

In conclusion, $\mathrm{CaBPs}$ do not act as endogenous ligands for InsP $\mathrm{P}_{3} \mathrm{Rs}$ but may participate in regulating $\mathrm{InsP}_{3}$ induced calcium release. 
1. Yang, J., McBride, S., Mak, D.O., Vardi, N., Palczewski, K., Haeseleer, F. and Foskett, J.K. (2002) Proc Natl Acad Sci U S A, 99, 7711-7716

\section{4.- MODULATION OF RYANODINE RECEPTORS (RYRS) CHANNELS BY DIHYDROPYRIDINE RECEPTOR (DHPR) PEPTIDE A (PepA)}

\section{PORTA M., NANI A., RAMOS-FRANCO J., FILL M.} IKEMOTO N.* AND J.A. COPELLO.

Dept. Physiology, Loyola University Chicago, Maywood, IL USA and *Boston Biomedical Research Institute, Watertown, MA USA

PepA (671Thr-690Leu) from the skeletal DHPR II-III loop interacts with the RyR channel. The functional consequences of that interaction are controversial. Here, we tested PepA action on skeletal RyR1 and cardiac RyR2 channel gating in bilayers. PepA (0.1-1 $\mu \mathrm{M})$ had little affect on quiescent channels in solutions that mimic the resting cell $\left(0 \mathrm{mV}, 100 \mathrm{nM} \mathrm{Ca}{ }^{2+}, 1 \mathrm{mM} \mathrm{Mg}^{2+} \& 1 \mathrm{mM}\right.$ ATP). However, PepA (1-50 $\mu \mathrm{M})$ was a very effective voltage dependent (Vm-dep) blocker of both RyR1 and RyR2 when previously activated by $\mathrm{Ca}^{2+}$, caffeine and/or ATP. Thus, PepA interacts with a site that is common to both RyR isoforms and within the SR membrane potential field. A key feature of PepA blockade was Vm-dep fast flickering (opening/closings) of the channel. Ryanodol (Ry) and Imperatoxin (Ip) are two very different RyRprobes (alkaloid \& peptide, respectively). Ry and Ip both induce intermittent long-lived sojourns to a subconductance state. PepA "flicker" blocked the Ry-induced subconductance state more effectively than full open events. In contrast, PepA did not "flicker" block the Ipinduced subconductance state but decreased the probability of observing it. Thus, these studies show that, 1) the Ry and Ip subconductance states are not equivalent and, 2) PepA and Ip compete at a common site that modulates gating and permeation. More importantly, these studies show that PepA is a useful probe for RyR function despite ongoing debate about the physiological significance of the PepA-RyR interaction.

Supported by NIH HL57832, HL64210 \& AHA 0130142N.

\section{5.- DOES $\mathrm{Ca}^{2+}$ PARTICIPATE IN NFkB ACTIVATION INDUCED BY HYPEROSMOTIC STRESS?}

\section{EISNER V., QUIROGA C., CRIOLLO A., IBARRA C., CEA P., CHIONG M., DÍAZ-ARAYA G. AND S. LAVANDERO.}

FONDAP Center for Molecular Studies of the Cell, Faculty of Chemical and Pharmacological Sciences, University of Chile.

We have previously demonstrated that hyperosmotic stress stimulates NFkB activation and cardiac myocyte apoptosis. $\mathrm{Ca}^{2+}$ is an important second messenger in cardiac cell death but its relationship with NFkB has not been investigated. Our results show that hyperosmotic stress stimulated intracellular $\mathrm{Ca}^{2+}$ transients assessed by fluo-3AM and epifluorescence microscopy. Hyperosmotic stress induces $\operatorname{IkB} \alpha$ degradation which was associated with nuclear translocation of NFkB isoforms (p65 and Rel B) and activation of NFkB-LUX transcription. DNA fragmentation (determined by agarose gel electrophoresis) and cardiomyocyte cell death (evaluated by cell viability) increased by hyperosmotic stress, effect that was enhanced by SN50 (a blocking peptide for NFkB activation) and Ad-
$\mathrm{IkB} \alpha$ (an adenovirus expressing a mutated $\mathrm{IkB} \alpha$ ) and $\mathrm{KN}$ 62 (calmodulin kinase inhibitor). This last inhibitor, but not cyclosporin A (calcineurin inhibitor) blocked $\operatorname{IkB} \alpha$ degradation induced by hyperosmotic stress.

We concluded that $\mathrm{Ca}^{2+}$ and calmodulin kinase participates in the NFkB signaling pathway activated by hyperosmotic stress through $\mathrm{IkB} \alpha$ degradation.

FONDECYT 1010246, FONDAP 15010006, Chilean Society of Cardiology Grant. VE and CI are CONICYT fellows.

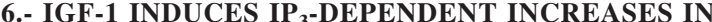 BOTH NUCLEAR AND CYTOSOLIC CALCIUM IN RAT CARDIAC MYOCYTES}

\section{IBARRA C., ESTRADA M., CARRASCO L., CHIONG} M., JAIMOVICH E. AND S. LAVANDERO.

Centro FONDAP de Estudios Moleculares de la Célula, ICBM, Facultad de Medicina y Facultad Ciencias Químicas y Farmacéuticas, Universidad de Chile.

In the heart, insulin-like growth factor-1 (IGF-1) is a prohypertrophic and anti-apoptotic peptide. However, the role of intracellular $\mathrm{Ca}^{2+}$ in the IGF-1 signaling pathways in cardiac myocytes remains unknown.

In cultured rat cardiomyocytes, IGF-1 induced a fast and transient increase in $\mathrm{Ca}^{2+} \mathrm{i}$ levels apparent in both nucleus and cytosol. Calcium was released from intracellular stores by an inositol-1,4,5-trisphosphate ( $\left.\mathrm{IP}_{3}\right)$-dependent signaling pathway. Intracellular $\mathrm{IP}_{3}$ levels increased after stimulation by IGF-1; neither ryanodine nor nifedipine prevented the IGF-1-induced $\mathrm{Ca}^{2+} \mathrm{i}$ increase, but ryanodine inhibited the basal, spontaneous $\mathrm{Ca}^{2+} \mathrm{i}$ oscillations observed in $\mathrm{Ca}^{2+}$-containing resting media.

Spatial analysis of fluorescence images showed an early increase in nuclear $\mathrm{Ca} 2+$, suggesting that $\mathrm{Ca}^{2+}$ released by IGF-1 was initially contained in the perinuclear region. The IGF-1-induced increase of $\mathrm{Ca}^{2+} \mathrm{i}$ levels was prevented by preincubation of cells with BAPTA-AM, thapsigargin, xestospongin $\mathrm{C}, \mathrm{U}-73122$, pertussis toxin and $\beta$ ARKct (a peptide inhibitor of $G \beta \gamma$ signalling). Pertussis toxin also prevented the IGF-1-dependent $\mathrm{IP}_{3}$ mass increase. Genistein only decreased but did not prevent the IGF1-induced changes in either $\mathrm{Ca}^{2+} \mathrm{i}$ or $\mathrm{IP}_{3}$. LY29402 (but not PD98059) prevented the IGF-1-dependent Ca2+i increase. Both pertussis toxin and U73122 prevented the IGF1-dependent activation of ERKs but not that of PKB.

We conclude that IGF-1 increases $\mathrm{Ca}^{2+} \mathrm{i}$ levels in cardiac myocytes through a pertussis toxin-sensitive $G$ protein PI3K - phospholipase C signaling pathway with participation of $\mathrm{IP}_{3}$ and perinuclear calcium stores.

Supported by FONDAP 15010006 and FONDECYT 1010246

\section{7.- MODULATION OF CAFFEINE ACTION ON SINGLE RYANODINE RECEPTOR (RYR2) CHANNELS BY ENDOGENOUS AGENTS}

PORTA M.*, DÍAZ-SYLVESTER P.L.*, NANI A.*, PÉREZ C.*, MEJÍA ÁLVAREZ R.*, ESCOBAR A.†, FLEISCHER S.\#, FILL M. AND J. A. COPELLO*

* Department of Physiology. Loyola University Chicago, Maywood, IL. †Department of Physiology. Texas Tech University, Lubbock, TX. \# Department of Biological Sciences, Vanderbilt University, Nashville, TN.

Caffeine is a pharmacological agonist of the cardiac ryanodine receptor (RyR2). Here, caffeine action on single RyR2 channels reconstituted in planar bilayers was defined 
in the presence of different endogenous RyR2-modulators. In simple solutions (only RyR2-modulator present was $\mathrm{Ca}^{2+}$ ), caffeine reversibly activated most RyR2 channels by altering its cytosolic $\mathrm{Ca}^{2+}$ sensitivity. Caffeine increased the affinity of its $\mathrm{Ca}^{2+}$ activation site and rendered the channels highly active at resting cellular $\mathrm{Ca}^{2+}(100 \mathrm{nM})$. Calcium-activated RyR2 displayed clear modal gating (periods of "low and high Po") while caffeine-activated channels were locked in a high Po configuration. Caffeine also decreased the affinity for $\mathrm{Ca}^{2+}$ of low-affinity $(\mathrm{mM})$ inhibitory sites. Caffeine was more effective on channels exposed to high lumenal $\mathrm{Ca}^{2+}$ levels. In complex solutions (containing near resting cytosolic levels of $\mathrm{Ca}^{2+} \mathrm{Mg}^{2+}$ \& ATP) most RyR2 channels were closed and did not activate upon caffeine addition. Caffeine efficacy increased only after elevation of cytosolic free $\mathrm{Ca}^{2+}$ levels $(300-500 \mathrm{nM})$. It appears that $\mathrm{Mg}^{2+}$ interacting with the cytosolic $\mathrm{Ca}^{2+}$ activation site reduces caffeine efficacy. Caffeine efficacy was also attenuated by ruthenium red and tetracaine but not by calmodulin or FKBP12.6. Thus, caffeine-induced $\mathrm{Ca}^{2+}$ release in cells may be initiated by a few eager channels ("starters"), which elevate local $\mathrm{Ca}^{2+}$ levels resulting in even more robust caffeine-activation of the RyR 2 channels. This work was supported by NIH HL57832 \& HL64210 to M.F. as well as AHA Grant 0130142 N to J.A.C.

\section{8.- ROLE OF STORE OPERATED CHANNELS IN TESTOSTERONE-INDUCED INTRACELLULAR CALCIUM OSCILLATIONS IN MYOTUBES}

\section{ESTRADA M. AND E. JAIMOVICH.}

Centro FONDAP de Estudios Moleculares de la Célula, ICBM, Facultad de Medicina, Universidad de Chile.

We studied the role of store operated calcium channel (SOC) on intracellular calcium oscillations induced by testosterone in primary myotubes, determined at single cell level by epifluorescence microscopy. Testosterone (100 $\mathrm{nM}$ ) induced a $\mathrm{Ca}^{2+}$ transient (lasting $60-120 \mathrm{~s}$ ), accompanied by oscillations in more than $80 \%$ of the myotubes. The frequency of these oscillations varied between individual cells. In $\mathrm{Ca}^{2+}$-free medium the $\mathrm{Ca}^{2+}$ increase was present, but oscillations were lost. Neither nifedipine nor ryanodine modified the oscillations, but the testosterone-induced $\mathrm{Ca}^{2+}$ increase was blocked by inhibitors of the $\mathrm{IP}_{3}$ pathway: U73122 and xestospongin $\mathrm{B}$. In $\mathrm{Ca}^{2+}$-free medium the intracellular $\mathrm{Ca}^{2+}$ store depletion was induced using thapsigargin; $\mathrm{Ca}^{2+}$ re-addition produced a fast intracellular $\mathrm{Ca}^{2+}$ increase, showing that capacitative $\mathrm{Ca}^{2+}$ entry $(\mathrm{CCE})$ is present in myotubes. Both testosterone and testosterone bound to albumin (T-BSA) produce CCE after $\mathrm{Ca}^{2+}$ re-addition protocol. Moreover, testosterone induced a 2-2.5-fold increase in $\mathrm{Mn}^{2+}$ entry measured as quenching of fluo-3 fluorescence. CCE was inhibited by 2APB and $\mathrm{La}^{3+}$, while nifedipine and verapamil had no effect. Moreover, $\mathrm{La}^{3+}$ inhibited $\mathrm{Ca}^{2+}$ oscillations, but not the sustained $\mathrm{Ca}^{2+}$ increase induced by testosterone. These results suggest that the testosterone-induced calcium signal can be divided into two components; the calcium transient results from calcium release from $\mathrm{IP}_{3}$-sensitive stores, while subsequent calcium oscillations are mediated by interplay between $\mathrm{IP}_{3}$-sensitive calcium stores and calcium influx through CCE.

Financed by FONDAP 15010006 and FONDECYT 1030988

\section{9.- MOLECULAR INTERACTIONS AND ACTIVITY OF THE TYPE-1 INOSITOL 1,4,5- TRISPHOSPHATE RECEPTOR: EFFECTS OF SH- REAGENTS AND OF $\mathrm{Ca}^{2+}$}

\section{J.B. PARYS, K. SZLUFCIK, G. BULTYNCK, N. NADIF KASRI, E. VERMASSEN, G. CALLEWAERT, L. MISSIAEN AND H. DE SMEDT}

Laboratorium voor Fysiologie, Campus Gasthuisberg O/N, Katholieke Universiteit Leuven, B-3000 Leuven (Belgium)

Structure and $\mathrm{Ca}^{2+}$-release activity of the inositol $1,4,5$ trisphosphate $\left(\mathrm{IP}_{3}\right)$ receptors $\left(\mathrm{IP}_{3} \mathrm{Rs}\right)$ are determined by intra- and intermolecular interactions. A7r5 smooth-muscle cells express both the type- $1\left(\mathrm{IP}_{3} \mathrm{R} 1\right)$ and the type- 3 $\left(\mathrm{IP}_{3} \mathrm{R} 3\right.$ ) isoforms, but are recognized as a functional model system for the former. In unidirectional ${ }^{45} \mathrm{Ca}^{2+}$-flux experiments on permeabilized A7r5 cells, we demonstrated that the sensitivity to thimerosal of $\mathrm{IP}_{3}$-induced $\mathrm{Ca}^{2+}$ release (IICR) was strongly $\mathrm{Ca}^{2+}$ dependent. Measured in the absence of $\mathrm{Ca}^{2+}$, IICR displayed a bell-shaped dependence on the thimerosal concentration, with a maximal release occurring at $5 \mu \mathrm{M}$ thimerosal. Interestingly, at a $\mathrm{Ca}^{2+}$ concentration of $1 \mu \mathrm{M}$, the $\mathrm{IP}_{3-}$ dependent fractional $\mathrm{Ca}^{2+}$ loss increased 3 -fold while becoming 5 -fold more sensitive to thimerosal. In other cell types, we previously demonstrated that thimerosal has only an inhibitory effect on $\mathrm{IP}_{3} \mathrm{R} 3$. To explain these effects, we investigated the intramolecular interactions occurring in $\mathrm{IP}_{3}$ Rs. The specific interaction occurring between the $\mathrm{N}$ terminal suppressor domain (a.a. 1-225) and the ligandbinding core (a.a. 226-604) of $\mathrm{IP}_{3} \mathrm{R} 1$-but not of $\mathrm{IP}_{3} \mathrm{R} 3$ was 3.3 -fold potentiated in the presence of thimerosal. Interestingly, this interaction was weakened by addition of $1 \mathrm{mM}$ EGTA (75\% inhibition) or of $10 \mu \mathrm{M}$ calmodulin (56\% inhibition) or sCaBP1 (63\% inhibition), which both share a $\mathrm{Ca}^{2+}$-independent binding site within the suppressor region. Presence of the $\mathrm{IP}_{3} \mathrm{R}$ agonists $\mathrm{IP}_{3}$ or adenophostin $\mathrm{A}$ did not affect the interaction efficiency. In contrast, the interaction between the N-terminus (a.a. 1-604) and the Cterminus of $\mathrm{IP}_{3} \mathrm{R} 1$ (a.a. 2170-2749) was not affected by thimerosal, but was inhibited by $\mathrm{IP}_{3}$ or adenophostin $\mathrm{A}$ (56\% resp. $69 \%$ inhibition) and might be $\mathrm{Ca}^{2+}$ dependent. Finally, to investigate the intermolecular interactions affecting the $\mathrm{IP}_{3} \mathrm{Rs}$, we performed immunoprecipitation experiments on whole-cell lysates. Interactions of $\mathrm{IP}_{3} \mathrm{R} 1$ with talin and of $\mathrm{IP}_{3} \mathrm{R} 3$ with talin, actin and protein kinase A were found. The functional role of these interactions and their modulation by $\mathrm{SH}$-reagents or $\mathrm{Ca}^{2+}$ must be further evaluated.

In conclusion, this study indicates an important role for both redox status and $\mathrm{Ca}^{2+}$ in the regulation of the structure and the function of the $\operatorname{IP}_{3} \mathrm{R} 1$ and emphasizes the role of intra- and intermolecular associations in the regulation of $\mathrm{IP}_{3} \mathrm{R} 1$ channel activity.

\section{0.- RYANODOL: A PROBE FOR RYANODINE RECEPTOR MEDIATED CALCIUM RELEASE}

\section{RAMOS-FRANCO J., NANI A., COPELLO J.A.,} GÓMEZ A.M.* AND M. FILL.

Dept. Physiology, Loyola University Chicago, Maywood, IL USA and *INSERM U390, CHU A. de Villeneuve, Montpellier 34295 FRANCE.

Ryanodine locks single ryanodine receptor (RyR) channels into a long-lived, sub-conductance state and is essentially an irreversibly pharmacological probe on the time frame of most physiological studies. Although the different 
ryanodine derivatives have very interesting actions on single RyR channel function, these other ryanoids are rarely used as physiological tools for the study of RyRmediated $\mathrm{Ca}$ signaling. Here, a simple chemical manipulation (saponization) was used to generate a crude ryanodol sample from high purity ryanodine. The single RyR channel blockade induced by this crude ryanodol was like that reported previously (Tinker et al., 1996). The ryanodol, when applied to single RyR2 channel in planar lipid bilayers, induced intermittent sojourns to a long-lived, sub-conductance state (i.e. the modified-state). The \% block (\% time spent in modified-state) increased with ryanodol concentration $\left(\mathrm{K}_{\mathrm{D}}=46.4 \pm 6.0 \mathrm{mM}\right.$; Hill Coefficient $=1.1 \pm 0.2$ ). Ryanodol \% block was tightly correlated to open probability (Po) regardless of whether channels were activated by $\mathrm{Ca}$, ATP or caffeine. High Po increased ryanoid affinity of the channel by changing the ryanoid dissociation rate constant. In intact and permeabilized cells, ryanodol reduced the average peak amplitude, width and duration of the image area of RyRmediated Ca sparks. Occasionally, ryanodol triggered trains of small Ca sparks. These studies show that ryanodol is an easily created and potentially useful probe for RyRmediated $\mathrm{Ca}$ signaling.

Supported by NIH HL57832, HL64210 \& HL071741.

11.- DIFFERENTIAL GENE EXPRESSION IN SKELETAL MUSCLE CELLS AFTER K+DEPOLARIZATION

JURETIC N. 1, GANGI L. ${ }^{2}$, MUNROE D. ${ }^{2}$, JAIMOVICH E. ${ }^{1}$ AND N. RIVEROS ${ }^{1}$.

${ }^{1}$ Centro FONDAP de Estudios Moleculares de la Célula, ICBM, Facultad de Medicina, Universidad de Chile, Santiago, Chile. ${ }^{2}$ Laboratory of Molecular Technology, NCI-SAIC, Frederick, MD, USA.

Skeletal muscle undergoes adaptive responses to exercise and to electrical stimuli with changes in gene expression at the level of structural proteins and energetic metabolism enzymes. In order to define the set of genes regulated by depolarizing stimuli, we used mouse oligonucleotide microarrays (Compugen 22K oligomouse, 21.920 genes). Total RNA from $\mathrm{C}_{2} \mathrm{C}_{12}$ myotubes was obtained at $0,2,4$, 18 and 24 hours after 5 min., $84 \mathrm{mM} \mathrm{K}+$ stimulation. cDNA prepared from control and depolarized samples was labeled with fluorescent dye $\mathrm{Cy} 3$ or $\mathrm{Cy} 5$ prior to hybridization to the microarray. From the analysis performed employing NCI-CIT Microarray Database (mAdb) tools, we focused our interest on 76 genes whose expression changed at least 2 fold up or down related to non-depolarized conditions. Among the changes detected, a number of genes were differentially expressed (7) or repressed (2) as early as 2 hr. after depolarization. Significant changes were found for genes involved in metabolism, signal transduction and stress response. Several selected genes detected by microarray analysis were confirmed by real time PCR. The study of the expression of these genes will contribute to clarify the mechanisms involved in membrane potential control of adaptive response in skeletal muscle cells.

Supported by FONDAP 15010006 and NCI-SAIC. N.J. thanks CONICYT for a graduate student fellowship.

\section{2.- TACHYCARDIA INCREASES RYR2 PROTEIN CONTENT IN THE HEART}

\section{SÁNCHEZ G., MACHO P., DOMÉNECH R. AND P. DONOSO.}

Centro FONDAP de Estudios Moleculares de la Célula e Instituto de Ciencias Biomédicas, Facultad de Medicina, Universidad de Chile, Santiago, Chile

Tachycardia induces changes in cardiac muscle that results in protection against the ischemic damage induced by coronary artery occlusion. The mechanism of protection is unknown. Cardiac ryanodine receptors (RyR2), responsible for the increase in intracellular calcium that triggers heart contraction, are likely to have a role in the changes induced by tachycardia.

We investigated the effect of electrically induced tachycardia on RyR2 content in sarcoplasmic reticulum (SR) vesicles isolated from dogs subjected to tachycardia ( 5 periods at $210 \mathrm{c} / \mathrm{min}$, five minutes each, with intervening periods of $5 \mathrm{~min}$ at basal heart rate, i.e. $120 \mathrm{c} / \mathrm{min})$. We found that SR vesicles from dogs subjected to tachycardia presented an increase in $\left[{ }^{3} \mathrm{H}\right]$-Ryanodine binding with no change in $\mathrm{Kd}$. Western blot analysis revealed that tachycardia increased RyR2 by 1.8 fold compared to controls, without modification of the phosphorylation status of the protein. Tachycardia also induced an increase in the phosphorylation level of the transcription factor CREB. No changes in ERK activation were found after tachycardia.

These results suggest that the protection induced by brief episodes of tachycardia could be mediated in part by changes in the synthesis of RyR2. The effects of tachycardia on the synthesis of other calcium transport proteins remain to be established.

Supported by FONDECYT Grants 1030449 and 15010006 .

\section{3.- SPECIFIC ENHANCEMENT OF IP ${ }_{3}$-MEDIATED $\mathrm{Ca}^{2+}$ SIGNALING IN MOUSE CORTICAL NEURONS EXPRESSING AN ALZHEIMER'S-LINKED MUTATION IN PRESENILIN-1}

\section{STUTZMANN G. E., LAFERLA F. M. AND I. PARKER.}

$\mathrm{IP}_{3}$-mediated $\mathrm{Ca}^{2+}$ release from the endoplasmic reticulum (ER) is a critical regulator of neuronal activity. Therefore, factors that interfere with ER signaling can have powerful and possibly neuropathological effects. For example, mutations in the presenilin (PS) genes, which lead to earlyonset Alzheimer's disease (AD), result in disruptions of intracellular $\mathrm{Ca}^{2+}$ signaling in dissociated cells. However, neurons are the principal cell type affected in $\mathrm{AD}$, yet the vast majority of $\mathrm{AD}$-linked $\mathrm{Ca}^{2+}$ studies have been conducted in non-excitable cultured cells. We therefore sought to characterize the effects of PS mutations on $\mathrm{Ca}^{2+}$ release using an intact brain slice preparation obtained from mutant PS knockin mice. $\mathrm{IP}_{3}-$ and spike-evoked $\mathrm{Ca}^{2+}$ signals were measured concurrently with neuronal activity by combining whole cell electrophysiology, video-rate 2-photon imaging and UV flash photolysis in cortical neurons filled with fura- 2 and caged $\mathrm{IP}_{3}$. We demonstrate that $\mathrm{Ca}^{2+}$ alterations due to $\mathrm{PS}$ mutations are specific to $\mathrm{IP}_{3}$-sensitive ER stores, and show an increase in strongly responding $\mathrm{IP}_{3}$ sensitive neurons in the PS mutant mice compared to matched non-transgenic controls. There is also a selective enhancement in the magnitude and rate of ER $\mathrm{Ca}^{2+}$ release, and this leads to a functional increase in $\mathrm{Ca}^{2+}$-sensitive downstream effects, such as the transient $\mathrm{IP}_{3}$-mediated 
membrane hyperpolarization. These data implicate PS in the modulation of neuronal $\mathrm{IP}_{3}$-evoked $\mathrm{Ca}^{2+}$ release, and strengthen the hypothesis that disruptions of $\mathrm{Ca}^{2+}$ signaling may be involved in the pathogenesis of Alzheimer's disease.

\section{4.- PARTICIPATION OF TRPC3/6 PROTEINS AND THE VITAMIN D RECEPTOR (VDR) IN STORE OPERATED CALCIUM ENTRY (SOCE) INDUCED BY $1 \alpha, 25(\mathrm{OH})_{2}$-VITAMIN $D_{3}$ IN SKELETAL MUSCLE CELLS}

KATZ S., SANTILLÁN G., AND R. BOLAND*.

Departamento de Biología, Bioquímica y Farmacia, Universidad Nacional del Sur. San Juan 670, (8000) Bahía Blanca, Argentina.

As part of its fast and non-genomic mode of action, 1 a, 25dihydroxy-vitamin- $\mathrm{D}_{3}\left[1 \alpha, 25(\mathrm{OH})_{2} \mathrm{D}_{3}\right]$ stimulates in chick skeletal muscle cells the release of $\mathrm{Ca}^{2+}$ from inner stores and extracellular cation influx through both voltagedependent and store operated $\mathrm{Ca}^{2+}$ entry (SOCE) channels. We investigated the involvement of TRPC $3 / 6$ proteins in SOCE induced by $1 \alpha, 25(\mathrm{OH})_{2} \mathrm{D}_{3}$. Two fragments were amplified by RT-PCR, exhibiting $>85 \%$ sequence homology with human, mouse and rat TRPC $3 / 6$ proteins. Northern and Western blots employing TRPC3/6-probes and anti-TRPC3 antibodies (which also react with TRPC6 of mouse, rat and human origin), respectively, confirmed endogenous expression of a TRPC3/6-like protein which exhibited a relative molecular weight of $140 \mathrm{kDa}$. Changes in $\left[\mathrm{Ca}^{2+}\right]_{\mathrm{i}}$ were recorded by spectrofluorimetric measurements in Fura-2 loaded cells. SOCE and $\mathrm{Mn}^{2+}$ entry induced by either thapsigargin or $1 \alpha, 25(\mathrm{OH})_{2} \mathrm{D}_{3}$ were reduced in muscle cells upon transfection with anti-TRPC3/ 6 antisense oligodeoxynucleotides (ODNs). In addition, after transfection of the cells with anti-VDR antisense ODNs, $\mathrm{Ca}^{2+}$ and $\mathrm{Mn}^{2+}$ influx induced by $1 \alpha, 25(\mathrm{OH})_{2} \mathrm{D}_{3}$ was inhibited. Co-immunoprecipitation of TRPC $3 / 6$ and VDR under non-denaturating conditions was observed, suggesting a physical association between both proteins. Therefore, we propose that endogenous TRPC3/6-like proteins and the VDR participate in the modulation of SOCE by $1 \alpha, 25(\mathrm{OH})_{2} \mathrm{D}_{3}$ in muscle cells, which seems to implicate VDR-TRPC $3 / 6$ interaction.

\section{5.- DIVERGENT EFFECTS OF PKA-MEDIATED PHOSPHORYLATION ON HOMOTETRAMERIC INOSITOL 1,4,5-TRISPHOSPHATE RECEPTORS}

STRAUB S. V., WAGNER L. E. AND D. I. YULE.

University of Rochester, Rochester, NY, 14642.

Agonist-induced $\mathrm{Ca}^{2+}$ release from inositol 1,4,5trisphosphate receptors (InsP3R) results in the generation of changes in cytosolic calcium concentration $\left(\left[\mathrm{Ca}^{2+}\right] \mathrm{c}\right)$ which are spatially and temporally shaped by the actions of numerous modulatory factors on the release channels and $\mathrm{Ca}^{2+}$-clearance mechanisms. In several cell types, agonist stimulation often results in the elevation of $\left[\mathrm{Ca}^{2+}\right] \mathrm{c}$ and cAMP. Consistent with this, we have previously shown that stimulation of pancreatic acinar cells with peptide agonists results in the generation of physiologically relevant "baseline" $\left[\mathrm{Ca}^{2+}\right] \mathrm{c}$ oscillations through a mechanism which involves the PKA-mediated phosphorylation of type III InsP3R. We are interested in elucidating the "crosstalk" between the $\mathrm{Ca}^{2+}$ and cAMP signal transduction pathways, especially as it relates to the modulation of $\mathrm{Ca}^{2+}$-release channels in physiological systems. In order to determine the effects of PKA phosphorylation on different InsP3R subtypes, we made use of the DT40 cell line, in which all 3 InsP3R were genetically knocked out. Utilizing digital calcium imaging of triple InsP3R knockout DT40 cells, it was found that PKA phosphorylation of transfected rat type III InsP3R results in a decreased ability of this receptor to release $\mathrm{Ca}^{2+}$, while the opposite effect was produced following phosphorylation of type II InsP3R. Site-directed mutagenesis of the 2 known PKA phosphorylation sites present in the type I InsP3R suggests the effects of phosphorylation at these sites are redundant, resulting in enhanced $\mathrm{Ca}^{2+}$ release from this receptor. These findings will be extended to determine the precise molecular mechanisms by which PKA-mediated phosphorylation results in altered $\mathrm{Ca}^{2+}$-permeability of InsP3R.

16.- ABNORMAL CALCIUM RELEASE CHANNEL/ RYANODINE RECEPTOR PHOSPHORYLATION MAY CONTRIBUTE TO SARCOPLASMIC RETICULUM DYSFUNCTION IN MYOCARDIAL STUNNING

VALDIVIA C.R., HEGGE J.O., MENTZER, JR. R.M. AND H. H. VALDIVIA.

University of Wisconsin, Madison, WI. USA.

We have previously reported that myocardial stunning (STUN) decreases sarcoplasmic reticulum (SR) calcium release channel/ryanodine receptor (RyR) function and that phosphorylation of normal RyRs by $\mathrm{Ca}^{2+}$ calmodulindependent protein kinase (CaMKII) also decreases single RyR channel activity. Since CaMKII may be activated during the $\mathrm{Ca}^{2+}$ overload that precedes STUN, this study was designed to test whether the depression of RyR function observed in STUN may be due to phosphorylation of RyRs by CaMKII. STUN was induced in anesthetized pigs $(n=5)$ with $10^{\prime}$ of left anterior descending coronary artery (LAD) occlusion and $2 \mathrm{hr}$ reperfusion (RP). After $\mathrm{RP}, \mathrm{SR}$ vesicles were isolated from LAD and non-stunned left circumflex (LC) regions. RyR activity was assessed with $\left[{ }^{3} \mathrm{H}\right]$ ryanodine binding $\left(\left[{ }^{3} \mathrm{H}\right] \mathrm{Ryd}\right)$. STUN reduced $\left[{ }^{3} \mathrm{H}\right]$ Ryd from $184 \pm 10 \mathrm{fmol} / \mathrm{mg}$ protein in normal $\mathrm{LC}$ to $141 \pm 14 \mathrm{fmol} / \mathrm{mg}$ protein. In both regions, endogenous CaMKII and RyRs co-segregated equally during SR isolation, suggesting that CaMKII may act as a modulator of RyRs in vivo. However, during in vitro CaMKII activation, LAD RyRs incorporated $32 \%$ less $\left[{ }^{32} \mathrm{P}_{\mathrm{i}}\right]$ from ATP than LC RyRs. Immunoblot analysis showed that STUN did not produce significant proteolysis of RyRs. Because CaMKII and RyRs remain stable in both regions, the results suggest that in vivo STUN increases the phosphorylation state of the RyR, making the channel less available for in vitro phosphorylation. In support of this hypothesis, a peptide inhibitor of CaMKII increased $\left[{ }^{3} \mathrm{H}\right]$ Ryd $52 \pm 10 \%$ in normal LC, but only $14 \pm 16 \%$ in STUN LAD $(\mathrm{n}=5, \mathrm{p}<0.05)$. We conclude that the depression of RyR function observed in STUN may be due in part to changes in the phosphorylation state of the channel. 


\section{SESSION 3}

1.- MEMBRANE IP ${ }_{3}$ RECEPTOR-DEPENDENT $\mathrm{Ca}^{2+}$ INFLUX IS AUGMENTED BY PROTEIN KINASE A IN THE SYNERGISM OF THE CILIARY BEAT FREQUENCY INCREASE INDUCED BY ATP AND ADENOSINE

\section{BARRERA N. P. ${ }^{1}$, SOLEDAD TORRES S. ${ }^{2}$, MORALES} B. ${ }^{3}$ AND M. VILLALÓN ${ }^{1}$.

${ }^{1}$ Pontificia Universidad Católica de Chile, Santiago Chile, ${ }^{2}$ Universidad de Valparaíso, Valparaíso - Chile ${ }^{3}$ Universidad de Santiago, Santiago - Chile

ATP and adenosine induce a synergic increase of the ciliary beat frequency (CBF) in cultured ciliated cells. We have previously shown that ATP response is mediated by phospholipase $\mathrm{C}$ and $\mathrm{IP}_{3}$ receptor activation. Using immunogold and electron microscopy, we observed that $\mathrm{IP}_{3}$ receptors type 1 and 3 in oviductal ciliated cells were localized in the nucleus and the endoplasmic reticulum, but type 3 was also localized in the plasma membrane. Using fluorescence spectroscopy, we observed that ATP or caged $\mathrm{IP}_{3}$ increased the intracellular $\mathrm{Ca}^{2+}$ free concentration $\left(\left[\mathrm{Ca}^{2+}\right] \mathrm{i}\right)$, initially from intracellular reservoirs followed by a $\mathrm{Ca}^{2+}$ influx. Addition of adenosine or intermediaries of adenosine transduction pathways, such as cAMP or protein kinase A (PKA) in the presence of ATP, induced a higher $\mathrm{Ca}^{2+}$ influx. Using radioimmunoreceptor and ELISA techniques we found an increase of $\mathrm{IP}_{3}$ and protein kinase $\mathrm{C}$ (PKC) induced by ATP. Using the patch clamp technique in whole cell recording, ATP triggered an influx of $\mathrm{Ca}^{2+}$, which is blocked by Xestospongin $\mathrm{C}$, an $\mathrm{IP}_{3}$ receptor inhibitor. In the presence of adenosine, we observed a higher ATP dependent- $\mathrm{Ca}^{2+}$ current, which is diminished by $\mathrm{H}-89$, a PKA blocker. Furthermore, in the inside-out configuration, $\mathrm{IP}_{3}$ and the catalytic PKA subunit triggered a higher $\mathrm{Ca}^{2+}$ current compare to $\mathrm{IP}_{3}$ alone. These results suggest that the synergistic response on $\mathrm{CBF}$ induced by ATP and adenosine depends on the PKA modulation of the membrane $\mathrm{IP}_{3}$ receptor that mediates the $\mathrm{Ca}^{2+}$ influx.

Supported by DIPUC/354/2002, CONICYT and FONDECYT 2010120.

\section{2.- NONGENOMIC ALDOSTERONE ACTION ON INTRACELLULAR CALCIUM AND VASCULAR TONE IN ARTERIAL VESSELS}

\section{LUIS MICHEA ${ }^{1}$, SERGIO LAVANDERO ${ }^{2}$ AND ELISA T. MARUSIC ${ }^{1}$}

Laboratory of Cellular and Molecular Physiology, University Los Andes ${ }^{1}$ and Departamento Bioquimica y Biologia Molecular, U.Chile ${ }^{2}$. Santiago- Chile.

Recently, rapid actions of aldosterone in vascular tissue have been described; among others, we have shown an increase on $\mathrm{Na}^{+} / \mathrm{H}^{+}$exchanger activity in human arteries. Also, we found that aldosterone has a biphasic effect on $\mathrm{Na}^{+}, \mathrm{K}^{+}$-ATPase activity: an early inhibition (nongenomic), and a later increase (genomic) in rat arteries. Here, we investigated whether aldosterone has a rapid action on vascular tone and $\mathrm{Ca}^{2+}{ }_{\mathrm{i}}$ in isolated resistance vessels. Further, we investigated if eplerenone a new specific antagonist, could block rapid aldosterone effects. Small diameter vessels loaded with $\mathrm{Ca}^{2+}$ fluorescent indicator FURA 2 AM, were cannulated and pressurized. Arterial diameter and $\mathrm{Ca}^{2+} \mathrm{i}$ were measured simultaneously by video-fluorescence microscopy. Aldosterone caused a rapid and sustained increase of $\mathrm{Ca}^{2+}$ levels $(\sim 20 \%$ of fluorescence ratio, $\mathrm{P}<0.05)$ that was associated with an $8 \%$ reduction in arterial diameter. Pretreatment with eplerenone suppressed both effects. Penylephrine response-curve $\left(5 \cdot 10^{-9} \mathrm{M}\right.$ to $\left.5 \cdot 10^{-6} \mathrm{M}\right)$ demonstrated additive effect of both hormones on vascular tone and $\mathrm{Ca}^{2+}$ levels.

It is known that activation of ERK $1 / 2$ and P38 are involved on aldosterone responses of epithelial tissue. No activation of ERK1/2 was observed. Inhibitors of ERK or p38 had no effect on aldosterone stimulus. PKC inhibitors blocked aldosterone action. Also, $1 \mathrm{mM}$ amiloride was an effective inhibitor. In summary, we have shown rapid aldosterone effects on arterial tone and intracellular $\mathrm{Ca}^{2+}$ of resistant vessels, and that $\mathrm{PKC}$ and $\mathrm{Na} / \mathrm{H}$ antiporter are involved in the nongenomic effects of this steroidal hormone. Supported by grant 1010185 FONDECYT.

\section{3.- THE EFFECT OF INTRALUMINAL $\mathrm{Ca}^{2+}$ OF THE ENDOPLASMIC RETICULUM (ER) ON $\mathrm{Ca}^{2+}$ HOT SPOTS IN SYMPATHETIC GANGLION NEURONS}

\section{Z CSERESNYES}

Department of Biochemistry and Molecular Biology, University of Maryland School of Medicine, Baltimore, Maryland, USA.

Video rate confocal $\mathrm{Ca}^{2+}$ imaging revealed that single action potentials (AP) generate $\mathrm{Ca}^{2+}$ hot spots, i.e. local perimembrane elevations of cytosolic $\mathrm{Ca}^{2+}$, in frog sympathetic ganglion neurons (Cseresnyés and Schneider, in press). The AP-induced $\mathrm{Ca}^{2+}$ transients are initiated by $\mathrm{Ca}^{2+}$ influx via voltage gated $\mathrm{Ca}^{2+}$ channels of the plasma membrane, and generated by $\mathrm{Ca}^{2+}$ induced $\mathrm{Ca}^{2+}$ release (CICR) via ryanodine receptors of the ER. The amplitudes of two consecutive $\mathrm{Ca}^{2+}$ transients separated by less than $100 \mathrm{~ms}$ were not significantly different, indicating that luminal free $\mathrm{Ca}^{2+}$ of the ER was not significantly lowered by one AP. When the ER of a neuron was depleted of free $\mathrm{Ca}^{2+}$ by multiple exposures to $10 \mathrm{mM}$ caffeine in $0 \mathrm{Ca}^{2+}$, the AP-induced $\mathrm{Ca}^{2+}$ transient disappeared, and was only recovered after the cell had been reloaded with $\mathrm{Ca}^{2+}$ by multiple brief depolarizations by high- $\mathrm{K}^{+}$. This high- $\mathrm{K}^{+}$ induced recovery was preceded by a refractory period of 34 minutes after the last high- $\mathrm{K}^{+}$exposure, during which the cell did not exhibit $\mathrm{Ca}^{2+}$ transients. The $\mathrm{Ca}^{2+}$ that entered the neurons during the high- $\mathrm{K}^{+}$exposures appeared to require re-distribution among various $\mathrm{Ca}^{2+}$ pools of the ER, before becoming available for release by CICR following an AP. We also investigated the effect of partial depletion of free luminal $\mathrm{Ca}^{2+}$ of the ER on AP-induced $\mathrm{Ca}^{2+}$ transients, by using TPEN to clamp ER free $\mathrm{Ca}^{2+}$ at progressively lower levels. Preliminary data indicate that TPEN, a membrane permeant low affinity $\mathrm{Ca}^{2+}$ chelator, is able to suppress AP-induced local $\mathrm{Ca}^{2+}$ transients and to chelate $\mathrm{Ca}^{2+}$ that enters the ER lumen during a high- $\mathrm{K}^{+}$ induced $\mathrm{Ca}^{2+}$ transient, or during RACT activity (Cseresnyés et al., 1997). Future studies will quantify the relationship between the luminal free $\mathrm{Ca}^{2+}$ of the ER, and the amplitude and time course of AP-induced $\mathrm{Ca}^{2+}$ transients. 


\section{4.- MULTICOLOR IMAGING OF $\mathrm{Ca}^{2+}$ PUFFS AND ENDOPLASMIC RETICULUM MORPHOLOGY IN THE XENOPUS EGG}

\section{BOULWARE M. J. AND J. S. MARCHANT}

Dept. of Pharmacology, University of Minnesota Medical School, Minneapolis

The $\mathrm{IP}_{3}$-sensitive $\mathrm{Ca}^{2+}$ release apparatus in the Xenopus oocyte is dispersed as a punctate network throughout the endoplasmic reticulum (ER), and is functionally visualized at low levels of $\mathrm{IP}_{3}$ through the localized activity of $\mathrm{Ca}^{2+}$ puffs (1). Such $\mathrm{Ca}^{2+}$ puffs reflect $\mathrm{Ca}^{2+}$ release from a small number of active $\mathrm{IP}_{3}$ receptors clustered at a particular site within the ER that remains relatively static with time $(2,3)$. However, during subsequent oocyte maturation, fertilization and cleavage of the Xenopus egg large scale reorganizations in ER structure occur, that lead to establishment of $\mathrm{Ca}^{2+}$ signaling polarities important for the early developmental program (4). How do such changes in ER structure influence $\mathrm{IP}_{3}$-evoked local $\mathrm{Ca}^{2+}$ signaling and lead to architectural partitioning of the $\mathrm{Ca}^{2+}$ release apparatus in a multicellular embryo? We have investigated the impact of (i) progesterone-evoked oocyte maturation and (ii) cortical rotation on both ER structure and $\mathrm{Ca}^{2+}$ signals using video-rate confocal methods. Our results demonstrate an increase in $\mathrm{IP}_{3}$ receptor sensitivity during maturation and a maintained $\mathrm{IP}_{3}$ receptor functionality during cortical rotation, in the face of the morphological changes in ER that occur during both events.

1. Parker I, Yao, Y (1991) Proc Royal Soc London B, 246: 269-27

2. Sun X-P, Callamaras N, Marchant JS, Parker I (1998) J Physiol 509: 67-80

3. Thomas D, Lipp P, Tovey SC, Berridge MJ, Li W, Tsien RY, Bootman MD (2000) Curr Biol 10: 1-8

4. Saneyoshi T, Kume S, Amasaki Y, Mikoshiba K. (2002) Nature 417: 295-299

\section{5.- IRON-GENERATED REACTIVE OXYGEN SPECIES MODULATE THE ACTIVATION AND LOCALIZATION OF ERK1/2 IN PC12 CELLS}

\section{MUÑOZ P. C..$^{1,2}$, HIDALGO C. ${ }^{3} \&$ M. T. NÚÑ̃EZ ${ }^{1,2}$}

${ }^{1}$ Departamento de Biología, Facultad de Ciencias, Universidad de Chile, ${ }^{2}$ Instituto Milenio CBB, ${ }^{3}$ Centro FONDAP de Estudios Moleculares de la Célula (CEMC) and ICBM, Facultad de Medicina, Universidad de Chile, Santiago, Chile.

Reactive Oxygen Species (ROS) participate as second messengers in synaptic plasticity. In particular, the ERK1/2 pathway is activated in response to an oxidative stimulus. Iron, potentially toxic, reacts with hydrogen peroxide $\left(\mathrm{H}_{2} \mathrm{O}_{2}\right)$ generating the highly reactive hydroxyl radical $(\mathrm{OH} \cdot)$. In this work, the effect of iron on the ERK1/2 pathway was studied. Concentration of ROS as a function of iron supplement were determined though the use of specific dyes for $\mathrm{H}_{2} \mathrm{O}_{2}$ and $\mathrm{OH}$. Incubation with iron produced a fast decrease in $\mathrm{H}_{2} \mathrm{O}_{2}$ concentration and a significant increase in the $\mathrm{OH}$. concentration. Incubation of PC12 cells with iron at different times produced a fast increase in ERK1/2 phosphorylation and activation, which was dependent on iron concentration. Moreover, iron changed ERK1/2 subcellular localization, inducing its nuclear translocation. Both ERK activation as well as nuclear translocation were blocked by the intracellular iron chelator deferrioxamine, by the antioxidant NAC, and the hydroxyl scavenger mannitol, suggesting that the ironinduced activation of the ERK $1 / 2$ pathway takes place through the generation of $\mathrm{OH} \cdot$. The data suggest that ROS generated by iron activate a signaling cascade relevant to synaptic plasticity.

Financed by project FONDECYT 1010657, by FONDAP project 15010006 and by project P99-031, Millennium Institute for Advanced Studies in Cell Biology and Biotechnology.

\section{6.- XESTOSPONGINS ARE NOT SERCA INHIBITORS, RATHER THEIR HYDROXYLATED DERIVATIVES ARE ALLOSTERIC RYR AGONISTS}

\section{TA T. $\mathbf{N}^{1}$, FENG W. ${ }^{1}$, MOLINSKI T. F. ${ }^{2}$ AND I. N. PESSAH $^{1}$}

${ }^{1}$ Department of Molecular Biosciences, School of Veterinary Medicine; ${ }^{2}$ Chemistry Department; University of California, Davis, CA 95616.

Microsomal calcium $\left(\mathrm{Ca}^{2+}\right)$ channels including inositol1,4,5-trisphosphate receptors ( $\mathrm{IP}_{3} \mathrm{Rs}$ ) and ryanodine receptors (RyRs) contribute precise regulation of spatial and temporal coding of $\mathrm{Ca}^{2+}$ signals in most animal cells. Xestospongin $\mathrm{C}(\mathrm{XeC})$ was shown to block of $\mathrm{IP}_{3}$-induced $\mathrm{Ca}^{2+}$ release and $\mathrm{IP}_{3} \mathrm{R}$-mediated signaling. We have further studied the specificity of Xe structures with and without a ring $-\mathrm{OH}$ substituent toward $\mathrm{IP}_{3} \mathrm{R}$, RyR, and SERCA activities using measurements of $\mathrm{Ca}^{2+}$ transport ATP hydrolysis, and $\left[{ }^{3} \mathrm{H}\right]$ ryanodine binding. $\mathrm{XeC}$ potently inhibits $\mathrm{IP}_{3} \mathrm{R}\left(\mathrm{IC}_{50}=458 \mathrm{nM}\right)$, but neither inhibits RyR 1 $\left(\mathrm{IC}_{50}>10 \mathrm{mM}\right)$ nor SERCA $\left(\mathrm{IC}_{10}>100 \mathrm{mM}\right)$. XeD, (i.e., 9$\mathrm{OH} \mathrm{XeC,} \mathrm{C} 9=$ tertiary alcohol) inhibits $\mathrm{IP}_{3}$-mediated $\mathrm{Ca}^{2+}$ release $\left(\mathrm{IC}_{50}=4 \mathrm{mM}\right)$ and lacks SERCA $\left(\mathrm{IC}_{10}>100 \mathrm{mM}\right)$ activity. Unexpectedly $\mathrm{XeD}$ enhanced both $\left[{ }^{3} \mathrm{H}\right]$ ryanodine binding, RyR1-mediated $\mathrm{Ca}^{2+}$ release from SR vesicles $\left(\mathrm{EC}_{50}=10.6\right.$ and $22.6 \mathrm{mM}$, respectively $)$, and directly activated RyR1 channels reconstituted in BLM Bifunctional ( $\mathrm{IP}_{3} \mathrm{R}$-inhibiting and RyR-activating) activities extended to additional hydroxylated xestospongins and araguspongins, but not to congeners lacking $-\mathrm{OH}$ moieties. These results show that xestospongins are $\mathrm{IP}_{3} \mathrm{R}$ blockers that lack direct SERCA inhibitory activity. Importantly XeD and related structures possessing a hydroxylated oxaquinolizidine ring may be valuable bifunctional reagents to ascertain $I_{3} R$ and $R y R$ contributions to cell signaling.

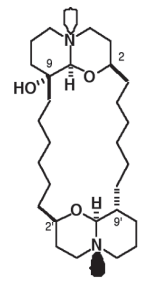

(+)-Xe D

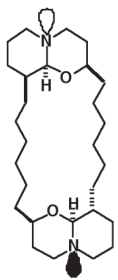

$(-)-\mathrm{Xe} \mathrm{C}$

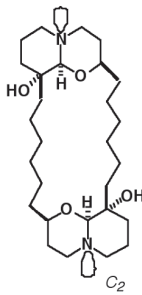

$(+)-A r C$

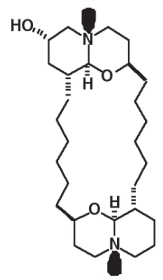

(+)-7-HO-XeA 
RYANODINE RECEPTORS/Ca ${ }^{2+}$ RELEASE CHANNELS FROM MAMMALIAN SKELETAL MUSCLE

\author{
ARACENA, P. ${ }^{1,2}$, TANG, W. ${ }^{2}$, HAMILTON, S.L. ${ }^{2}$, \\ HIDALGO, C. ${ }^{1}$
}

${ }^{1}$ Centro FONDAP de Estudios Moleculares de la Célula, Facultad de Medicina, Universidad de Chile, Casilla 70005, Santiago 7, Chile, and ${ }^{2}$ Department of Molecular Physiology and Biophysics, Baylor College of Medicine, Houston, TX 77030, USA.

Ryanodine Receptors/Ca ${ }^{2+}$ release channels (RyR channels) are modulated by several small molecules, and by proteinprotein interactions with a wide arrange of proteins, which includes calmodulin and FKBP12. Mammalian skeletal muscle RyR channels (RyR1 channels) are also modulated by endogenous redox active molecules including the glutathione redox couple and nitric oxide; moreover, RyR1 channels are susceptible to both $S$-nitrosylation and $S$ glutathionylation. It has been shown that $S$-nitrosylation of RyR1 channels modifies their interaction with calmodulin. However, it is not clear if these modifications also have effects on the channel interaction with FKBP12. In the present study, we used different redox agents to modify the redox state of proteins present in mammalian skeletal muscle triads. We then assessed the effect of these modifications on FKBP12 interaction with RyR1 channels by equilibrium binding assays. Our results suggest that only $S$-nitrosylation significantly decreases FKBP12 binding to triads but $S$ glutathionylation does not. Moreover, FKBP12 does not appear to be susceptible to any of these modifications, suggesting that changes on FKBP12 binding to RyR1 channels arise from S-nitrosylation of the channel protein. We conclude that different redox modifications of RyR1 produce different functional effects on both channel activity and protein-protein interactions.

Supported by FONDAP \#15010006 and NIH \#AR41802.

\section{8.- NADPH OXIDASE GENERATES REACTIVE OXYGEN SPECIES AFTER DEPOLARIZATION OF RAT SKELETAL MUSCLE CELLS}

\section{PEÑA M. ${ }^{1}$, ESTRADA M. ${ }^{2}$, ESPINOSA A. ${ }^{2}$, HIDALGO C. ${ }^{2}$ AND E. JAIMOVICH ${ }^{2}$ \\ 1 Centro de Investigaciones Biomédicas (CIBIOMED) "Victoria de Girón", Ave 146 No 3102, Playa, Ciudad Habana, Cuba ${ }^{2}$ Centro FONDAP de Estudios Moleculares de la Célula, Instituto de Ciencias Biomédicas (ICBM), Facultad de Medicina, Universidad de Chile, Chile}

Reactive oxygen species (ROS) have been frequently involved in cell damage. Nevertheless, recent evidence has demonstrated that the generation of ROS could be part of physiological events as intracellular signals. Nonphagocytic NADPH oxidase, a source of ROS generation, has been shown to participate in cellular signals in some cell types. However, the role of this enzyme complex in skeletal muscle has not been studied. Our aims were to study the generation of ROS in primary cultures of rat skeletal muscle upon membrane depolarization. 2' 7 ' dichlorofluorescein diacetate was used to measure ROS using confocal microscopy. Cells were depolarized with 65

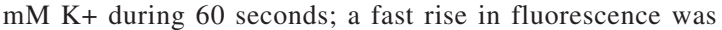
evident in the first few seconds. When the NADPH oxidase inhibitor, diphenyleneiodonium was used, the fluorescence increase was blocked. Nifedipine, a voltage sensor inhibitor, also blocked depolarization induced ROS production. Our results are consistent with NADPH oxidase activation by membrane depolarization, generating ROS that could be involved in regulation of intracellular signals in muscle cells. The mechanism for NADPH oxidase activation has yet to be explored. Financed by FONDAP 15010006 and IUPAB.

\section{9.- $\mathrm{Ca}^{2+}$ SIGNALING PATHWAYS IN THE ANTIAPOPTOTIC ACTION OF IGF-1 ON CULTURED CARDIAC MYOCYTES}

\section{ROCCO P., IBARRA C., FONCEA R., CEA P., MALDONADO C., CHIONG M., QUEST A. AND S. LAVANDERO.}

FONDAP Center for Molecular Studies of the Cell, Faculty of Chemical and Pharmacological Sciences, University of Chile.

We have previously shown IGF-1 prevents cardiac cell death. The signaling mechanisms involved in these actions are not fully understood. In cultured cardiac myocytes, IGF-1 activates multiple signaling pathways, including ERK, PKB/PI3K and PLC-g. In this work, we investigate the role of IGF-1-dependent $\mathrm{Ca}^{2+}$ signaling pathways on the attenuation of apoptosis induced by hyperosmotic stress. In cultured neonatal cardiac myocytes exposed to IGF-1, fast and transient (10-20 s) increases in cytosolic and nuclear $\mathrm{Ca}^{2+}$ were observed. IGF-1 also caused a rapid stimulation of phosphoinositide turnover (170\% vs control, at $30 \mathrm{sec})$, with a significant increase in IP3 mass $(4.5$-fold at $30 \mathrm{sec})$. Calmodulin kinase (CaMK) and classical protein kinases $\mathrm{C}$ (cPKCs) were also activated by IGF-1 at 5 min (1.6-fold) and 2-5 min (2-fold), respectively. IGF-1 induced PKCa translocation $(10 \mathrm{~min})$ from the soluble to the particulate fraction. Antiapoptotic action of IGF-1, determined by DNA laddering, was attenuated by cyclosporine A (calcineurin inhibitor), GO5876 and BIM-1 (cPKCs inhibitors), but not KN62 (CaMK inhibitor). Collectively, these results suggest that some $\mathrm{Ca}^{+2}$ dependent signaling pathways are involved in the antiapoptotic effects of IGF-1 in cardiac myocytes.

FONDECYT 1010246, FONDAP 15010006, PG107UCH, SOCHICAR. PR and CM are CONICYT fellows.

\section{0.- MULTIFUNCTIONAL CELLS IN HUMAN PITUITARY ADENOMAS: IMPLICATIONS FOR PARADOXICAL SECRETION AND TUMORIGENESIS}

\section{SENOVILLA L. ${ }^{1}$, NÚNEZ L ${ }^{1}$, DE CAMPOS J.M. ${ }^{2}$, DE LUIS D.A. ${ }^{2}$, ROMERO E. ${ }^{3}$, GARCÍA-SANCHO J. ${ }^{1}$, VILLALOBOS C. AND A. SÁNCHEZ1.}

${ }^{1}$ Instituto de Biología y Genética Molecular (IBGM), Universidad de Valladolid - CSIC, ${ }^{2}$ Hospital Universitario Del Río Hortega and ${ }^{3}$ Hospital Clínico Universitario, Valladolid, Spain.

The anterior pituitary (AP) contains five main cell types, each one secreting a different AP hormone. Stimulation by hypothalamic releasing hormones (HRHs) induces an increase of the cytosolic free calcium concentration $\left(\left[\mathrm{Ca}^{2+}\right]_{\mathrm{c}}\right)$ and hormone release. It is generally accepted that each $\mathrm{HRH}$ specifically stimulates secretion of a single AP hormone, but this paradigm has been challenged recently. We have shown that some AP cells can store more than one hormone (polyhormonal cells) and respond to several $\mathrm{HRHs}$ (multiresponsive cells) in rat and mouse (1-3). Multifunctional cells could be involved in paradoxical secretion (AP hormone secretion evoked by a noncorresponding $\mathrm{HRH}$ ) and transdifferentiation (phenotypic switch between mature cell types without cell division). 
Pituitary tumors are characterized by their extreme heterogeneity and by paradoxical secretion. Here we have characterized cell phenotypes of a series of 15 freshly dispersed human pituitary adenomas including prolactinomas, MEN-1, non-functioning Cushing's disease adenomas. Cells were typed by assessing expression of HRH receptors and AP hormones at the single-cell level. This was achieved by combination of calcium imaging followed by multiple sequential immunocytochemistry (3) in the same, single cells. We found a large phenotypic heterogeneity among the different pituitary tumors, among the different tumors of the same type and even among cells from the same tumor. In $40 \%$ of the tumors studied all $(>90 \%)$ of the cells bore multiple HRH receptors. The remaining tumors also contained large populations of multiresponsive cells. Polyhormonal cells were less abundant. In 53\% of the tumors more than $80 \%$ of the cells were multifunctional (multiresponsive and/or polyhormonal). Our results indicate that paradoxical secretion could be due to expression of multiple HRH receptors and suggest that alterations of cell plasticity could be involved in pituitary tumorigenesis.

Work supported by grants from MCYT (BFI 2001-2073) and FIS (01/0769)

1. Villalobos C, Núñez L, García-Sancho J (1996) FASEB J 10: $654-660$

2. Villalobos C, Núñez L, Frawley LS, García-Sancho J, Sánchez A (1997) Proc Natl Acad Sci USA 94: 14132 14137

3. Nuñez L, Villalobos C, Senovilla L, García-Sancho J (2003) J Physiol (London) 549: 835843

11.- TESTOSTERONE INDUCES RAPID $\mathrm{Ca}^{2+}$ INCREASES INDEPENDENT OF INTRACELLULAR ANDROGEN RECEPTOR ON CARDIAC MYOCYTES

\section{VICENCIO J.M., ESTRADA M., CHIONG M., JAIMOVICH E. AND S. LAVANDERO.}

Centro FONDAP de Estudios Moleculares de la Célula, ICBM, Facultad de Medicina y Facultad Ciencias Químicas y Farmacéuticas, Universidad de Chile.

Anabolic steroids produce cellular hyperthropy, in some cell types and this process is mediated by intracellular $\mathrm{Ca}^{2+}$ increases, however it is unknown if androgens produce cardiac hyperthrophy associated to $\mathrm{Ca}^{2+}$ signals. Epifluorescence studies in fluo3-AM loaded cardiac myocytes showed that $100 \mathrm{nM}$ testosterone induced a rapid $(<2 \mathrm{~min})$ and transient $(5 \mathrm{~min})$ intracellular $\mathrm{Ca}^{2+}$ increase. This response was not affected in $\mathrm{Ca}^{2+}$-free medium. Preincubation with ryanodine did not affect the signal, whereas depletion of intracellular $\mathrm{Ca}^{2+}$ stores with tapsigargin abolished the testosterone-induced $\mathrm{Ca}^{2+}$ increase. Immunocytochemistry showed translocation of androgen receptors from cytosol to nucleus $2 \mathrm{~h}$ after stimulation. Cyproterone, an antagonist of androgen receptor, did not modify the $\mathrm{Ca}^{2+}$ increase. Moreover, testosterone covalently bound to albumin, which does not permeate the cell membrane, also produced intracellular $\mathrm{Ca}^{2+}$ increases, suggesting the participation of a membrane receptor. The $\mathrm{Ca}^{2+}$ signal was inhibited in cells transfected with adenovirus bARKct ( $\mathrm{G}$ protein bg subunit scavenger). The ensemble of results show that testosterone produced a rapid and transient intracellular $\mathrm{Ca}^{2+}$ increase in cultured cardiomyocytes, independently of intracellular androgen receptor; this probably represents a new action mechanism for this hormone in heart cells.

Financed by FONDAP 15010006 and FONDECYT 1010246
12.- LIPID RAFTS ISOLATED FROM SKELETAL MUSCLE TRIAD VESICLES CONTAIN CAVEOLIN-3 AND L-TYPE CALCIUM CHANNELS

BARRIENTOS G., QUEST A. F. AND C. HIDALGO.

Centro FONDAP de Estudios Moleculares de la Célula and ICBM, F. Medicina, U. de Chile, Santiago, Chile.

Lipids rafts, plasma membrane regions rich in glycosphingolipids and cholesterol, are insoluble in nonionic detergents, such as Triton $\mathrm{X}-100$ at $4^{\circ} \mathrm{C}^{1}$, and can be isolated as light-buoyant density fractions in sucrose gradients. Caveolae are morphologically well-defined, caveolin-rich membrane structures that are also isolated as detergent-insoluble complexes. Skeletal muscle transverse tubule (T-T) membranes have cholesterol and sphingomyelin contents similar to lipid rafts$^{2}$; however, despite the abundant presence of caveolin-3 in intact skeletal muscle fibers, typical caveolae-like structures are not observed in T-T membranes ${ }^{3,4}$. Caveolae structures may be absent in T-T membranes as a consequence of the structural constraints imposed by close association with the $\mathrm{SR}$ in triads. T-T membranes contain L-type calcium channels (DHPR). In response to T-T depolarization, SR calcium release channels (RyR) open due to voltageinduced conformational changes of DHPR that trigger fast calcium release and muscle contraction.

Here Triton $\mathrm{X}$-100-insoluble fractions were isolated from triad vesicles (containing about $10 \%$ T-T membranes) at $4^{\circ} \mathrm{C}$. Western blot analysis revealed the presence of caveolin-3 and DHPR in such fractions. To our knowledge, these results are the first description of the presence of caveolin-3 and DHPR in lipid rafts isolated from T-T membranes associated with triads, and hence devoid of sarcolemmal contamination. Caveolin-3 null mice display severe abnormalities in T-T structure ${ }^{3}$. Therefore, potential functional consequences of DHPR association with cavolin-3 are the subject of future studies.

Supported by FONDAP 15010006.

\section{References:}

1. Hooper NM (1999) Mol Membr Biol 16: 145-156

2. Rosemblatt $\mathrm{M}$, Hidalgo, C, Vergara, C, Ikemoto $\mathrm{N}$ (1981) J Biol Chem. 256: 8140-8148

3. Galbiati, F. et al. (2001) J Biol Chem 276: 21425-21433

4. Munoz, P. et al. (1996) J Biol Chem 271: 8133-8139

\section{3.- ON THE ROLE OF P2X RECEPTORS AND CONNEXIN COMPOSED CHANNELS DURING MYOGENESIS}

ARAYA, R AND J. C. SÁEZ

Departamento de Ciencias Fisiológicas, Pontificia Universidad Católica de Chile, Santiago Chile.

Physiological $\left[\mathrm{Ca}^{2+}\right]_{0}$ and pre-fusional $\mathrm{Ca}^{2+}$ influxes are required for normal differentiation, but the pathway involved in this $\mathrm{Ca}^{2+}$ movement remains unknown. We have shown that $\mathrm{P} 2 \mathrm{Xs}$ receptor blockade in $\mathrm{C}_{2} \mathrm{C}_{12}$ skeletal muscle cell line inhibits cell differentiation and fusion and reduces gap junctional communication (GJC) (Mol Biol Cell 11:113a, 2000). In this work, we tested the functional expression of $\mathrm{P} 2 \mathrm{X}$ receptors (ionotropic channels permeable to Lucifer yellow (LY, -2) and ethidium bromide $(\mathrm{EtBr},+1)$ during differentiation of $\mathrm{C}_{2} \mathrm{C}_{12}$ cells and the spreading of cell signals through gap junctions (GJ) from ATP-sensitive to ATP-less or -insensitive cells. We studied the uptake of $\mathrm{LY}$ and $\mathrm{EtBr}$, in cells induced to differentiate in the presence or absence of $40 \mathrm{mM} 182$ - 
glycyrrhetinic acid b-GA) or $1 \mathrm{mM}$ octanol, GJ blockers. At $24 \mathrm{~h}$ of differentiation, cells did not show LY and EtBr uptake. However, exogenous $150 \mathrm{mM}$ ATP caused a strong dye uptake in a small fraction of cells. In these cultures, LY and EtBr-labeled cell clusters were observed. At $48 \mathrm{~h}$ of differentiation cultures showed more positive LYlabeled cell clusters than $24 \mathrm{~h}$ before. At this time, cells showed a high basal LY and EtBr uptake. The LY and EtBr spread to neighboring cells from cells showing strong dye uptake was hindered by GJ blockers. The ATP-induced and basal LY and EtBr uptake (at 24 and $48 \mathrm{~h}$, respectively) were completely blocked by oATP, a P2X receptor blocker. We proposed that $\mathrm{P} 2 \mathrm{X}$ receptors mediate the $\mathrm{Ca}^{2+}$ influx required for skeletal muscle differentiation. Moreover, the spreading of LY from ATP sensitive cells to insensitive ones suggest that GJC coordinates cell signaling triggered by extracellular ATP (e.g. $\mathrm{Ca}^{2+}$ ) during myogenesis. -

14.- CALCIUM IMAGING AND TYROSINE KINASE PHOSPHORYLATION CHANGES IN DIFFERENT MAMMALIAN SKELETAL MUSCLE CELL LINES IN RESPONSE TO $1 \alpha, 25(\mathrm{OH})_{2}$-VITAMIN $\mathrm{D}_{3}$

\section{BUITRAGO, C.*, ESTRADA, M.\#, BOLAND, R.*, JAIMOVICH, $\mathbf{E}^{\#}$.}

*Dept. Biología, Bioquímica y Farmacia, Universidad Nacional del Sur. Bahía Blanca 8000-Argentina. \#Instituto de Ciencias Biomédicas, Facultad de Medicina, Universidad de Chile. Santiago 6530499-Chile

Agonist induced changes in intracellular $\mathrm{Ca}^{2+}$ levels $\left(\left[\mathrm{Ca}^{2+}\right] \mathrm{i}\right)$ in mammalian cells control several cell functions like secretion, cell division, gene expression and muscle contraction. Specific profiles of the calcium signals are associated to cellular responses. The increase in $\left[\mathrm{Ca}^{2+}\right] \mathrm{i}$ may induce activation of enzymes. $\mathrm{Ca}^{2+}$ is an important cofactor for activation of MAPKs, specifically ERK 1/2. The hormone $1 \alpha, 25(\mathrm{OH})_{2}$-vitamin $\mathrm{D}_{3}$ exerts direct effects on muscle cell $\mathrm{Ca}^{2+}$ metabolism and thereby on contractility and growth. The non-genomic actions of $1 \alpha, 25(\mathrm{OH})_{2} \mathrm{D}_{3}$ in muscle cells involve the activation of voltage-dependent $\mathrm{Ca}^{2+}$ channels (VDCC) and release of inositol trisphosphate $\left(\mathrm{IP}_{3}\right)$ which mediates $\mathrm{Ca}^{2+}$ mobilization from intracellular stores and modulates store-operated $\mathrm{Ca}^{2+}$ (SOC) channels. The hormone also induces tyrosine phosphorylation of several proteins, among which, MAP kinase (ERK1/ ERK2), PLCg and c-myc are its major targets. Moreover, in rat muscle cells, testosterone stimulates inner store $\mathrm{Ca}^{2+}$ release and MAPK via a $\mathrm{G}$ protein-coupled receptor and depolarization-induced slow $\mathrm{Ca}^{2+}$ transients activate early genes in skeletal muscle cells.

In this study, we investigated the effects of $1 \alpha, 25(\mathrm{OH})_{2} \mathrm{D}_{3}$ on $\left[\mathrm{Ca}^{2+}\right] \mathrm{i}$ and on phosphorylation and activation of ERK 1/ 2 in cultured normal rat skeletal muscle cells and murine normal NLT cell line in comparison with dystrophic mdx XLT 4-2 and dysgenic myotubes from the GLT cell line, which do not express the alpha(1) subunit of the DHPR.

Neonatal rat myotubes and muscle cell lines were loaded with fluo-3 AM followed by stimulation with 1-10 nM $1 \alpha, 25(\mathrm{OH})_{2} \mathrm{D}_{3}$ and a temporal sequence of $100-200$ images in periods of 2 seconds was recorded using an epifluorescence microscope. A marked increment in $\left[\mathrm{Ca}^{2+}\right] \mathrm{i}$ was observed 50 $100 \mathrm{~s}$ after hormone addition, usually linked to oscilations with a $20 \mathrm{~s}$ period. Spatial differences were observed in fluorescence, which was greater in the cell nucleus. In normal cell lines, less differentiated, the fluorescence increase occurred a few seconds after hormone stimulation.

Results of our analyses demonstrated that $1 \mathrm{nM}$ of $1 \alpha, 25(\mathrm{OH})_{2} \mathrm{D}_{3}$ induces rapid oscillations in $\left[\mathrm{Ca}^{2+}\right] \mathrm{i}$ in several cell types. Primary cultures of rat muscle cells show steroid hormone-dependent ERK 1/2 phosphorylation larger than that of muscle cell lines. Furthermore, $1 \alpha, 25(\mathrm{OH})_{2} \mathrm{D}_{3}$ activation of ERK $1 / 2$ was kinetically correlated with $\mathrm{Ca}^{2+}$ changes observed in hormone stimulated cells.

Financed by FONDAP 15010006 and Fundación Antorchas.

\section{5.- CARBACHOL INDUCED CALCIUM SIGNALING IN TRYPANOSOMA CRUZI EPIMASTIGOTES VIA A $\mathrm{Na}^{+} / \mathrm{H}^{+}$EXCHANGER ACTIVATION}

\section{BONANSEA S.; BOLLO M. AND E. MACHADO- DOMENECH.}

Molecular Biology Department. University National of Río Cuarto. Río Cuarto. Córdoba. Argentinabuba@arnet.com.ar

In a previous study we reported that stimulation of Trypanosoma cruzi epimastigote forms with carbachol resulted in Ins $(1,4,5) P_{3}$ increase level and $\mathrm{Ca}^{2+}$ mobilization from intracellular stores; Ins $(1,4,5) P_{3}$ variation was abolished by 12 -myristate 13 -acetate ester (PMA), an activator of protein kinase C [Marchesini, et. al. (2002) Mol. Biochem. Parasitol. 120, 83-91]. Now, we report that PMA significantly increased the $\mathrm{Ca}^{2+}$ mobilization induced by carbachol, whereas 1-(5isoquinolinesulfonyl)-2-methylpiperazine (H7), an inhibitor of the kinase, produced a significant decrease of calcium signaling. The PMA effect was inhibited when epimastigotes were preincubated with $\mathrm{H} 7$. The addition of the $\mathrm{Na}^{+} / \mathrm{H}^{+}$ionophore monensin evoked $\mathrm{Ca}^{2+}$ increase from acidic intracellular stores in the presence and absence of extracellular sodium. In a $\mathrm{Na}^{+}$free-medium, the $\mathrm{Ca}^{2+}$ mobilization induced by carbachol decreased, while the Ins $(1,4,5) P_{3}$ increase remained unchanged. This $\mathrm{Ca}^{2+}$ signaling progressively increased when the $\mathrm{pH}$ of the medium changed from 7.0 to 7.8. The presence of $5-(\mathrm{N}-$ ethyl-N-isopropyl)-amiloride (EIPA), an inhibitor of the $\mathrm{Na}^{+} / \mathrm{H}^{+}$exchanger, inhibited $\mathrm{Ca}^{2+}$ signaling; this effect was reverted by monensin. Carbachol was also able to induce the alkalinization of the acidic compartment, which was inhibited by EIPA. These results suggest that the activation of a Na+ $/ \mathrm{H}^{+}$exchanger followed by the $\mathrm{Ca}^{2+} / \mathrm{nH}^{+}$antiporter from acidic intracellular stores is a mechanism that triggers $\mathrm{Ca}^{2+}$ signaling in $T$. cruzi epimastigotes, with PKC being directly or indirectly involved.

\section{6.- MEMBRANE DEPOLARIZATION INDUCES PHOSPHORYLATION OF CAMP-RESPONSE ELEMENT-BINDING PROTEIN VIA A CALCIUM AND PROTEIN KINASE C ALPHA DEPENDENT PATHWAY IN SKELETAL MUSCLE CELLS}

\section{CÁRDENAS C., MÜLLER M., JAIMOVICH E., PÉREZ F., BUCHUK D., QUEST A.F.G, AND M. A. CARRASCO.}

Centro FONDAP de Estudios Moleculares de la Célula, Instituto de Ciencias Biomédicas, Facultad de Medicina,Universidad de Chile, Casilla 70005, Santiago 6530499 Chile.

Membrane depolarization of skeletal muscle cells in culture induced slow inositol 1,4,5-trisphosphate-mediated calcium signals that regulate the activity of transcription factors such as jun and fos. Here we investigated the possibility that such calcium signals regulated CREB phosphorylation 
by a protein kinase C (PKC)-dependent mechanism. Western blot analysis revealed the presence of seven PKC isoforms (PKC $\alpha,-\beta 1,-\beta 2,-\delta,-\varepsilon,-\theta$, and $-\zeta)$ in rat myotubes. Pre-treatment of myotubes with either bisindolymaleimide I or Gö6976, both PKC inhibitors with a preference for calcium-dependent isoforms, blocked CREB phosphorylation as efficiently as the calcium chelator BAPTA. Short-term stimulation with the phorbol ester tetradecanoyl phorbol acetate (TPA) which activates calcium-dependent and -independent isoforms but not atypical PKCs was sufficient to promote CREB phosphorylation and activation. Following chronic exposure to TPA that triggered complete down-regulation of all responsive isoforms except $\mathrm{PKC} \alpha$, CREB was still phosphorylated upon myotube depolarization. Fractionation experiments and immunocytochemical analysis revealed selective and rapid PKC $\alpha$ translocation to the nucleus following depolarization with kinetics similar to those of $\mathrm{IP}_{3}$ liberation and calcium release. Nuclear $\mathrm{PKC} \alpha$ translocation, as well as CREB phosphorylation and activation, were blocked by $2-\mathrm{APB}$, an $\mathrm{IP}_{3}$ receptor inhibitor, and the phospholipase $\mathrm{C}$ inhibitor U73122. In the muscle cell line $\mathrm{C} 2 \mathrm{C} 12$, which only expressed three PKC subtypes (PKC $\alpha,-\varepsilon$ and $-\zeta)$ and, most notably, lacked the other calcium-dependent isoforms PKC $\beta I$ and PKC $\beta I I$, CREB phosphorylation in response to depolarization occurred with similar kinetics as in isolated rat myotubes. Furthermore, all treatments shown in primary myotubes to either inhibit $\mathrm{PKC} \alpha$ or to prevent its translocation to the nucleus also abolished CREB phosphorylation in C2C12 cells. These results strongly implicate nuclear calcium increases and selective PKC $\alpha$ translocation to the nucleus in CREB phosphorylation and activation induced by skeletal muscle cell depolarization.

Financed by FONDAP 15010006 and FONDECYT 1030988. C. Cárdenas thanks Comisión Nacional de Investigación Científica y Tecnológica (CONICYT) and MECESUP UCH9903 for a graduate student fellowship. 